Portland State University

PDXScholar

7-29-1976

\title{
Coordination in Social Service Systems: the Area Agency on Aging as a Case Study
}

Terrie Todd Wetle

Portland State University

Follow this and additional works at: https://pdxscholar.library.pdx.edu/open_access_etds

Part of the Social Work Commons

Let us know how access to this document benefits you.

\section{Recommended Citation}

Wetle, Terrie Todd, "Coordination in Social Service Systems: the Area Agency on Aging as a Case Study" (1976). Dissertations and Theses. Paper 592.

https://doi.org/10.15760/etd.592

This Dissertation is brought to you for free and open access. It has been accepted for inclusion in Dissertations and Theses by an authorized administrator of PDXScholar. Please contact us if we can make this document more accessible: pdxscholar@pdx.edu. 
COORDINATION IN SOCIAL SERVICE SYSTEMS:

THE AREA AGENCY ON RGING AS A CASE STUDY

by

TERRIE TODD WETLE

A dissertation submitted to the faculty of Urban Studies in partial fulfillment of the requirements for the degree of

DOCTOR OF PHILOSOPHY

Portland State University

1976

(c) Terrie Todd Wetie 1976 
TO THE OFFICE OF GRADUATE STUDIES AND RESEPRCH:

The members of the Committee approve the thesis of

Terrie Todd Wetle presented July 29, 1976.

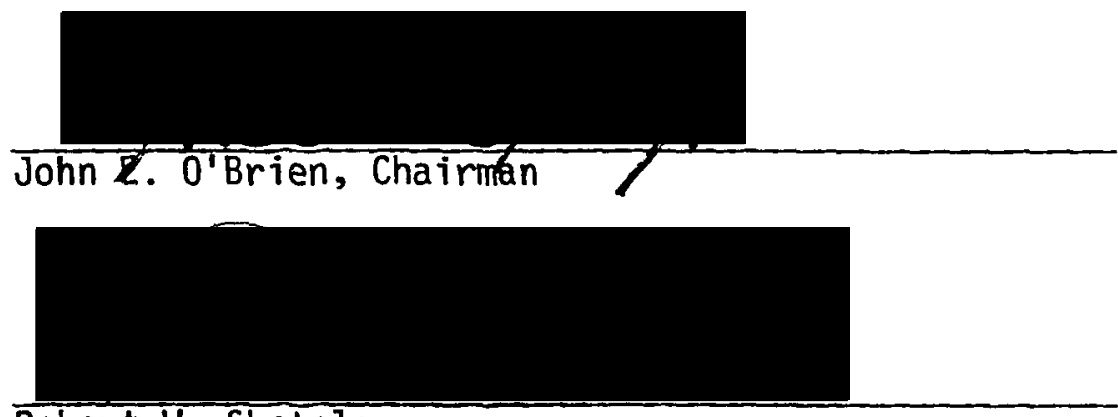

Robert W. Shotola
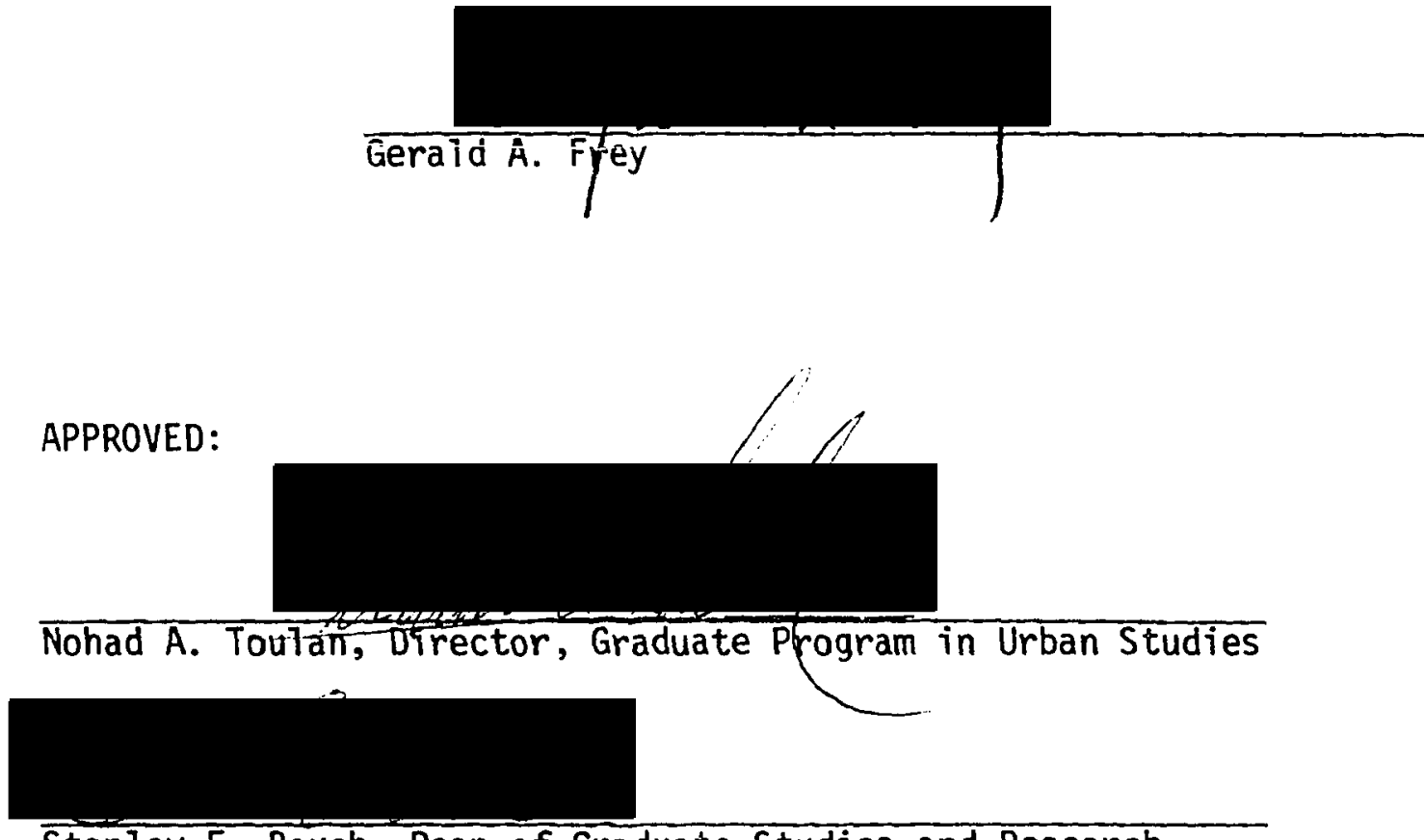

- Stanley E. Rauch, Dean of Graduate Studies and Research 
AN ABSTRACT OF THE THESIS OF Terrie Todd Wetle for the Doctor of Philosophy in Urban Studies presented July 29, 1976.

Title: Coordination in Social Service Systems: The Area Agency on Aging as a Case Study.

APPROVED BY MEMBERS OF THE THESIS COMMITTEE:

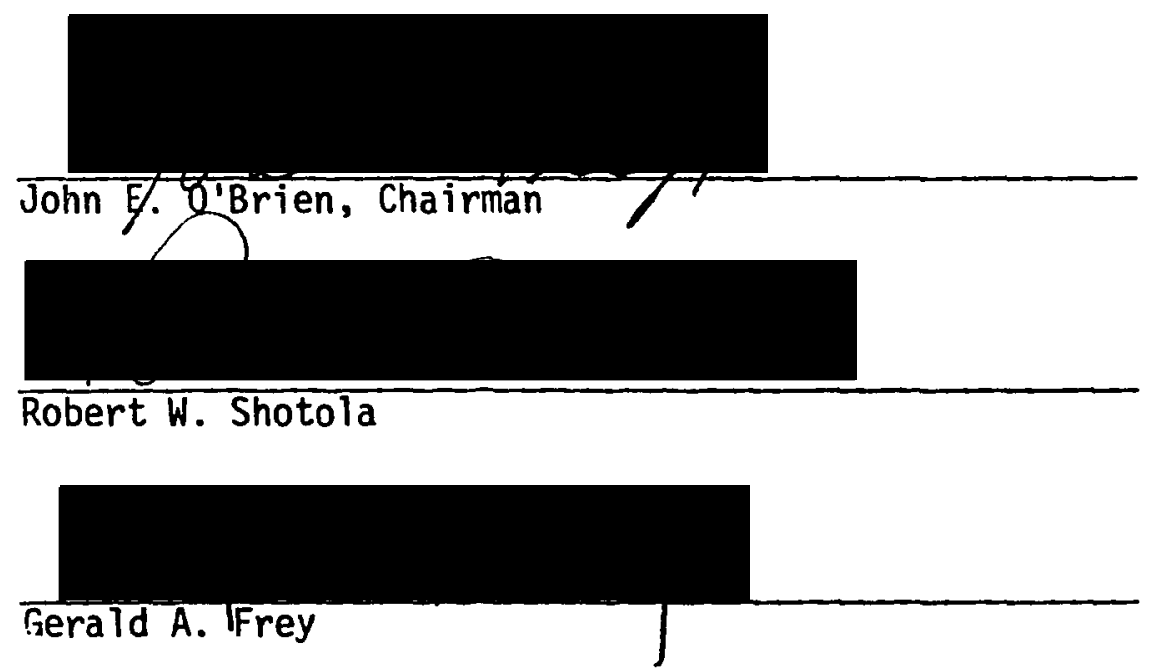

It is the purpose of this research to examine the interactions between organizations and the work of coordinating agencies in influencing those interactions using social exchange theory. A model was developed, incorporating elements of exchange theory, and the components of that model examined in the community. Techniques of change and the outcomes of activities of the coordinating agency were examined in an effort to develop a "case study" of a coordinating agency's activity in the community. 
Historically, social services were provided in the community through informal, often familial, networks. With the urbanization of society, social services have become more formalized and specialized with a remarkable increase in the number of individual agencies. Movement from a "growth" to a scarcity economy and new federal ism as well as concern with duplication, overlap, and gaps in services have led to an interest in the coordination of these activities. The Area Agency on Aging, considered by many to be a forerunner to the Allied Services Act, was implemented in 1973 by the federal government for the purpose of coordinating services to the elderly in the community. The goal of the Area Agency is the development of a comprehensive coordinated community service system. The activities of six such coordinating agencies as well as the social service organizations in their areas were studied to determine the explanatory value of social exchange theory. Additionaliy, attitudes of service providers toward various tactics for community change as well as the perceived outcomes of coordinating agency activities were investigated.

The study of the Area Agency on Aging as a coordinating agency in the community was accomplished in two waves of data collection. The first, consisting of indepth interviews with 84 individuals in six areas, took place from May through July of 1975 . The second wave involved indepth interviews and a mailed survey. Data were collected from 191 individuals in 126 agencies in three areas, urban, rural and urban/rural mixed. The data were coded and anaiyzed 
by computer to determine trends and relationships. The interview schedules were analyzed for specific cases. These objective and subjective data were used to "reconstruct" this study of interaction and coordination.

A model, Organizational Interaction Model, was derived utilizing social exchange theory. This model contains the elements of commodities: funding, information, access to influentials, clients, staff and technology; valuing criteria: integration, status, world view, autonomy, domain and power; and arenas of exchange: planning, contracts and letters of agreement, hearings and meetings, evaluation and monitoring, and client transfers. These elements were examined, and their explanatory value for activities in the community involving organizations and coordinating agencies was determined.

Change techniques, involving varying types as well as levels of intervention, were studied in terms of their perceived appropriateness by community organizations. The data suggested changes in activities of coordinating agencies, social planners, and makers of policy. Perceived outcomes of coordinating agency activity over the past three years show positive impacts in the community generally, though individual impacts vary.

Finally, the implications of these findings are discussed for coordinating agencies as well as local and federal policy makers, with suggestions for future research. Social exchange theory offers rich ground for the study of community service systems and the coordination of interactions within communities. 


\section{ACKNOWLEDGMENTS}

To my Committee:

John 0'Brien, who provided a constant encouragement, unfailing interest, and surprising patience,

Jerry Frey, who offered a practical view and helpful, substantive suggestions, and

Robert Shotola, who both improved the content and showed me the possibility of another way.

To Tom and Mary, who offered support, understanding, time-outs, and love, and

To Portland State University, where I learned important lessons in the importance of poticy, procedures, and patience. 
TABLE OF CONTENTS

PAGE

ACKNOWLEDGMENTS ...........................

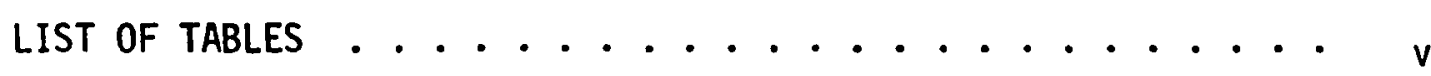

LIST OF FIGURES ......................... vii

CHAPTER

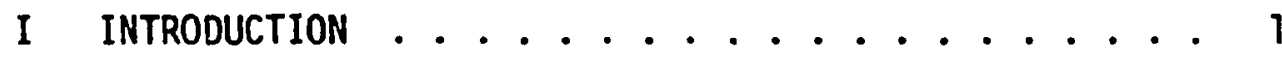

The Practical Issue: Coordination of

Services............ 1

The Theoretical Issue: Organizational

Interactions.......... 5

The Findings: Implications for Policy .... 6

II REVIEW OF THE LITERATURE. . . . . . . . . 7

Introduction .............. 7

Organizations.............. 8

Organizational Interdependence ...... 10

Organizational Interactions and

Linkages ........... 16

Organizational Networks. ........ 21

Organizational Coordination. ...... 25

Social Exchange Theory . . . . . . . 43 
TABLE OF CONTENTS (Continued)

PAGE

CHAPTER

III A MODEL FOR INTERORGANIZATIONAL STUDY. . . . . 55 Introduction ............... 55

Organizational Interaction Mode1...... 55

Change Techniques.......... 72

Outcome Variables ........... 74

Conclusion ................ 81

IV METHODOLOGY ................ 82

Introduction ................ 82

Procedures ............. 83

The Sample ............ 85

Instruments ................. 90

The Variables ............. . 92

Data Analysis ............ 96

V RESULTS .......................... 97

Introduction .............. 97

The Model and Organizational Interaction .. 97

How Can a Third Party Influence the Interaction Between Organizations? . . 1 121

Change Techniques ......... 150 
TABLE OF CONTENTS (Continued)

PAGE

CHAPTER

V (Continued)

Outcomes................ 154

Conclusion. .............. 161

VI CONCLUSIONS AND RELEVANCE TO THE COMMUNITY

SETTING ................. 163

Application of the Organizational

Interaction Model. . . . . . . 163

Change Techniques.............. 169

Outcomes. . . . . . . . . . 170

Social Exchange Theory and Organizational

Interaction. ............... 171

Conctusion. . . . . . . . . 174

BIBLIOGRAPHY. .......................... 176

APPENDICES. . . . . . . . . . . . . . 202 


\section{LIST OF TABLES}

TABLE

PAGE

I Elements Requiring Coordination ......... 36

II Techniques for Promoting Community Change ..... 75

III Comprehensive/Community System Model (CCS). . . . . 80

IV Description of Sample Areas .......... 87

V Profile of Study Communities. . . . . . . . . 88

VI Descriptions of Sample Organizations ...... 89

VI-A Reported Difficulty in Obtaining Commodities. . . . 98

VII Perceived Security of Budget. . . . . . . . 99

VIII Difficulty Obtaining Commodities by Area . . . . 106

IX Importance of Values to Cormunity Organizations . . 107

$X$ Community Organizations' Views of Interrelation of Aging Programs. . . . . . . . . 109

XI Importance of Valuing Criteria by Area . . . . . 116

XII Coordinating Agencies' Perception of Usefuiness and Control of Exchange Commodities ..... 123

XIII Level of Interaction of the Coordinating Agency by Area. . . . . . . . . . . 130

XIV Problems in Serving Elderly Clients ........ 131

XV Comparison of Ranking of Commodities Between CA

Directors and Agencies in the Community ... 139 


\section{LIST OF TABLES (Continued)}

TABLE

PAGE

XVI Help from Coordinating Agency in Obtaining Commodities by Area . . . . . . . . 140

XVII Perceived Appropriateness of Tactics for

Promoting Community Change . . . . . . 153

XVIII Differences in Reported Appropriateness of

Change Techniques by Area. . . . . . . 155

XIX Evaluation of Outcomes of Coordinating

Agency Activities............ 158

XX Community Interaction Model ........... 164 


\section{LIST OF FIGURES}

Figure

Page

1. Diagram of the Organizational Interaction Mode1 ............... . . 57

2. Community Sectors.............. 77 


\section{CHAPTER I}

INTRODUCTION

It was the purpose of this research to examine the interactions between organizations in their communities and the work of coordinating agencies in influencing those interactions. The data collected from community organizations and coordinating agencies were examined to determine the explanatory value of the Community Transactions Model. That model, developed from social exchange theory, consists of three major elements, commodities of exchange, valuing criteria and exchange arenas. Of additional interest were the change techniques, rated according to level of appropriateness by community organizations. Finally, respondents were asked to rate the outcome of the activities of the coordinating agencies. These findings were related to specific community experiences to suggest their application to the community social service system in a variety of settings.

I. THE PRACTICAL ISSUE: COORDINATION OF SERVICES Historically, services were provided in the community through informal, often familial, networks. With the urbanization of society, social services have become more formalized and specialized 
with a remarkable increase in the number of individual agencies. (Tonnies, 1957). During this period there occurred a shift to the delivery of services by philanthropic organizations and then a further shift to the government sector. With this tremendous growth in the size, number, and variety of organizations, financed, controlled, or subsidized by government, concern has grown over the network comprised of these agencies. Part of this concern relates to potential gaps in the fabric of the service community, needs for services which are not met. Another major concern is with the overlap, duplication, and thus waste. (Lauffer, 1974).

Two recent developments have brought this concern into national focus. The first is the change from a growth economy to one marked by scarcity of resources. While much of this attention has been focused on "natural resources such as fossil fuels and food, the same trend has been seen in the governmental services sector. Recession and inflation have lowered the availability of public money for new projects and many municipal and county hudgets are nearly bankrupt across the country. More often than not, the budgets to receive the earliest and most severe cuts are those for social programs. Local and state governments in all parts of the nation are seeking ways to put their tax dollars to their most effective use. Coordination of programs for the purpose of achieving efficiency and cutting costs is thinly veiled by rhetoric about the best delivery of services for the public good. (Gold, 1973). 
This scarcity of money available for publ ic services is compounded by a sense of disillusionment in the "Great Society". The faith of the "sixties" in alleviation of suffering and social problems by infusion of massive amounts of funding into the social services sector has been shaken by lack of evidence as to the effectiveness of such an approach. The skepticism of Congress is matched by skepticism at a local level and that same skepticism offers a rationale for decreasing social services at the local level and thus relieving strained budgets.

A second development is the growth of what has been termed by some the "new federalism". New federalism is marked by an increase in decentralization of the federal government. It places more responsibility on state and local government for program planning and execution through an increase in block grants and a decrease in categorical funding. Revenue sharing has been one of the more apparent elements of this movement. The new federalism places an increasing burden on the local comunity to do social planning. It also provides another pressure to coordinate the activities of agencies in the community. (Rice, 1974).

The Ailied Services Act was proposed as an element of new federalism. It was the intent of this act to take a number of steps toward coordination of social services within communities, including the right to transfer certain amounts of funds from one categorical grant to another. That act has yet to pass Congress. However, 
the initiative behind that Act, as well as other timely events, came together to bring about the 1973 Comprehensive Service Amendments to the 01der Americars Act of 1965 (Pub L 93-29, 87 Stat. 3645) (Gold, 1974). Title III of these amendments has the stated purpose to "encourage and assist State and Area Agericies to concentrate resources in order to develop greater capacity and to foster the development of comprehensive and coordinated service systems to serve older people." The implementation of this 1 aw in 1973 brought into being, across the country, a new "coordinating agency". (Gold, 1973).

Coordinating agencies are not new to communities (Mott, 1968). Efforts to coordinate certain services, primarily health; and activities, fund raising through the Community Chest and have been around since the thirties. More recently these activities have been expanded to include coordination of training, client transfers, information and advocacy. Studies have been done examining the work of coordinating agencies, usually by health care systems, but few if any have attempted to apply social exchange theory in their activities. It was the intent of this study to provide a framework for understanding and explaining the work of these coordinating agencies.

It is hoped that the information presented here will have value not only to the coordinating agency, in terms of viable techniques and cautionary notes, but also to the policy makers at all levels in their choices between alternatives for community change. 
Finally, but no less importantly, it is hoped that the exploratory work done here on a model for describing community transactions will have value to social science researchers interested in the coordination of service.

II. THE THEORETICAL ISSUE: ORGANIZATIONAL INTERACTIONS Interactions between organizations are a relatively recent area of concern for social researchers (Etzioni, 1964). In the past, the major focus related to intraorganizational issues (Barnard, 1938; Weber, 1947; Simon, 1945; March et al, 1958), with a few exceptions (c.f., Selznick, 1949; Dill, 1958). These studies have suggested causes, styles and barriers to organizational interaction but do not offer a comprehensive theory for organizational interaction (Benson, 1975).

Social exchange theory is generally applied to interactions between individuals. This research, utilizing the principies of exchange theory, constructed a model for organizational interaction and then tested that model in the community. The major components of that model are the commodities which are exchanged, the valuing criteria used by organizations to determine exchanges and the arenas in which the exchanges occur. The model is presented in Chapter III. Social exchange theory provides the dynamics of this model. The major propositions, stated very briefly, are as follows. Individuaîs (organizations) enter into transactions to obtain needed goods or services and tend to seek some profit (Ferguson, 1969). 
Commodities exchanged include sentiments as well as tangible objects (Blau, 1964). Exchanges may be direct or indirect, restricted or generalized (Levi-Strauss, 1949; see Ekeh, 1968). Exchanges may be simultaneous or sequential with reciprocity expected (Gouldner, 1960). Finally, exchange patterns become institutionalized (Malinowski, 1922). Social exchange theory is discussed in depth in Chapter II.

III. THE FINDINGS: IMPLICATIONS FOR POLICY

An interview and survey instrument were developed utilizing the rnodel and concepts from interorganizational research and social exchange theory. Data from 191 respondents and three coordinating agency directors were considered and analyzed.

Measures of change techniques and the impact of the coordinating agency in the community were developed (see Chapter III). The purpose of these measures was to determine the response of organizations in community to the work of the coordinating agency. These findings were then related back to the organizational interaction model. The results are discussed in Chapters V and VI, discussing conclusions and relevance to the community setting. Suggestions are made which have relevance for coordinating agencies, social planners and policy makers. 
CHAPTER II

\section{REVIEW OF THE LITERATURE}

\section{INTRODUCTION}

This chapter examines the factors related to organizational interactions and coordination. The purpose is to determine the circumstances under which interaction occurs and the elements of those circumstances which can be manipulated by a third party to influence those interactions. While the topics discussed here may appear to be general or even somewhat peripheral, the purpose is to present the background thinking which forms the framework for consideration of organizational interaction.

The first step is to develop a definition of organization, as a unit of interest for this study. From there, the discussion leads to organizational interdependence, its definition and the factors leading to it. One outcome of organizational interdependence is the deveiopment of linkages. These linkages are the avenues of interaction between organizations. Types of linkages as well as the circumstances likely to lead to their formation are traced. When organizations become inter-linked, networks are formed and these networks are a part of the environment of the community. The major interest of this study is the coordination which occurs among the organizations in the community network. Definitions of coordination are presented along with both barriers and facilitators to coordinative activities. 
The revien of the literature to this point provides a setting and the actors for organizational interaction. What is needed is a perspective to explain the dynamics of the transactions. This is provided by social exchange theory. A historical perspective is presented along with the major propositions advanced by this theory. This, then sets the stage for building an Organizational Interaction Model in Chapter III.

\section{ORGANIZATIONS}

This section examines past and current thought on organizations with the purpose of developing the definition to be used for this research. Much organizational research looks at individuals within organizations, or component parts of organizations, but it is the intent of this study to focus on the organization and its relationship with other organizations in the community. This is accomplished through reports of individuals who work within the organizations. While it is true that the activities of organizations are carried out by individuals, the rationale for this empirical approach is well presented by Herman Turk (1970),

Our rationale lies in the assumption that ind $i-$ vidual behaviors depend on the presence of organizations that encourage or accept them, and that organizations are primary determinants of regularities and uniformities of human potential for such behaviors. Organizations must be assumed to be both the formulators and the means of individual action; organizations are the actors which comprise any large and complex structure.

The definition of the concept of organization is somewhat problematic. Brinkerhoff and Kunz (1972) point out that in the most 
simplistic sense organiztion, "implies recurrent patterned relationships between various parts of some unit". Etzioni (1969) defines organizations as "social units which are predominantly oriented to the attainment of specific goals". Hillery (1968) differentiates between communal organizations as "heavily institutionalized systems which lack defining goals", and formal organizations which ". . following Parsons, are characterized by primary orientation toward accomplishment of a specific goal"(p. 189). By a specific goal is mean one whose product is identifiable, whose product can be used by another system and whose output is amenable to contract, in the sense roughly that it can be bought and sold. (Hillery, 1968).

Brinkerhoff and Kunz (1972) make a distinction between "formal" and "complex" organizations. To them, formal organizations are del iberately established and include, "formal role prescriptions, a formal incorporation, by-1aws, an organizational chart, etc." (p.XV). Their definition of the complex organization includes the same components as that of the formal organization, but additionally includes ". . . such notions as multiple hierarchical levels, multiple functions, or multiple role systems". The concept of complexity does not "arise out of size alone, but out of interrelationships among the parts of the organization" (Brinkerhoff and Kunz, 1972). Blau (1968) presents the defining criterion of a formal organization as ". . the existence of procedures for mobilizing and coordinating the efforts of various, usually specialized, sub-groups in the pursuit of joint objectives" (p.298). Kaufman's (196!) definition of organization refors to all sets 
of human beings who exhibit: boundary demarcation, replenishment, elicitation of effort, coordination of effort, and channels of distribution (Guetzkow (1966) deliberately avoids inclusion of characteristics such as "cooperative relationship", "collective goal or output", and "ma intenance of hierarchical structure" in constructing his definition which ". . . designate(s) those groups of individuals in which interaction is mediated and indirect (but not excluding the direct) of somewhat enduring continuity, falling in size between face-to-face clusters and the larger collectivities, such as cities, states and societies" (p. 14).

In an effort to keep the definition as meaningful and specific as possible, while at the same time capturing the important basic components presented above, the following definition for an organization will be used:

An organization is defined as a social unit, del iberately established, predominatly oriented to the attainment of specific goals.

It is not the intent of this work to examine organizations per se but rather the interaction between them. To move the discussion from the definition of organizations toward organizational interactions, organizational interdependence must be considered.

\section{ORGANIZATIONAL INTERDEPENDENCE}

Litwak and Rothman (1970) contend that some level of interdependence must exist before organizational interaction will take place. This section describes interdependence, its causes, its 
many forms, and the levels most suitable for interaction. To give historical perspective, the concept of integration is presented as an introduction to the topic of interdependence.

The most basic definition of integration is "to bring together (parts) into a whole." An expansion of this definition is "a state in which the behavior of the individual is in harmony with the environment" (Barnhart, 1947, 1961). Durkheim (1897, 1951) was the first social researcher to systematically examine social integration. In his famous monograph on suicide, he demonstrated a relationship between the degree to which individuals are integrated into cohesive groups and their inclination to various types of suicide. (De Fleur, et al., 1971, 1976). As published in 196n, Durkheim related integration to two types of solidarity. "Mechanical solidatiry" is the integration of parts through common values and beliefs. These values and beliefs constitute a collective conscience that enables persons and groups to cooperate successfully. In contrast, "organic solidarity" is integration through interdependence; the parts of the whole reciprocate services as do the parts of an organism.

Parsons $(1937,1951)$ expanded on Durkheim's view in his discussion of normative integration. Such integration is achieved when the focal elements in the cultural system -- the society's common values -are institutionalized in structural elements of the social system. This occurs at three levels. Most general in application are norms that apply to certain categories or kinds of persons, such as men and women or mothers. Next are normative controls of collectives, such as 
schools or businesses. Finally there are structural roles within collectives such as teacher, pupil. Sanctions as well as specifications of correct conduct exist at each level. (See Angell, 1968).

Landecker (see Sills, 1968) distinguished four types of integration. Cultural integration is the consistency among cultural standards. Normative integration is the consistency between cultural standards and the conduct of persons. Communicative integration describes the extent to which the network of communication permeates the social system, and functional integration is the degree to which there is mutual interdependence among the units of a system of division of labor. (Angell, 1968). Litwak and Rothman (1970) defined a state of interdependence as occurring when "the acts of one organization affect those of another in an immediate way" (p. 147). They point out that in some sense, every individual affects another and that in the extreme, all organizations can be considered interdependent.

Hawley (1968) distinguished between two types of interdependence: symbiotic, on the basis of their complementary differences, and commensual on the basis of their supplementary similarities. Thomas (1957) suggests that interdependence can be facilitative (e.g., five agencies providing different services to the same client) or competitive (firms competing for a fixed market).

Litwak and Rothman contended that competitive interdependence requires "adjudicative functions".

The key point about competitive interdependence is that cooperation occurs under conditions of mistrust or threat. Ideally, the organizations involved would like to el iminate the others. This is an underlying 
threat despite their mutually avowed cooperation. As a consequence, any difference which might arise is always bound to be disputed. It is for this reason, we hypothesize that to be effective, there must be some way of settling disputes.

By contrast, facilitative interdependence means that each organization can gain from cooperating with the other. If differences arise, each calls for further clarification on the assumption that differences can only be a consequence of errors in communication ( $p .162,1970$ ).

Litwak and Rothman (1970) further contended that "partial interdependence" is the ideal basis for maintaining a confederation of organizations. A state of complete dependence would lead to merger and if there were no interdependence there would be no linkages. In their discussion of partial interdependence they inclucied the concept of reciprocity or symmetrical exchanges.

More precisely, there cannot be extreme asummetry in aid. In cases of extreme asymmetry in interdependence, we would hypothesize no linkages at all or complete merger depending on the inclination of the non-dependent member ( $p .148,1979$ ).

Both Blau (1964) and Litwak (1965) agreed that "modern symmetries" are consistent with interorganizational linkages and are important determinants of their shape. This thought is expanded by Litwak and Rothman (1970)

[S]ymmetry of dependence need not involve a direct exchange of similar services at a given moment of/ in time. Rather it may involve limited time lag as well as exchange of different services and indirect paths of exchange.

Litwak and Rothman (1970) also distinguished between homogeneous and sequential interdependence. In a homogeneous network, resources to one will help all. In a sequential system, each part is tied to the next in such a way that a large input of resources to one could break 
down the system. He used an example of a juvenile criminal justice system in which the schools and police serve as the intake for the system, the courts are the evaluation unit and diagnostic agencies, and probation and treatment agencies provide therapy. If, for example, the intake agencies were to receive a large amount of additional resources, the remainder of the system might be overlooked. The following reactions might take place:

(1) alter the rate of productivity

(2) take on the functions of the faltering institutions

(3) join in an effort to produce more funds for other agencies

(4) seek technological breakthroughs which enable other agencies to handle more tasks with the same resources.

Aldrich and Herker (1975) suggested three levels of study of organizational interdependence. These are: interdependence between two organizations, between focal organizations and their organizational sets, and among all organizations in a network of organizations. Mindl in and Aldrich (1975) and Pugh (1969) add to this list, the dependence of the organization to its more general environment, relating this variable to aspects of organizational structure.

Finally, awareness of interdependence can vary. McDonough (1968), as reported by Litwak and Rothman (1970), presents three distinct forms of awareness of interdependence.

(1) the urganization designates someone to coordinate

(2) the nembers of the organization are aware of a need for coordination

(3) the larger public are aware of theneed for coordination (p.150) Litwak and kothman (igjô) pointed out that organizations can be in 
states of interdependence and not recognize it, citing the example of numerous welfare organizations providing services to the same welfare families. This lack of awareness is not limited to the nature of interdependence but extends to lack of knowledge of the existence of the organization in the system.

The other side of the issue of lack of awareness of interdependence is overestimating the level of interdependence. Morris and Binstock (1966) have pointed out that all too often agency personnel meet with each other and attempt to coordinate their activities when, in fact, there is not sufficient interdependence to warrant it.

Litwak and Rothman (1970) contended that the higher the level of awareness of interdependence, the more effective are formal modes of linkages. This issue is discussed in more detail in the section on linkages.

Finally, level of awareness relates to cooperation and conflict. Brody (1963) explored the hypothes is that increased conflict would lead to breaks in contacts between large social groups. Contrary to his expectation he found that the greater the potential conflict, the greater the interaction. He explained this by pointing out that where people are aware of their interdependence, the increased competition forces them into closer cooperation. 
This brief review has demonstrated that some level of interdependence is necessary for organizational interaction. It is contended that partial interdependence is most conducive to interactions and that an accurate and adequate level of awareness is necessary for appropriate and meaningful interactions to occur. Given an appropriate level and awareness of interdependence, organizational interactions and linkages are likely. The conditions surrounding such linkages and interactions are presented in the next section.

\section{ORGANIZATIONAL INTERACTIONS AND LINKAGES}

To understand the circumstances under which organizations interaci, one must examine the nature of the interactions and the formation of interorganiztaional linkages. Benson (1975) contended that research in interorganizational relations is deficient because of "conceptual confusion and overlap". It is his view that the interorganizational relationship has proven to be a "complex, variegated, multilevel phenomenon". This section is intended as a brief overview of some of the considerations of interorganizational linkages and interactions.

Etzioni (1964) pointed out that substantial information is known about individual interaction, but little is known about organizational interrelationships. Aldrich (1970) contended 
that there are two principal ways to conceptualize interorganizational relations:

1. as relations between sub-parts of a larger unit, such as the level of relations between organizations in a community (Aiken and Alford, 1970; Turk, 1970; Warren, 1967), or

2. as relationship between a particular organization or social unit and other social units, such as between selected voluntary organizationa and other organizations (Aiken and Hage, 1968; Lefton and Rosengren, 1966), (p. 1).

This research examines both types of interorganizational relations.

Aldrich (1972) described three sets of assumptions which lead to the study of interunit relations:

1) Cooperative relations are "good", i.e., have beneficial effects upon performance, through efficient use of resources (Warren, 1967, Reid, 1964; Douds and Rubenstein, 1966), coordination of efforts and nonduplication of services. Curming (1968), however, has documented how such relations may also be conceived as a system of control over deviants.

2) Interorganizational relations are a means whereby organizations can maximize their use of resources in the interest of innovation and change (Hage and Aiken, 1968; Levine, White and Paul, 1963). The focus here is upon creating the conditions in organizations 
or cormunities for achieving higher levels of cooperative relations or joint programs which facilitate resource maximization.

3) Contracts, doma in consensus, overlapping boards, joint planning and programs are responses to environmental uncertainties (Cyert and March, 1963) which center around problematic contingencies (p.8). The study of interorganizational relationships is relatively new. As stated earlier, the major focus until recently was the organization and its internal function (Weber, 1947; Barnard, 1938; Simon, 1945; March and Simon, 1958). There were a few early exceptions, namely Selznick's (1949) work on the T.V.A.; Ridgeway's (1957) study of manufacturer-dealer relationships; Dill's (1958) comparative study of two Norwegian firms; Parson's (1959) concern with adaptation, goal attainment, pattern maintenance and integration; Levine and White's (1961) research on health and welfare agencies; Elling and Halebsky's (1961) study of hospitals; and Litwak and Hilton's (1962) study of cormunity chests and social service exchanges.

These studies examined various aspects of the organization's relationship with its environment. For the purpose of this study, the focus is narrowed to include only the interactions between the organizations and other organizations in the community. The fundamental question being, under what conditions do organizations interact. Benson (1975), in looking at service delivery, held that interactions ". . are ultimately dependent upon resource acquisition. Considerations of resource adequacy determine, within fairly restrictive limits, the nature of interactions in the performance of mandated functions" (n.23!). 
Benson (1975) following Yuchtman and Seashore (1967) assumed that,

Organization decision makers are typically oriented to the acquisition and defense of an adequate supply of resources. Such orientation becomes, for decision makers, an operational definition of the purposes of the organization and thus of their responsibilties as decision makers. (These) abstract purposes, charter goals and the like come to be translated into ongoing programs, established structures, and the training, history of personnel ( $p$. 231).

Not all interaction or linkage formation can be described as simple outgrowth of resource acquisition. The complexity of the matter was suggested by Litwak and Meyer (1966) who demonstrated in a study of Detroit schools that those organizations best able to form linkages were those with "extra" resources. The issue of resource acquisition as the basis of organizational interaction will be discussed in more detail in the section concerned with social exchange theory.

Closely related to the concepts of organizational interaction are organizational linkages. In fact, some authors view a linkage as a form of interaction (Hage, 1973; Litwak and Rothman, 1970). Linkages between organizations can be conceived of in a variety of ways; passage of information, transfers of clients or funds, inputoutput exchange and the sharing of facilities (Levine and white, 1961; Thompson, 1962; Aiken and Hage, 1968; Litwak, 1970). A number of authors have suggested various factors around which types of linkages can be arranged.

Lehman (1975) offered the following list: (1) type of control, (2) types of resources exchanges, (3) scope of interorganizational relations (how many different kinds of resources are involved), 
(4) sailience of interorganizational relations (how germane are the resources, i.e., goal relevant vs. ancillary) and (5) symmetry of interorganizational relations (direction of flow of resources, i.e., one-way or reciprocal).

Thompson and McEwen (1958) differentiated relationships by activities. Their list included:

(1) Competition, where there is no direct contact between the organizations though they share a common relation to some third party.

(2) Bargaining, in which there are 1 imited agreements between the two parties concerning the exchange of goods and services.

(3) Co-optation, where leadership elements of one organization are taken into another.

(4) Coalition formation, in which organizations become formally committed to joint decisions.

It should be noted that these activities are ranked in order of increasing interdependence and decreasing sovereignty of the organization.

Black and Kase (1963) presented a similar classification of relations between organizations: 1) informal understandings between agencies, 2) formalized referral procedures, 3) functional coordination, 4) joint programs or sharing of forces, and 5) interdiscipl inary staff for pilot projects. Klonglan (1969) adds "representation of other agencies on the board" and "in-service training of other staff" to the list.

Johns and Demarche (1957) suggested the following dimensions 
around which interagency relationships may be classified; those involving "further acquaintance with other agency leaders"; those resulting in an exchange of information; those which, in addition to furthering acquaintance and exchanging information, "result in specific consultation with representatives of other agencies"; those which, in addition to the above, result in "definite planning with representatives of other agencies" and those which result in "definite operating responsibilities with representatives of other agencies."

These typologies are based mainly on cooperative process or intensity of relationship but there are other potential factors. Litwak and Rothman (1970) examined the formality of linkages, ranging from impersonal rules through "friendship-type" links. An example of linkages characterized by impersonal rules would be the exchange of books between libraries, accomplished via written forms according to published rules. A mid-range of formality is evidenced by special linkage organizations such as the community chest, AMA, etc. These are characterized by paid staff whose purpose is to maintain the link. At the extreme end of informality are "friendshiptype" links which resemble primary group contacts between members of the agencies involved. Much of this type of interaction occurs informally between executives of the organizations invoived, i.e., over lunch or in presumably social situations (private clubs or parties).

Aldrich (1972) distinguished between "institutional" linkages, such as domain consensus, overlapping boards and committees, and "operational" linkages, such as information exchange, referrals, and 
shared resources of various kinds. He contends that the former may be based upon common values and understandings while the latter are based more on complimentarities in task.

Finally, Hollister (1966) speculated that there is pressure for internal consistency between the internal structure of organizations and their linking mechanisms. Thus, for example, rationalistic organizations would be most consistent with linkage structures which were formalistic, while human relations structures would be most consistent with structures which were primary group oriented.

It becomes evident that the study of linkages is a complex and multi-faceted task. Yet underlying the area is a recognition that linkages and interactions are somehow related to needs and transfers of basic resources. These basic resources include information, clients, funds, staff, and program (Levine and White, 1961; Thompson, 1962; Aiken and Hage, 1968).

As organizations develop linkages with each other, a network of organizations is formed. The next section describes various points of view relative to community networks, in an effort to describe the environment in which organizational interactions occur.

\section{ORGANIZATIONAL. NETWORKS}

In describing the environment in which organizational interactions occur, a discussion of the various perspectives of the concept of community is presented. The purpose is to better understand the broad place in which these interactions occur, and the function of interactions in determining the nature of that place. 
Rubin (1969) suggested that community is to be found in those social ties which bind the individual meaningfully to the larger society. These ties are found in concrete organizations and are characterized by primary and secondary interaction of the members. Such ties may be constituted within occupational roles, ethnic group affiliations, or religious groups. (See Warren, 1974). Rubin (1969) contended that locality is a relatively unimportant variable in defining community. Kaufman (1959) took a slightly different view:

Community must be differentiated from the local society, even though it is a locality-oriented phenomenon. It is best defined and investigated in terms of community actions, actions of coalitions of local people and organizations around local concerns (p. 9).

Bernard (1968) taking an approach from political science presented the following definition:

A community . . . is a territorially bounded social system or set of interlocking or integrated functional subsystems (economic, political, religious, ethical, educational, legal, socializing, reproductive, etc.) serving a resident population, plus the materiai cuiture or physical plant through which the subsystems operate (p. 163).

There is a general minimization of the importance of affect in these definitions. Tonnies $(1887,1957)$ utilized feelings and affect in putting forth his ideas of Gemeinschaft and Gesellschaft. Gemeinschaft refers to a "community of feeling" (a kind of associative unity of feelings and emotions) that results from likeness and shared life experience. "Natural will" (springing from individual's temperament, character and habits) predominates in Gemeinschaft relationships. 
Gesellschaft is predominated by rational will, and volition is dominated by thinking and the distinction between ends and means. Relationships are contractual and values are monetary. (Miner, 1974). Roland Warren (1974) presented two theoretical orientations for viewing the community. The first is what he called "concrete collectivity" by which he meant an

$$
\begin{aligned}
& \text { can be ciearly distinguished from its environment and } \\
& \text { is capable of acting as a social entity in its own right, } \\
& \text { thus having a set of its own interests which are clearly } \\
& \text { distinguishable from the interests of its constituent } \\
& \text { parts, and having its own specifically identifiable } \\
& \text { shared values and norms and being canable of developing } \\
& \text { goals and taking action toward accomplisning them (p. 1-2). } \\
& \text { The second, termed the "new ecology", views the community not } \\
& \text { as a collective entity but as "the simple aggregate of the clustered } \\
& \text { interaction of people and organizations occupying a restricted geo- }
\end{aligned}
$$$$
\text { graphic area, whose aggregate interaction, in both structure and function }
$$$$
\text { demonstrates not chaos or randomness but large areas of systematic }
$$$$
\text { inter-connections." There are often shared norms and values, but }
$$$$
\text { unlike the collectivity view, they tend to come from the macro-culture }
$$$$
\text { rather than being community-specific. The community's interest is }
$$$$
\text { "merely some aggregate of the individual interests of the parts" }
$$$$
\text { (Warren, 1974). }
$$

Elizabetil Bott (1957) presented what appears to be a combination of the two views. She did not look for a collectivity called community, but instead saw the community function performed within identifiable networks of relationships surrounding each individual. These individual networks, she found, are not random but systematically structured. 
(See al so, Scherer, 1972; Wellman and Craven, 1973; Warren, 1974).

The current study follows, more closely, Warren's (1974)

second model, the "new ecology". Warren called this the new ecology because:

.. . the ecological approach lends itself to analysis of the systematic nature of interaction and exchange patterns without making the assumption of collectivity orientation, or that the existence of systematic relationships implies a Parsonian collectivity. It is directed at the units which interact, and looks to the systemic nature of that interaction, rather than focusing on the inclusive system as the unit of analysis.

The new ecology is an ecology of social rather than physical space. It concerns itself with the systematic ways in which people and organizations interact within and across sectors of community concern. The existence of social space is implicitly recognized in terms such as field of interaction, organizational domains, and sectors of activity (p. 15).

One of the assumptions underlying the current research is that "communities" don't act. Instead, organizations and individuals act. Warren (1974) emphasized this by pointing out that what we often describe as "community actions are actions of particular combinations of individuals and organizations". These can either occur as coalitional activity within a sector (usually in larger cities) or follow the more conventional "community development" approach, by organizing a de facto formal organization representing various sectors.

The point is made in this section that community may be viewed either as the place in which interactions occur or as the aggregate of those interactions. Each of these definitions has meaning for this research. In the first instance, the community presents a place in wnich organizationai interactions occur. i̇ offers a set of norms 
a history, a combination of resources, and a set of actors. On the other hand, the community is the set of systematic exchanges and patterned interactions (Warren, 1974). In order to distinguish between these two meanings, the former definition will be called community; the latter will be called community network.

The community network requires some level of cooperation, if not coordination in order to exist. The next sections define and compare the concepts of cooperation and coordination, emphasizing the circumstances under which each is likely to occur.

\section{ORGANIZATIONAL COORDINATION}

This section develops a definition of coordination differentiating the concept from that of cooperation. Many of the definitions of cooperation are examined to determine the thread that ties them together. Barriers as well as pressures to cooperation are discussed and compared. As cooperation is less spontaneous and increasingiy directed, it becomes, for purposes of this research, coordination. The definition of coordination is followed by a discussion of the barriers and facilitators of coordination.

Cooperation was defined by Young (1949) as "joint striving with other or others for a good, goal, or value." Nisbet (1968) expanded this definition to describe cooperation as "joint or collaborative behavior that is directed toward some goal and in which there is common interest or hope of reward."

Cooperation may be voluntary or involuntary, formal or informal but always there is a combination of efforts toward a specific end in which aii of the participants have a stake, real or imagined (Nisbet, 1968) ( $P .384$ ). 
and Coordination Among Primitive Peoples. Demetrius Gusti (1941) studied formal systems of cooperation both within and among rural Rumanian villages.

More recentiy, interest in cooperation has been found among the industrial psychologists (directed cooperation), the child psychologists (spontaneous cooperation) and the social ecologists (unconscious cooperation). (Nisbet, 1968, and Long, 1958). Each discipline carries its own definitions and assumptions related to the concept.

Cooperation can be viewed as an ethical norm, a most honored value. Some philosophers make cooperation synonymous with the whole fabric of morality. Cooperation can be a social process, central to evolution and related to both change and stability. Finally, cooperation can be viewed as a social structure, seen in the many organizations created for the purpose of pursuing goals. (Nisbet, 1968).

Nisbet (1968) continued to list five types of cooperation.

Automatic, which refers to varied types of impersonal coordination, jointness of behavior and mutuality of interest that arise directly from ecological position (e.g., modern economy and relations between religious groups).

Traditional, which is regulated neither by instinct, volition, nor simple location but by traditional norms (e.g., Chinese clans, merchant guilds).

Contractual, in which the terms of cooperation are specific and conditional upon the will of the participants or governed by regal sanctions (e.g., credit unions, consumer cooperatives).

Directed, which is incidentally derivative of common recognition of a goal or norm (e.g., military organizations, modern complex organizations). 
Spontaneous, which is situational in character, usually occurring when some amity is present, unprescribed by contract or command ( $p .385$ ).

Levine and White (1961) held that for all views of cooperation, the basic underlying motivator is scarcity.

Theoretically, then, were all the essential elements in infinite supply, there would be little need for organizational cooperation as an ideal. Under actual conditions of scarcity, however, interorganizational exchanges are essential for goal attainment ( $p .585$ ).

Levine, et al. (1963) added a cautionary note.

We should not assume that executive personnel always know their organizational self interest and are ever acting in its behalf. In fact, over concern with the immediate acquisition of elements may have long-run negative consequences ( $p$. 1192).

In their 1963 study of problems in providing medical care and social services, Levine (et al., 1963) described seven categories of cooperation, based on what was sought, i.e., (1) more referrals, (2) more or better case information, (3) more or better personal services to patients, (4) more non-human resources (technical information, equipment, etc.), (5) more money, (6) more information on agency services, and (7) more planning and/or cooperation.

In addition to scarcity as a motivator for cooperation, empirical studies indicate that the normative structure of the community values and thus pressures the organization into cooperation. In his study of coordinating councils, Basil Mott (1968) discussed this finding.

Examples of disinclination of council members to work together in manipulating their external environment are more difficult to find than examples of cooperation. This is true partly because it can be 
costly to be uncooperative in our society. Organizations as well as people are expected to be cooperative even though cooperation may not serve their best interests (p. 70).

Despite these elements leading toward cooperation, there are many bases for resistance to cooperation on the part of organizations. The first such barrier is fear of losing autonomy. Thompson (1967) held that a central tenet of the organizational literature is that leaders of organizations attempt to maximize the autonomy of the organization they lead, to decide for themselves how they will spend their money, on what programs and services for which clients. Desire for autonomy often makes organizational leaders reluctant to enter into interdependent service delivery systems. A1though organizations may be willing to enter some cooperative relationships, to transfer clients (Levine and White, 1961) and to attempt joint programing (Aiken and Hage, 1968), they are reluctant to join together in the same delivery system. Thus, fear of losing autonomy places a limitation on the level of acceptable cooperation.

Lack of information is another potentiai barrier. Banfield (1961) pointed out in his analysis of comunity decisions that efforts to coordinate organizations frequently floundered because there was no knowledge upon which to base decisions. Moreover, the members of the various organizations were not in sufficient personal contact nor did they trust each other sufficiently to coordinate through proper channels. Competition, defined by Nisbet (1968) as a process in which efforts toward a comon objective are separate and in rivalry with one another, 
has been viewed by most authors as a barrier to cooperation (Mott, 1968; Banfield, 1961). Nisbet (1968), however, bel ieved that competition and cooperation have a "contributory" relation with one another.

Competition requires at least the degree of prior cooperation that is necessary for the setting of rules and imposing of sanctions without which, competition becomes open war. Conversely, it is doubtful that cooperation would be the major force it is were it not for pressures of competition that spur some to cooperate with others as a means of enhancing their effectivenss in the struggle for existence (p. 385).

Another barrier to cooperation relates to the differences between world view held by various professionals and between world view held by professionals and non-professionals (Levine, et al., 1963). Professionals from different disciplines tend to hold different values, assumptions and perceptions of problems and needs. Thus, a physician would be more likely to view a client's problems as health related, a social worker may view that same client's situation quite differently. This lack of agreement in world view can lead to resistance to cooperation.

Different authority structures for organization may be potential barriers to cooperation (Levine, et al., 1963). An organization with a clearly defined, authoritarian, hierarchy is quite likely to have difficulty in cooperating with an organization which is very egalitarian with little vertical hierarchy. Johns and Demarche (1951) also described "personality conflict" as a condition presumed to be a barrier to cooperation as are "vested interests" (either individual or organizational). Participation in a cooperative relationship, such as being a 
member of a coordinating council can be costly as pointed out by Basil Mott (1968).

Sometimes the members of the council felt that it was a potential threat both in their relations with groups in their environment and in their relations with each other.

Participation in the Council opened new channels of interaction with outside agencies, and thus exposed the members to new influences from the environment that could threaten a member agency's autonomy and the security of its functions and resources. For example, an agency sometimes found that its relations with the Coundil could cause an unfavorable change in the attitudes and expectations... from outside groups toward its activities. Occasionally, regular lines of access to influential organizations were weakened or bypassed as a result of Council action. Membership on the Council also created involvements that sometimes could not be shed easily without cost. For example, gaining a reputation for being uncooperative could cause legislators or budget examiners to be less sympathetic to an agency when funds were approved (p. 72).

Administrators, however, have expressed considerable concern about reducing barriers to cooperation, and in achieving greater coordination among health and welfare agencies. Levine and White (1961) contended there is empirical evidence that "interagency cooperation per se is necessarily related to organizational effectiveness." There is good reason to believe that for some agencies, at least some organizational objectives would be furthered by greater cooperation with other agencies. But organizations seeking empirical evidence of positive outcomes of coordination would have difficulty in finding such data.

This is not to mean that no such evidence is available. Basil Mott (1968) presented the following narrative to describe cooperative 
actions and their benefits.

The discovery of common interests among agencies led to joint training of their professional and management personnel, such as joint participation in a high level management training program under the auspices of the Civil Service Department. The agencies also found it mutually advantageous to develop better procedures for the overlapping interests in improving the quality of educational services to persons confined to state institutions led to agreement on an extensive series of recommendations for improving $1 i$ brary services to inmates. Although other factors were influential, the preparation by most of the Council's standing committees of one or more guides to available state services, ... attributed in large part to the direct benefits received by the members. By spreading the word about their programs, and by learning the dimensions of other's services, they facilitated the exchange of resources, such as clients and information (p.68).

As cooperative efforts include increasing degrees of "directedness", i.e., some third party (which may be one or more of the involved organizations) "orchestrating" the cooperation, coordination occurs. The concept of coordination is closely related to cooperation. So closely that the definitions of coordination used by some authors are indistinguishable from definitions of cooperation. Brinkerhoff and Kunz (1972), for example, defined coordination as "the orderly arrangement of group efforts". Aiken, et al. (1975) made more specific the definition of coordination as "the articulation of elements in a social-service system so that the comprehensiveness of, compatability among and cooperation among elements are maximized".

March and Simon (1958) defined coordination as "the problem of arranging the signaling system for independent conditionsl activities", and they discuss two methods of coordination as a part of this definition; coordination by pian and coordination by feedback. The primary difîerence 
between these is the degree to which activities are standardized. Thompson (1967) utilized the concept of coordination as adequate linkages of organizational parts so that objectives can be achieved. Like March and Simon, he emphasized the degree of sequencing and linkage of various programs or other elements.

Aiken, et al. (1975) concluded that a definition of coordination must include the following elements. The first is comprohensiveness, that is that the system contain all the resources and programs necessary to service clients. The argument for this component forwarded by Terryberry (1968) and others holds that coordination is inherently conservative and applicable only to stable, unchanging systems if consideration is 1 imited to programs currentily in the system. The next component is compatability, meaning that all components of the system are appropriately sequenced and linked. Finally, a definition of coordination must contain an element of cooperation. This relates to the quality of the relationships between the human actors in the delivery system. Cooperation, by their definition, contains both a behavioral component (common effort, joint operation) and an attitudinal component (willingness to work together, absence of selfishness).

It can be noted that definitions of coordination may be either related to a product, i.e., a state of the network (Brinkerhorf, et al., 1972) or to a process, i.e., arranging elements in the network (Aiken, et al., 1975; March, et al, 1958). This research utilizes a process definition related to the efforts of a third party to influence interactions within the community network. 
For this siudy, coordination is defined as goal directed intervention in the community network.

Given the necessary components are available for coordination, why does coordination happen? Likert (1967) șaw cooperation, in the sense of "favorable attitudes and confidence and trust", as a necessary condition for coordination within an organization and this would seem to apply even more to the relationships between organizations. Aiken, et al., offered the following explanation:

There are different problems of coordination for each level. At the institutional level, the problem is primarily one of gaining sufficient resources from the environment of the service delivery system: for example, funding from federal, state and local governments as well as private sources. At the organizational level, programs and service components are invariably conceived, developed, and delivered by service delivery organizations, whether a county welfare department, a private rehabilitation organization like Goodwill Industries, or a local mental health center. Whether these programs and services are concentrated in a single superagency or scattered across a host of autonomous agencies that may offer competing and overlapping programs the central problem is linking these diverse program elements into a coherent "system" of service deivery. The recipient, or consumer of the service delivery system is best coordinated at the level of the individual case worker. The critical problem here is to ensure that the client has the services needed in the proper sequence and at the proper time. Finally, information needs to be coordinated at all levels of the service delivery system that is, information about obtaining resources from the environment, transforming these resources into programs and services, and delivering them effectively to clients $(1975$, p.16). Levine, White and Paul (1963) described the force toward coordination as being a function of certain needs of individual organizations. 
Every organization has some kind of goal or objective toward which it directs its activities:

It must have recipients to serve (directly or indirect1y); it must have resources in the form of equipment, specialized knowledge, or funds; and it must have the services of personnel to direct these resources to the recipients. Few, if any, organizations have access to enough of these elements to attain their objectives fully. Under realistic conditions elements are scarce and organizations must select the particular functions, services or activities which permit them to achieve their ends as fully as possible (p. 1185).

There are additional problems facing the service community in the delivery of the appropriate services to the client in need. This 1ist includes: fragmentation of services (March, 1968; Gilbert, 1972); inaccessability of services (Gilbert, 1972); lack of accountability of service delivery systems (March, 1968; Gilbert, 1972; Kahn, 1972); discontinuities in services (Gilbert, 1972); dispersal of services (March, 1968); wastefulness of resources, ineffectiveness of services and short term commitment (Aiken, et al., 1975). Each of these problems is potentially affected by coordination.

Litwak and Rothman (1970) list still another reason for coordination.

A single organization is designed to deal with one goal or one mean, or multiple goals or means but only if they are consistent and can be ordered in some rational way. By contrast, it is suggested that a confederation of organizations is ideally suited for maintaining differences ... the entire political theory of "checks and balances" is based on the idea that there are governmental processes which are different, not completely consistent with each other, and which must be preserved (p.140).

There is an additional argument supporting coordination which relates to economies of scale. This argument moves in two directions. 
Litwak and Rothman (1970) agreed that the costs in maintaining the kind of communication and centralized authority needed to expand a single organization to meet all community needs can become too great, leading to the splitting off of organizations into small units which coordinate with each other. Additionally, where tasks are idiosyncratic or non-standardized, a series of small organizations cooperating as a confederation might have greater speed and flexibility than one large organization. The other aspect of the economies of scale argument relates to the observation that individual organizations can reduce costs by sharing certain functions. For example outreach, or training could be a coordinated effort rather than repeated by each individual organization.

Once it is assumed that there is a situation appropriate for coordination to occur, what are the elements to be coordinated? Aiken, et al. (1975) listed four: programs and services, resources, clients and information. These elements are related to the components of comprehensiveness, compatability, and cooperation in Table I (Aiken, et al., 1975). What Aiken et al. (1975) described in Table $I$ is a conceptualization of an ideal type community service system. Each of the elements is presented in its optimum relationship relative to comprehensiveness, compatibility and cooperation. This table will be instrumental in the development of the Organizational Transactions Model in Chapter III. A more detailed description of Table I follows. 
Table I

ELEMENTS REQUIRING COORDINATION *

\begin{tabular}{|c|c|c|c|}
\hline \multirow[b]{2}{*}{ System Element } & \multicolumn{3}{|c|}{ Aspect of Coordination } \\
\hline & Comprehensiveness & Compatibility & Cooperation \\
\hline Programs & $\begin{array}{l}\text { all needed services, a continuum } \\
\text { of care }\end{array}$ & $\begin{array}{l}\text { all needed sequences; all } \\
\text { needed joint programs }\end{array}$ & $\begin{array}{l}\text { professionals work together } \\
\text { and with other parties }\end{array}$ \\
\hline Resources & all needed funds and autonomy & $\begin{array}{l}\text { correct allocation on basis } \\
\text { of client need and case } \\
\text { load }\end{array}$ & $\begin{array}{l}\text { resource controllers work } \\
\text { together and with other } \\
\text { parties }\end{array}$ \\
\hline Clients & $\begin{array}{l}\text { all eligible clients are treated } \\
\text { and in all area in which they } \\
\text { have needs }\end{array}$ & $\begin{array}{l}\text { services are received in } \\
\text { correct sequence consis- } \\
\text { tent with individual needs }\end{array}$ & $\begin{array}{l}\text { client representatives work } \\
\text { together and with other } \\
\text { parties }\end{array}$ \\
\hline Information & \multicolumn{3}{|c|}{$\begin{array}{l}\text { central recold keeping (clierts), directory of services (programs), knowledge about available } \\
\text { resources, and continuous feedback relative to the operation of the system at all three levals }\end{array}$} \\
\hline
\end{tabular}

* Summarized from Aiken, et al. (1975) 
The coordination of programs and services was defined by Benson (1975) as work coordination. Work is coordinated to the extent "that programs and activities in two or more organizations are geared into each other with a maximum of effectiyeness and efficienty". This could include a range of activities ranging from an understanding of the types of services provided by an organization through sharing of staff to provide such services or abdicating certain responsibilities to another organization.

Benson, et al. (1973) developed three dimensions of work coordination: the extent of agency interaction, the degree of program articulation and the flexibility of relationships. Their discussions of each are presented below.

The extent of agency interaction can be assessed using a variey of indicators such as referrals, providing information about services, sharing clients' files, collaborating in the formulation of programs, and planning jointly the services to specific clients. The adequacy of services to cl ients should, in general, relate positively to the frequency and breadth of such interactions.

Program articulation reiates to the extent to which programs of network agencies coordinate with each other. It can be measured by analysis of the effective division of labor between organizations, the way in which several programs are geared into each other, and the way in which competitive features between programs are minimized.

Flexibility of relationships refers to the extent to which agencies are free from formal rules or guidel ines that inhibit the sharing of services to eligible clients. The interaction between agencies is said to be more adaptable and flexible when it is dependent more upon the judgment of personnel rather than dictated by an overly complex set of rules. Flexibility can be lost by extensive formalization of relationships (p. 4). 
Coordination of resources is often related to conflict management, in that many conflicts arise because of scarcity of resources. Aiken, et al. (1975) discussed coordination and cooperation in terms of the "resource controllers".

Cooperation implies a consistent set of values controlling the use of resources. Concretely, such coordination involves the integration of resource controllers, that is, various government agencies and private agencies that control funding and thus have power over organizations in the service delivery system. Each of these resource controllers has different values and therefore different priorities. Enough cooperation among resource controllers must be achieved so that all values are represented and they do not cancel out each other's efforts (p. 13).

Coordination of clients refers to concepts such as "case management", "case accountability", and "case monitoring". The major concern is that the client receive the appropriate service at the right time, with the least amount of bureaucratic problems. Kahn (1972) stressed the importance of this type of coordination. Aiken, et a1. (1975) pointed out that there are certain types of clients for whom coordination is particularly important. These include: "the mentally retarded, patients for medical services (particularly those with chronic or disabling diseases), the physically disabled such as the blind . . . ." In essence, coordination is particularly important for those who might have difficulty negotiating the system on their own.

Problems in the coordination of clients are frequent. Acceptance of clients in social service organizations depends on social, cultural, and historical factors, not just the needs of the client (Friedson, 1966; Cumming, 1968; Fried, 1969). Agencies sometimes refer 
clients to places that profit the agency rather than to places good for 'clients (Greenly and Kirk, 1973). Additionally, agencies like to have the "right" clients, frequently those most responsive to services or those most "attractive" to public sympathy rather than those with the greatest need (Aiken, et al., 1975).

Coordination of information relates both to new inputs, sharing and feedback. Aiken, et al. (1975) described two types of information coordination: internal and external. External coordination of information concerns the degree to which information about service opportunities is available to those who are not yet in the system but who seek to make use of it. Internal coordination of information involves the operation of service delivery systems themselves and relates to evaluation and feedback. Namely, are the programs accomplishing the goals they were designed to achieve.

As pointed out earlier, by Banfield (1961), efforts to coordinate organizations frequently fail because of a lack of knowledge upon which to base decisions. Conner's (1966) analysis of decision making contained an "ignorance axiom". "Given no information to the contrary, any actor will assume any other actor's motivations and evaluations are similar to his own". (see Camilleri, et al., 1972). This, in many cases, leads to mistaken predictions and assumptions. Coordination of information requires accurate, complete information, wherever possible, and closely relates to the coordination of clients, resources, programs, and services.

Once the elements of coordination are present and the "push to coordinate" occurs, how does coordination happen? 
Edward Lehman (1975) in his study of the coordination of health care systems, presented three types of mediation.

Laterally linked field or interorganizational feudalism, in which the activities of the member units are more heavily oriented toward information and consultation than joint decision making. The member units retain control of strategic resources and the responsibility for wielding systematic power is dispersed among the administrative centers of member organizations.

Mediated interorganizational configurations, in which formal units coordinate the articulation of several organizations. It consists of a plurality of organizations, each unit of which has its own set of goals and collaborates periodically with the others. Collaboration is facilitated by an agency that funnels resources, communications and services. The ratio of co-decision making activities is higher here than in laterally linked feudai ism.

Guided interorganizational configurations: empires and corporations, which are specifically concerned with co-decision making and presumes that control is exercised by an agency acting for or on the system as a whole. This agency may be one of the organizations or a corporation.

Litwak and Rothman (1970) also referred to levels of coordination in making a distinction between autonomous versus dependent 1 inkages. Dependent linkages are those which can set up negotiations but must return to member organizations for ratification of decisions. Autonomous linkages are those from which legally binding decisions can come. 
Examples of these are union arbitrators or a community chest which funds members. They continued on to explain that organizations are least likely to surrender autonomy in situations in which they feel their existence threatened. They are, however, more likely to surrender autonomy to an impartial expert.

Fears of losing autonomy were found by Basil Mott (1968) to be an important barrier to coordination and cooperation.

The principal costs of discouraging cooperation in managing their direct relationships were the potential threats to agencies' functions and resources implicit in joint decision making. No matter how i ittile autonomy is lost by letting outsiders in on one's affairs, there is always the possibility that vital interests may be compromised (p. 72).

Another barrier to coordination is formed by the ideological commitments of professionals in various agencies. These ideologies may affect the way the world is viewed, how need is defined, what treatments are considered appropriate and which outcomes are considered successful. As Aiken, et al. (1975) stated ". . . not unexpectedly, each profession, generally perceived its own area of expertise as the critical one."

The clients themselves may pose a barrier in that ideologies of various organizations or professionals conflict with their own. Additionally, various client groups may have different interests and resources. For example, the interests and resources of middle class elderly may be different than elderly from the working class. These conflicting interests frequently can cause a cancellation of effort rather than a channeling of energy. 
Resource controllers may be divided and uninterested in the problems of the difficult client (Aiken, et al. 1975). Scarcity of resources has already been mentioned as a barrier to cooperation by Litwak and Rothman (1970) and others. Lack of resources leads to competition which can be a barrier to coordination, however, certain kinds of competition for scarce resources can lead to coordination, where joint efforts may result in resource acquisition (see section on cooperation).

Finally, resistance to coordination may be explained as resistance to change. Resistance to change has been studied (Mann and Williams, 1969; Zaltman, et al., 1973, Hage, 1974) and one established finding is that resistance to change decreases if those affected by the change are allowed to participate in planning and implementation (Coch and French, 1948; Selznik, 1949).

The form of resistance to coordination may range from unobtrusive unwillingness, through dramatic refusals to participate, to attempts to block coordinative efforts (Mott, 1968). Coser (1956) pointed out that "... conflict is not necessarily the opposite of coordination and while excessive conflict may easily prevent coordinated action, minimal conflict may be consistent with coordinated action and riay even prove to be positively helpfur."

Assuming that coordination of organizational interactions is a goal, this section has presented an overview of the elements to be coordinated, the forces which bring about coordination and barriers to coordination. What is missing is a theoretical perspective which 
ties together these pieces into a meaningful whole. Such a perspective is offered by social exchange theory, which is discussed in Section VII.

\section{SOCIAL EXCHANGE THEORY}

The theoretical perspective for this dissertation, social exchange theory, presents a multi-discipl inary background. This section will briefly trace the history of social exchange theory and discuss the ma.jor propositions of this theory.

The selection of a theoretical perspective is influenced by many factors. Some are directly related to the investigator's personal experience and preference. Others are more directly related to the nature of the research. Additionally, the more formal criteria for evaluating a theory may be taken into consideration. Baggaley (1964) presented a set of such criteria for consideration.

Internal consistency is the first criteria listed by Baggaley. This requirement holds that there must be no logical contradictions involved in the relationships between theoretical constructs. Yerifiability relates to operational definitions and applies to the translation between theoretical constructs and empirical data. A theory which covers a wide range of phenomena is ordinarity more intellectually satisfying than one restricted to a small domain of observations, and this refers to the criteria of comprehensiveness, the range of phenomena the theoretical framework attempts to encompass. Another criteria relates to the closeness of fit of theory to data. Baggaley points out that, generally speaking, the more comprehensive a theory, 
the less likely it is to give a close fit to the data. The final criteria listed by Baggaley is parsimony, i.e., the simpler the theory the better. Parsimony is often accomplished by sacrificing comprehensiveness and closeness of fit.

This list is not intended to be exhaustive. Other criteria have been offered and used, such as, heuristic value and level of explanation (Ha:1, et al., 1967). The purpose of this list is to suggest potential criteria for the evaluation of social exchange theory as a perspective for this dissertation.

Additionally, Glaser and Strauss (1967) hold that theory serves other purposes as well, namely: (1) to enable prediction and explanation of behavior, (2) to be usefur in theoretical advance, (3) to be useful in practical applications, (4) to provide a perspective on behavior for research in particular areas of behavior.

It is intended that the theoretical perspective chosen will adequately meet Baggaley's criteria as well as those purposes outlined by Glaser and Strauss.

The Origins and History of Social Exchange Theory

Social exchange theory finds its origins in economics, psychology, anthropology, and sociology. Each discipline offers both common and unique ideas to the overa 11 perspective entitled "exchange theory".

The first basis is derived from classical economic theory's descriptions of an individual's market beha:ior. Samuelson (1967) listed the following as one of his basic definitions of economics. 
Economics is the study of those activities which, with or without money, involve exchange transactions among people (p. 4).

This definition leads to two basic assumptions, central to economic theory (Ferguson, 1969).

(1) Each consumer seeks to maximize his utility and satisfaction through the exchanges in which he participates.

(2) Full knowledge of: the range of goods and services available on the market, the exact price of each, and his money income of the planning period is necessary (p. $11-12)$.

In actuality, these assumptions are not entirely rigid. In the first case, the consumer does not always seek to absolutely maximize his satisfaction, but regularly will seek instead to achieve some profit, not necessarily the maximum. In the second, while "some knowledge" is necessary, "complete knowledge" as defined above, is rarely, if ever, achieved.

Economic exchange theory is generally characterized by bilateral complete transactions in which the two parties or groups agree on the values of the commodities exchanged. While some authors stress the importance of money in the determination of the value of the commodities exchanged, there is general recognition that many factors, including the value structures of the participants influence transactions (Ferguson, 1969).

It is important to keep in mind that the transaction includes not only benefits (e.g., the value of the commodities received) but also costs. These costs are not calculated simply as the value of the commodities, but include considerations such as the effort required to make the exchange. Additionally, the motivation of gain is not the only determining factor of an exchange. Adam Smith in 1761 pointed out that: 
To reward is to recompense, to renumerate to return good for good received.

To punish, too, is to recompense, to renumerate though in a different manner, it is to return evil for evil that has been done (1761, p. 139, see Blau, 1967, p. 19).

Behavioral psychologists emphasize the importance of reinforcers as determinants of behavior. This view places stronger importance on the individual actor of a dyad or group. A reinforcer is anything which alters the probability of a response. If a man is more likely to work if given money for that work, then money, by definition, is a reinforcer. Harrison (1972) distinguished between primary and secondary reinforcers. A primary reinforcer is anything which will diminish a biological deficit or hardship (food, water, heat). Secondary reinforcers, such as money, approval from others, and promotions, are thought to acquire reinforcing properties through classical conditioning. The comodities of exchange discussed by economists are reiforcers and are governed by similar rules.

An increased emphasis on the range of values applied to a single commodity is made by both behavioral and social psychologists (Kendler, 1968). Rewards, or satisfactions, derived from the relationship with another individual or group were seen by Thibaut and Kelly (1959) as the motivation for interaction. This view is in the context of game theory. The important factor here is the "outcome", or the difference between reward and cost. They conceptualize the patterning of interaction, most explicitly within dyads, as a function of the actors making choices among alternative responses, Because of their emphasis on outcomes as determinants of interaction choices, they devote considerable attention to conceptualizing the criteria whereby actors evaluate their respective 
outcomes, present and anticipated (Solomon, 1970).

George Homans $(1950,1961)$ expanded social exchange theory by applying principles of behavioristic psychology to social interaction. He presents the important elements of exchange theory as:

Activities, which refer to all behavior involving objects and may include transactions of physical objects and materials to other people.

Sentiments, which include feel ings, emotions, attitudes, and beliefs, or the affective-cognitive components of behavior : . . attitudes are overt behavior and can be directly observed, such as the desire for social approval.

Interaction, which refers to activity directly affecting the relationship of two individuals, i.e., a man rewards or punishes another $\operatorname{man}(p, 30-31)$.

This emphasis on sentiments and values greatly expands on the thinking of economists relative to the valuing of commodities. The exchange transaction is made more complex by an increased consideration of the motivation of the participants as much more than maximizing simple economic gain. The following propositions are central to Homans' theory,

1. 'If in the past the occurrence of a particular stimulussituation has been the occasion on which a man's activity has been rewarded, then the more similar the present stimulus-situation is to the past one, the more likely he is to emit the acvitity or some similar activity, now, In other words, we tend to retain behavior that is satisfying ( $p .53)$.

2. 'The more often within a given period of time a man's activity rewards the activity of another, the more often the other will emit the activity.' Activity and reward tend to be related in the relation of Peraon and other. A simple illustration is our tendency to help those who thank us (p. 54). 
3. 'The more valuable to a man a unit of activity another gives him, the more often he will emit activity rewarded by the activity of the other.' Value, like satisfaction, is a determinant and is measurable in the rate of exchange. When we must choose between two satisfying activities, we tend to select the one with value (p. 55).

4. 'The more often a man has in the recent past received a rewarding activity from another, the less valuable any further unit of that activity becomes to him.' Satiation may appear, which will lower the frequency of the given activity (Homans, 1961; see also Sargent and Williamson, 1966, p. 56).

It should be noted that predicting behavior from these propositions is somewhat problematic since propositions two and four appear to predict opposite outcomes from similar situations. Thus, frequency of reward leads both to an increase and a decrease in activity level. Interpretation leads us back to the economic concept of marginal utility, i.e., at some point, each additional unit of a commodity is of less value than the last. Thus, we could predict an increase in the reinforced behavior to a point, after which a decrease and eventual satiation (cessation of the behavior) would occur. (Samuel son, 1967; Kendler, 1968). Homans (1961) contended also that an individual compares his payoff not oniy to his oun costs and rewards (absolute profit) but also to the rewards, costs, and profits of those persons with whom is he in interaction (relative profit). Homans viewed these comparisons as based on "distributive justice."

Ekeh (1968) pointed out that the satisfaction or dissatisfaction that issues from such a comparison is purely "psychic and is in point of fact the process that is inyolved in the phenomenon known as relative deprivation".

Anthropoligists have taken a different perspective and offer 
valuable additions to the view of exchange as developed thus far, Observation of "primitive" societies led to a new understanding of the function and significance of the exchange of gifts and commodities. Marcel Mauss (1954) in his book, The Gift, stated:

In theory. . gifts are voluntary but in fact they are given and repaid under obligation .... Further, what they exchange is not exclusively goods and wealth, real and personal property, and things of economic value. They exchange rather, courtesies, entertainments, ritual, mi 7 itary assistance, women, children, dances, and feasts, and fairs in which the market is but one element and the circulation of wealth but one part of a wide and enduring contact (p.l,3).

Levi-Strauss (1964) summarized Mauss' conclusions as follows:

. . first of all, in primitive societies, exchange consists less frequently of economic transactions than of reciprocal gifts; secondly, these reciprocal gifts have a much more important function in these societies than in (sic.) ours; finally, this primitive form of exchange is not wholly nor essentially of an economic character, but is what he (Mauss) calls a 'total social fact', i.e., an event which has at the same time social and religious, magic and economic, utilitarian and sentimental, legal and moral significance (p. 43)

Mauss stressed the point that in primitive societies, social exchange is not so much an interpersonal matter, as much as intergroup. Talcott Parsons (1961) pointed out that Mauss demonstrated that while individuals carry on the exchanges, these are meant to estabiish a relationship between persons who occupy focal positions in a social structure, In other words, the motives for exchange are primarily social and only secondarily economic. we do not $f$ ind simple exchange of goods, wealth and produce through markets established among individuals, For it is groups and not individuals which carry on exchange, make contracts and are bound 
by obligations; the persons represented in the contract are moral persons, clans, tribes and families; the groups, or the chiefs as intermediaries for the groups, confront and oppose each other (Mauss, 1975, in Parsons, et al, 1961 , p. 169).

Bronislaw Malinowski (1922), in his description of the Trobriand Islanders, illustrated the permanence of patterns of interaction and exchange, Once an exchange relationship has been established it becomes a social institution. At the same time, social norms determine which exchange relationships will be established. The relative permanence of exchange networks and the interdependence between social norms and exchange are important features in current conceptualizations of social exchange theory.

Levi-Strauss' (1964) theory of exchanges was summarized bv Ekeh (1968). First, exchange is a group phenomenon, even though individuals are the actors engaging in it. Secondly, Levi-Strauss viewed exchange as more prominent in "primitive societies rather than in Western societies". Thirdly, exchange promotes group integration, with the needs of the group more important than those of the individuals engaging in the exchange transactions. Fourthiy, exchanges are of two types: genera?ized and restricted. In restricted exchanges, the transaction is between two individuals or groups. In generalized exchange, there is not a direct transaction between two individuals in the sense that an individual receives from the individual to whom he gives. Rather $A$ gives to $B$ who gives to $C$ and so on, Eventually $A$ may receive, as in

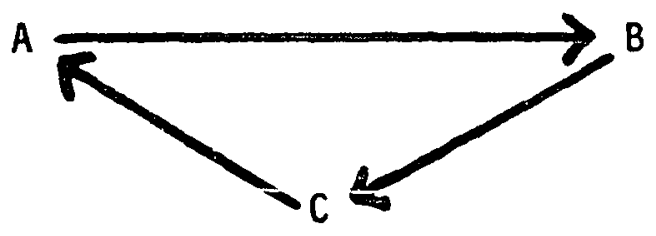


Levi-Strauss believed that generalized exchange is superior to restricted exchange because:
a function progress by way of restricted exchange is greater than local ( $i, e_{,}$, original) groups to partici- pate in exchange .... On the other hand, generalized exchange possesses a great fecundity: in effect, gener- alized exchange allows the group remaining the same in extension and composition, the realization, in heart of (sic.) this mechanically stable group, a greater organic solidarity (Levi-Strauss, 1949; See Ekeh, 1968, p. 548).
The first point encompasses Mauss' explanation of the societal
influence on exchange. Expanding on the second point, while Mauss saw only "survivals" of exchange in modern society, Levi-Strauss viewed exchange as important in Western society, though more "formalized and
As Coser and Rosenberg (1964) explain, ... even in Western societies, social life is governed to a very large extent by exchanges between persons. Both in formal relations (as in political parties) and in informa $i$ relations (when strangers first confront each other) social exchange, at least at the symbolic level, is a mode of behavior in Western societies (p. 76). prominent" in primitive societies.

The economic impact of Christmas, as a "giant potlash" (sic.) cannot be ignored as an example of a vast exchange operation, (Coser and Rosenberg, 1964).

Peter Blau (1964, 1967) examined social exchange in some depth. To him, social exchange, ", , may reflect any behavior oriented toward socially mediated goals". He differentiates social exchange from economic exchange in the following ways:

Social exchange differs in important ways from strictly economic exchange. The basic and most cruciai 
distinction is that social exchange entails unspecified obligations. The prototype of an economic transaction rests on a formal contract that stipulates the exact quantities to be exchanged. Social exchange, in contrast, involves the principle that one person does another a favor, and while there is a general expectation of some future return, its exact nature is not stipulated in advance (Blau, 1964, p. 93).

Blau listed other differences as well. In his view, only social exchange tends". . to engender feelings of personal obligation, gratitude and trust." The benefits of social exchange also differ. In addition to not having an exact price (in contrast to economic commodities) the specific benefits exchanged are sometimes primarily values ". . as symbols of the supportiveness and friendliness they express . . . ." Blau (1964) continues:

The fact that furnishing benefits to others tends to produce... social rewards is, of course, a major reason why people often go to great trouble to help their associates and enjoy doing so. We would not be human if these advantageous consequences of our good deeds were not important inducements for our doing them. There are, to be sure, some individuals who selflessly work for others without thought of reward, but these are virtually saints and saints are rare (Blau, 1964, p. 16).

Social exchange, as defined by Blau (1964), is 1 imited to actions that are "contingent on rewarding reactions from others and that cease when these expected reactions are not forthcoming." It is the obligation engendered by the initial act which sets up the chain of interaction, Gouldner (1960) pointed out that the need to reciprocate for benefits received in order to continue receiving them serves as a "starting mechanism" of social interaction and group structure.

Failure to reciprocate can lead to imporiant social consequences 
such as loss of credit and loss of trust and it ", . ultimately brings about exclusion from further exchanges and a general decline in social status...." (BTau, 1964), On the other hand, Francois 1a Rochefoucauld (1940) contended that "excessive eagerness to discharge an obligation is a form of ingratitude."

Aristotle (1926) recognized the complexity of the social exchange relationship when he stated, ", , benefactors seem to love those whom they benefit more than those who have received benefits love those who have conferred them" (see Blau, 1964).

Trust played an important role in the exchange relationship and societal solidarity for Blau (1964).

Since trust is essential for stable social relations, and since exchange obligations promote trust, special mechanisms exist to perpetuate obligations and thus strengthen bonds of indebtedness and trust ... Social bonds are fortified by remaining obligated to others as well as by trusting them to discharge their obligation ... ( $p .99)$.

Finally, Blau examined the social context in which the exchange takes place. First, the "role sets" of the participants govern the aiternative opportunities for each. Second, group standards detemine rates of exchange and any member who deviates from this norm is the object of group pressure. Third, potential coalitions of weaker members restrain the activities of more powerful members, Fourth, power differences eventualiy change the group in such a way that the more powerful may be able to compel exchanges without offering fair returns, Finally, the social context may influence an exchange indirectly (Blau's example: giving a waiter a large tip to impress your friends).

This leads us to sociai exchange theory as we find it today. The 
basic components of contemporary exchange theory came from a number of disciplinary approaches, many complemetary and some contradictory. To sumarize briefly, the following statements are made:

1. Man enters into transactions (exchanges) to obtain needed goods, services.

2. Man tends to seek some profit (benefit greater than cost) in his exchanges. (This is a softening of the classical economic assumption of maximization of profit).

3. Commodities exchanged include sentiments and actions as well as objects.

4. Valuing of commodities includes both tangible and intangible considerations (feelings, values, norms).

5. Exchanges may be direct or indirect, restricted or generalized.

6. Exchanges may be simultaneous or sequential.

7. Reciprocity follows exchange.

8. Exchange patterns become institutionalized.

It has been the purpose of this review to present a briet historical background and current thinking on the major issues related to organizational interactions and coordination. The propositions and ordering of the world described by social exchange theory, as well as the components of organizational interaction will be used to build a model, the Organizational Transactions Model, in the next chapter. This model will then be tested in the community to determine its explanatory value relative to the interactions between organizations and between organizations and the coordinating agency. 
CHAPTER III

A MODEL FOR INTERORGANIZATIONAL STUDY

\section{INTRODUCTION}

The purpose of this chapter is to build a model with which to study organizational interactions, utilizing social exchange theory. This model contains three major sections. The first is the Organizational Interactions Model. This model provides a format for investigating the circumstances of organizational interaction. Exchange theory provides the dynamic properties of the model and the static properties come from organizational theory and research. The model contains three sets of elements: commodities, valuing criteria, and arenas of exchange.

The next two sections relate directly to the work of a third piarty attempting to influence interactions between organizations. The former sectioin develops a set of change techniques, potential tactics of a coordinating agency. The last section contains the outcome measures, developed as an ideal type of coordinated cormunity system utilizing the community aectors model and goal statements from coordinating agencies in the community.

II. ORGANIZATIONAL INTERACTION MODEL

This section develops the Organizational Interaction Model. The three basic sets of components of this model were determined by the 
elements necessary for an exchange to occur. First, there must be something to exchange (commodities). Secondly, the parties must hold values which make that exchange desirable (valuing criteria), and finally, there must be some opportunity for the exchange to take place (arenas). A description is made of each category including its derivation and potential usefulness.

The general categories, as well as the elements contained in each have been derived, in part, from theory and previous empirical findings and in part from field experience and a technical panel (See methods, Chapter IV). They are intended to break down the larger issue into more manageable parts, rendering greater explanatory value. Nonetheless, as with many intial taxonomies, some gaps or overlap may occur. It is the intent of this research to determine the general usefulness of this model in describing the circumstances under which exchanges occur between organizations, and to further apply the mode? in examining the work of coordinating agencies.

The format for this section is to take each of the three categories: commodities, valuing criteria, and arenas of exchange; and to discuss the choice of elements within each. The entire model is presented for reference in Figure ?. 


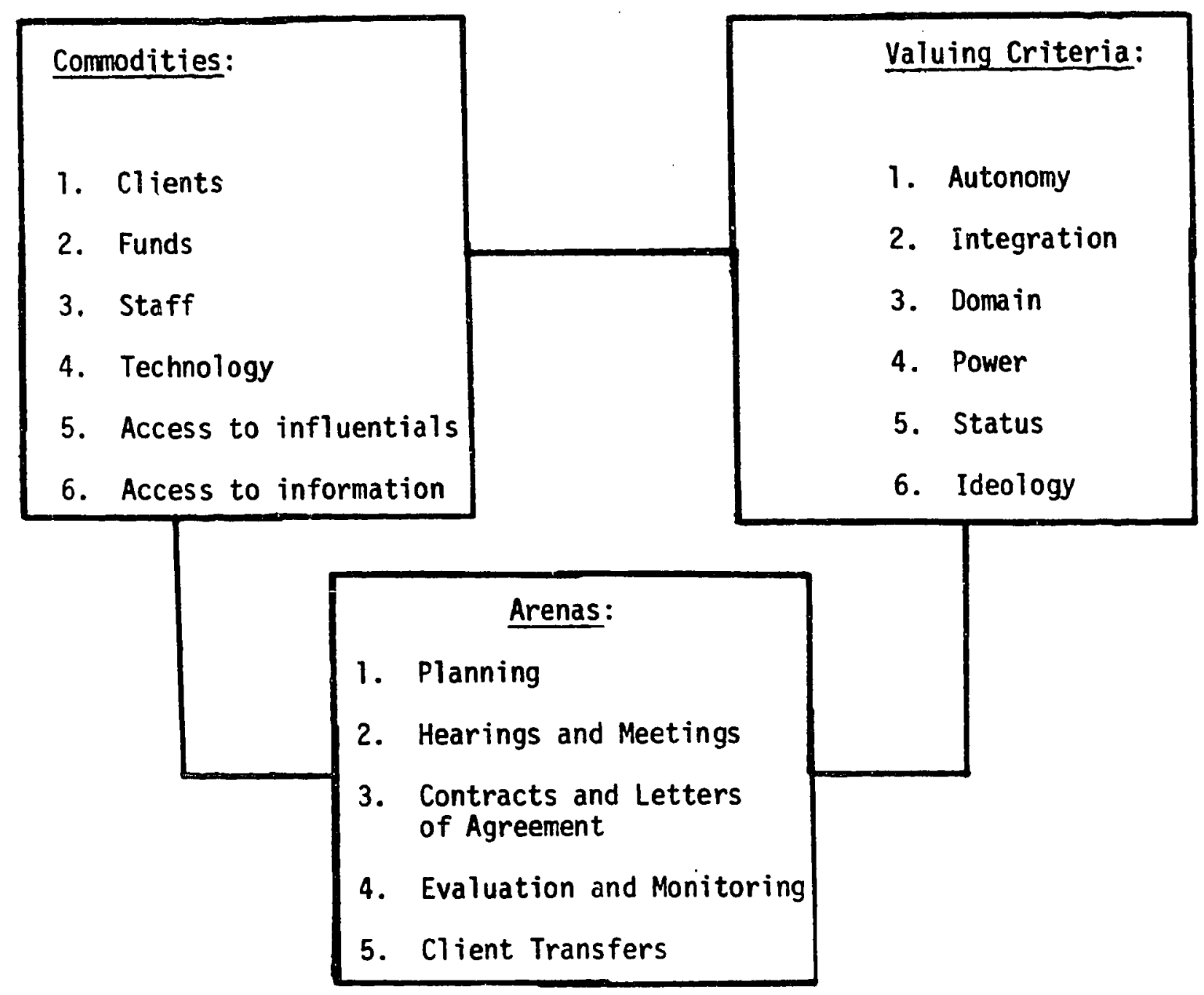

Figure 1. Diagram of the Organizational Interaction Mode?.

\section{Commodities}

Previous literature suggested a variety of elements

thought to be important for organizational survival. From this list six basic commodities were chosen on the basis of their potential importance. These commodities were reviewed by technical panel members to determine the face validity of the items. The elements are: clients, funding, stâf, information, techñology, and access to influentiałs. 
Each comnodity will be described in turn, including discussion of their importance to the organization, and their potential for manipulation by the coordinating agency.

\section{Clients}

Clients are of basic importance to social service agencies (Kahn, 1972; Aiken, et al,, 1975). Often the funding level of an agency, as well as its prestige in the community, is directly related to the number and type of clients it serves. Beyond that, the difficulty of finding and screening potential clients can be extremely costly. Exchanges involving $\mathrm{clients}$ can be problematic in that some clients have trouble negotiating the system (Kahn, 1972; Aiken, et al., 1975). Additionally, acceptance of clients by social service organizations depends on social, cultural, and historical factors, not just the needs of the client (Friedson, 1966; Cumming, 1968; Fried, 1969). Agencies sometimes refer clients to places that profit the agency rather than the client (Greenly and Kirk, 1973). Agencies like to have the "right" clients (Aiken, et al., 1975), clients who are attractive to the public or responsive to treatment. Clients also are not inanimate. They often are instrumental in the exchanges involving them, making the consideration of cilients complex.

The coordinating agency can play a role in the acquisition and coordination of clients (Mott, 1968). Some coordinating agencies provide referral services while others coordinate consultations and case reviews (Kahn, 1972). Finally coordinating agencies may play a role 
with clients who otherwise have difficulties in negotiating the system (Aiken, et a1, , 1975).

\section{Funding}

Funding is another relatively self evident commodity. Every agency requires some input of resources to survive. Exchange of money for goods or services is the most often cited method of influencing the behavior of another (Aiken, et al., 1975). Yuchtman and Seashore (1967) assumed that ". . organizational decision makers are typically oriented to the acquisition and defense of an adequate supply of resources." Scarcity of resources was offered as a cause of both competition (Nisbet, 1968) and cooperation (Levine and White, 1961).

The coordinating agency may play a role with funding by coordinating the acquisition of funding (Levine, et al., 1963) as well as the allocation of funding (Aiken, et al., 1975). Many of the authorities cited consider scarcity of funding to be an important reality in the community and a driving force behind most cooperative and coordinative efforts (Levine and White, 1961).

\section{$\underline{\text { Staff }}$}

The staff of an organization can be considered one of its basic resources. The potential to increase the number or quality of staff can influence an organization's behavior. Exchanges may include recruitment of staff, sharing of staff, and temporary exchanging of staff (Benson, et a1,, 1973). Klonglan (1960) added upgrading of staff 
through inservice training to this list.

The coordinating agency may assist by helping the agency both to obtain new staff and to upgrade present staff (Mott, 1968). They also can be instrumental in organizing staff exchanges and training sessions between organizations in the community.

\section{Information}

Information is a complex commodity to consider. Levine, et al. (1963) hold that information is the key commodity which determines the flow of all others.

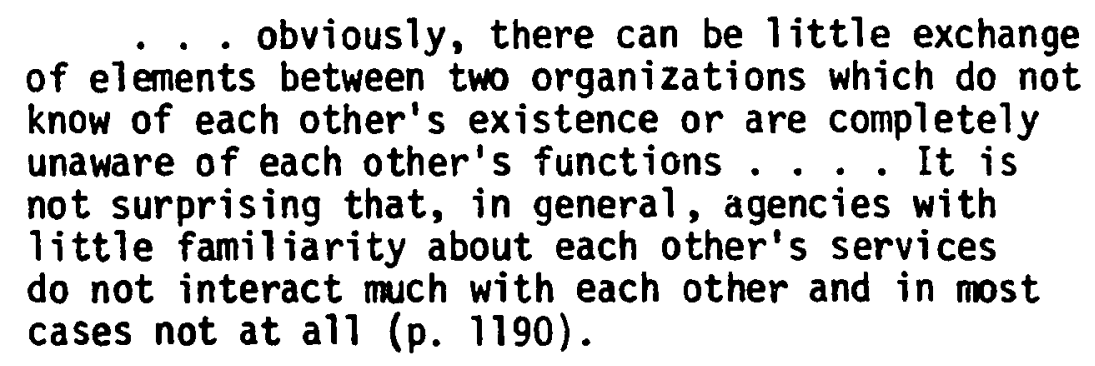

In a time when a confusing array of programs, grants, regulations, and guidelines change daily, access to information can be a valuable commodity. Early and reliable information can be both a pathway to other commodities as well as exchangeable itself.

The coordinating agency can use information in a variety of ways. First, information may be used as a commodity of exchange for desired behaviors. Additionally, information can be used to make organizations aware of potential exchanges (Banfield, 1961), or to change their attitudes toward other commodities (for example, placing a higher value on the elderly as clients). Feedback of information derived from evaluations can lead to program improvements and to more efficient and 
appropriate delivery of seryices. Aiken, et al. (1975) viewed information as the one resqurce which has influence on all categories of coordination.

\section{Technology}

Some authors consider technology to be a form of information (Aiken, et al., 1975). For the purposes of this study, technology is placed in a separate category to differentiate it from more general information. The technology offerable in an exchange can involve a variety of activities, including improvements in planning, evaluation, service delivery approaches, office procedures, client referral, and the like. Technology can take the form of training, technical assistance, or consultations.

The coordinating agency may play a role in providing for the group of organizations technology which may be costly for any individual to obtain. By coordinating training, for example, staff from a number of agencies may take part, reducing costs and, as a side benefit, providing opportunities for additional interaction.

\section{Access to influentials}

Power is considered by some authors (Tawney, 1931, Weber, 1947; Emerson, 1972) to be very important if not the most central value to organizations. One route to power is through access to influentials. Like information, access to influentials is both an exchangeable commodity as well as a route to other commodities. It aiso can confer status and 
legitimacy. The value of access to influentials is often underestimated by organizations entering into exchanges. Given the advocacy role of many organizations (Lauffer, 1974), access to influentials is a potentially important comodity.

Coordinating agencies may use this commodity by developing special access points either through their auspice agency (Area Agency on Aging housed in city government) or by deliberately developing ties with influentials in other exchanges (providing information for example). Access to influentials requires ongoing exchange relationships but may be very helpful in the work of the coordinating agency.

\section{Conclusion: Commodities}

This list of commodities is not complete in that other items may be exchanged, including sentiments. It is the purpose of this list to include the important commodities, as presented by theorists and observers of interorganizational interactions.

It should be noted that at any point in time, the commodities described above have some distribution in the community. Some commodities have a finite quantity such as funding or staff, while others are nonfinite such as information or technology. These latter commodities are usually not specifically exchanged with an individual organization more than once (most organizations would not seek to exact some piece of information twice), but the same piece of information can be exchanged with a number of separate agencies.

Once the commodities of exchange are determined, the next factor 
determining the exchange transaction are the values held by the participants. They will be discussed in the next section.

\section{Valuing Criteria}

Commodities are assessed in terms of cost and benefit by certain valuing criteria. While organizations in a community are generally assumed to hold similar sets of values, the importance of any particular value varies from organization to organization. Thus, any point in time, an organization assessing a commodity for potential exchange may place a unique worth on that commodity, because of the relative positions of the values in that organization's value hierarchy. The list of valuing criteria may be long, however, the following array of six valuing criteria are those most often mentioned in the literature.

Each of these criteria will be discussed in terms of its potential meaning to individual organizations and to the coordinating agency in its attempts to influence those interactions.

The operationalization of the variables related to valuing criteria is somewhat more problematic than the commodities. The "names" of the commodities carry with them definitions which are relatively common among the population of social service agencies. Herman Turk (1975) defended the use of this sort of "sensitizing terminology." While a "client" may differ from one agency to the next because of el igibility requirements or agency purpose, the general term "client" has enough specificity in general usage to meet the requirements of this research. The valuing criteria, however, utilize terminology 
about which there is much less agreement. "Power" may mean quite different things to two different agencies. In an effort to address this difficulty, a definition of each valuing criteria was provided whenever the term was used, and in most cases, the definition was presented in place of the term. Those definitions are as follows:

Power -- the ability to exercise control over other organizations Autonomy -- to be independent and self-governing Integration -- to form linkages with other organizations in the service system

Doma in -- to maintain the "boundaries" of the agency (i.e., to avoid overlap of services, clients, etc.)

Status -- to maintain or increase prestige or "image" in the community

Ideological Horld View -- to engage in activities consistent with the "philosophy" of the agency.

Power

Power refers to an organization's ability to exercise control. Tawney (1931) defined power as the "capacity of an individual or group of individuals to modify the conduct of other individuals or groups in the manner which he (or they) desires, and to prevent his own conduct from being modified...." Max Weber (1947) defined power as the ". . probability that one actor within a social relationship will be able to carry out his own will despite resistance". An organization which places a high value on power is more likely to enter into exchanges 
which protect, enhance or demonstrate its power.

The coordinating agency should take into consideration the importance of power to the organizations with which it works. If any organization considers power to be important, the coordinating agency may frame the exchange in such a way as not to be a threat. If the importance of power interfered with coordination, the coordinating agency may attempt to change the importance of that value.

\section{Autonomy}

Autonomy is somewhat related to power. It is the organization's ability to be self-governing and independent. The acquisition of resources can sometimes lead to decreases in autonomy (i.e., a certain funding source might require certain structural or organizational changes). An organization which places a high value on autonomy would most likely be influenced by exchanges which would allow a maximum independence. Previous authors suggest that all organizations in a community are interdependent to some degree. "Partial interdependence" is the ideal bas is for maintaining a confederation of organizations (Litwak and Rothman, 1970). However, interdependence must be balanced with the organization's need for autonomy. Thompson (1967) held that a central tenet of the organizational literature is that leaders of organizations attempt to maximize the autonomy of the organization they lead. Discussions of "turf battles" are common in the literature and a recognized part of service delivery in the community.

The coordinating agency must carefully consider this value. 
Coordination often involves apparent and real threats to the autonomy of arganizations. The coordinating agency can handle this threat by minimizing the loss of autonomy or by making the payoffs attractive enough. They may also attempt tc change the organization's perception of the importance of autonomy.

\section{Integration}

Some authors view integration as the opposite end of a continuum from autonomy (c.f., Warren, 1975). Integration refers to the development of Iinkages among a set of organizations. Linkages thus developed may have a variety of outcomes, ranging from the facilitation of sharing information and support to elaborate forms of interdependence. Integration is a form of coordination. Those organizations which consider integration to be important are more likely to be involved in transactions with other organizations, given available cormodities and the ability to exchange. Mott (1968) described the social desirability of integration for organizations. Organizations face social pressure to at least "appear" to be willing to become integrated.

Coordinating agencies should foster the importance of integration for community organizations and offer them opportunities to form those linkages.

\section{Domain}

Domain refers to a set of elements relating to the purpose, task, client population, and geographic and social boundaries which define an 
organization. Levine, et al., expanded:

When we speak of donain consensus between two agencies, we are referring to the degree to which they agree and accept each others claims with regard to problems covered, services offered, and population served (1963, p. 1191).

Agreement over domain facilitates coordination (Levine and White, 1961) and unclarified domains often lead to conflict and competition (Levine, et a1., 1963).

The coordinating agency can facilitate organizational agreement over domains by providing information regarding organizational purpose and function. They should be aware of an organization's perception of its domain so that exchanges which support that doma in are offered. Finally, a coordinating agent may attempt to change the perception of domain by encouraging inclusion of a new service, client group or geographical area.

\section{$\underline{\text { Status }}$}

The status of an organization refers to its relative rank or position in the community; it is also closely related to prestige. An arganization will usually become involved in transactions which maintain or increase status. Collins described how community status can influence resource flow.

The comunity's stratification system is usually reflected in the organizational hierarchy. of course, the influence is reciprocal: status in the organization is reflected in the community ... Organizations pursuing goals defined by the public as socially significant were in a better position to obtain the resources necessary for their continued functioning (1946, p. 294). 
The coordinating agency should offer exchanges which increase or protect the status of organizations. They should recognize an organization's view of its own status as well as the status of others.

\section{Ideology or World View}

World view is a category which is the collection of values and attitudes held by the organization which comprise its philosophy, including its orientation to "causes" such as humanitarianism, profit seeking, education, equal opportunity, and the like. Levine, et al. (1963) discuss differences in world view as a serious barrier to cooperation. As Aiken, et al. (1975) stated,". . not unexpectedly, each profession generally perceives its own area of expertise as the critical one." Differences in world view are not simply a function of professionalism. They can include autocratic versus democratic leadership, liberal versus conservative philosophy, formal versus informal organization, specialization versus generalization, and so on.

Consideration of world view is important for the coordinating agency. World view will, to some degree, predict the response of organizations to potential exchanges. The ccordinating agency may attempt to change certain aspects of world view if a block to coordination occurs.

\section{Conclusion: Valuing Criteria}

This list of valuing criteria is not intended to be complete, but rather a selection of those values held by organizations which 
influence their willingness to enter into exchange. This selection was made on the basis of the suggestions of authors in the area of interorganizational research as to the more important values for organizations. It should be noted that the last criteria on the list, world view, is actually a summary of a number of values.

Two components of the model are now in place. The third is an opportunity for the change to occur. This has been titled the "arenas" of exchange.

\section{Arenas of Exchange}

The arenas of exchange represent the transactional situation within which the stage is set for exchanges to occur. The list of such arenas could be seemingly unlimited since parties potentially can make exchange wherever and whenever they interact. However, for the purposes of this study, five arenas were chosen as representative of the types of situations in which social service agencies are most likely to enter into exchanges. These arenas include social occasions, tasks, negotiation of written agreements, and other exchanges.

\section{Planning}

Planning is a major task of any organization, whether short-term (the business of the day or week) or long-term (directions for the agency for the next five years). The various activities involved in planning (i.e., determining need, assessing resources, assigning priorities to programs, etc.) offer opportunities for the interactions which can lead 
to transactions. The planning process itself generates information about commodities available for exchanges and actors with whom exchanges can be made. If that planning is conducted by a coordinating agency for the community or particillar set of clients, the opportunity for interaction among organizations is enhanced considerably.

\section{Hearings and Meetings}

Hearings and meetings, whatever their purpose, are much like planning in that they often offer opportunities for actors to identify each other and their commodities. Physical proximity, attending and participating in the same meeting, is likely to lead to interaction which, in turn, increases the likelihood of exchange. Hearings and meetings can be used both by service agencies or coordinating agencies to disseminate information which is most likely to lead to beneficial exchange.

\section{Contracts and Letters of Agreement}

Contracts and letters of agreement usually outline the conditions of a given exchange or graup of exchanges. However, the process of making such a contract or letter of agreement, itself offers opportunity for other exchanges of interest to the parties. The coordinating agency may, by arranging for the making of contracts and other formal agreements between organizations, have a great deal of influence over the transactions in the community. 


\section{Evaluating and Monitoring}

Evaluating and monitoring are ongoing processes which offer broad opportunities for interaction as well as the gathering of information of relevance to exchanges (Wildavsky, 1972). These processes often uncover commodities which are needed or in surplus and therefore available for exchange. If the coordinating agency is involved in this process, they can use the information thus gathered to influence the exchanges of organizations which are being monitored and evaluated or which are involved with such organizations.

\section{Client Transfers}

Client transfers involve the sharing or referral of clients and client specific information. This process, while itself involving exchange, al so leads to other interaction and sets the stage for future exchanges. The coordinating agency, if involved in information and referral, is offered rich opportunity to use client transfers as a technique for influencing the transactionsl behavior of organizations. Referrals of clients can be problematic (Greenly and Kirk, 1973), but do offer opportunities for other sorts of exchanges.

\section{Conclusion: Arenas of Exchange}

The opportunities for exchanges to occur (arenas) are essential in addition to commodities and values. Any situation, event, or process which offers opportunity for interaction is a potential arena. The current list of five was chosen because of their general pervasiveness 
in the community. An additional consideration in their choice was the observation that these elements are often related to the activities of a coordinating agency (Aiken, et al., 1975).

It should be noted that many of these "arenas" offer some sort of end-product which is of value to the community (a plan, contract, or information for example). Some are finite, such as a contract or hearing, wirile others are more continuous, planning, evaluation and monitoring. However, all offer opportunity for additional negotiations for exchange and it is that element of their existence which is of most interest to this study.

Conclusion: Organizational Interaction Model

The six commodities listed in the model are assumed to be exchanged by organizations in the community. The utility of any particular commodity is a function of the way the six valuing criteria listed above are held by the organizations in the community. The rate and direction of exchange of the commodities can be influenced by a coordinating agency in many arenas. Five common arenas are listed in the model. The objectives of the coordinating agency can be achieved by the timely introduction of conmodities within the exchange arenas over which it has control, taking into account the valuing criteria of the organizations it is trying to influence.

III. CHANGE TECHNIQUES

A list of potential change techniques was developed to determine 
the attitudes of respondents toward various types of intervention by a third party. The rationale for that list, as well as the items themselves, are presented in this chapter.

Intervention Tactics

A review of the literature suggests a variety of types of intervention on the part of government and/or a coordinating agency. Five of the more commonly mentioned categories relative to social service agencies are: exercise of authority, resolution of conflict, training, funding, dissemination of information and control of clients. In addition to types of intervention there are differences relative to level of intervention. Therefore, the list of change techniques was constructed in such a way as to represent levels of intervention within types of intervention. As an example, "Acting as ultimate judge when organizations differ" was considered to be a higher level of intervention than "Bringing together conflicting parties to clarify issues", though they belong to the same type of intervention, resolution of conflict.

The list was presented to the technical advisory panel (See Appendix) for their review. Their suggestions were incorporated into the final list. That list is in Table II.

It was assumed that organizations would consider these tactics to be appropriate in varying degrees. The purpose of including this list in this research was to develop a hierarchy of techniques for promoting community change, arranged in order of perceived appropriateness. 
The model for research now includes the model for organizational interactions and techniques for promoting change. The final portion of the model is the measure of outcome of the activities of the coordinating agency.

\section{OUTCOME VARIABLES}

A criticism of exchange theory is that it presents a tautology: people enter into exchange because they need resources; we know a resource is needed because people are entering exchanges (Emerson, 1972). It is hoped that by examining the outcome of exchange activities, in the community, a step can be taken out of that logical circle. It was therefore determined that for the purposes of this study certain "outcome" variables should be defined and measured to evaluate, in some part, the work of the coordinating agency in the community.

The first step in this process was the division of the community into those sectors which have impact on the elderly. That division was made on the basis of past field work in the community and the advice of the technical panel. The six resulting sectors are listed and defined below:

Sector I: The Coordinating Agency. This sector includes the direct Administrative and Planning units as well as the auspice agency in which the coordinating agency is located. In this study, the Area Agency on Aging or Sector I is the "focal organization" around which the investigation proceeded.

Sector II: The Human Services Sector consists of the broad 


\section{TABLE II}

TECHNIQUES FOR PROMOTING COMMUNITY CHANGE

\section{Tactic Considered Appropriate}

1. Providing facts regarding new legislation and funding

2. Providing information about organizations to make it easier for them to work together

3. Circulating future plans of service organizations and governments

4. Providing profiles of individual staff of service agencies

5. Short term in-service training to service providers for special techniques

6. Technical assistance to provide service agencies new methods

7. Assessing compliance to contracts

8. Evaluation of program effectiveness

9. Establishing uniform standards for service delivery

10. Authority to approve/disapprove all aging programs

11. Bringing together conflicting parties to clarify issues

12. Setting rules whereby differences between organizations can be worked out

13. Acting as ultimate judge when organizations differ

14. Fee reimbursement for services delivered

15. Utilizing competitively awarded service contracts for desired behavior

16. Unrestricted grants to build agency capacity

17. Centralized $\mathrm{client}$ intake for multiple service agencies 
spectrum of health, education, and welfare programs including those which serve the general public as well as those which are specifically designed for the target group, in this case the elderly. This sector would include Social Security, Public Welfare, Senior Transportation Projects, Community Mental Health Programs, Senior Centers, etc.

Sector III: Client Groups is the sector which covers organizations of potential and current clients in social service programs. In this case, senior groups, councils on aging, etc.

Sector IV: Local Governmental Sector includes Mayors, City Commissioners, County Commissioners, Judges, and other elected officials within the community.

Sector V: Other Agencies, organizations, and associations including entities such as newspapers, church groups, neighborhood associations, and civic clubs as well as general planning organizations and organizations which are engaged in the mobilization of resources such as United Good Neighbors.

Sector VI: State Government, in this case including the State Program on Aging.

This list originally contained seven sectors, the seventh sector being funding sources. However, in pretests of the interview instrument it was determined that respondents tended not to use that category in their conceptualizations, choosing instead to use the sector to which the funding agent might be assigned. Thus, if the State Program on Aging was a provider of funds for them, they would use Sector VI, State Government. If they received county funds, they would use Sector IV. Therefore, 
in the field study itself, only the six sectors listed here were presented.
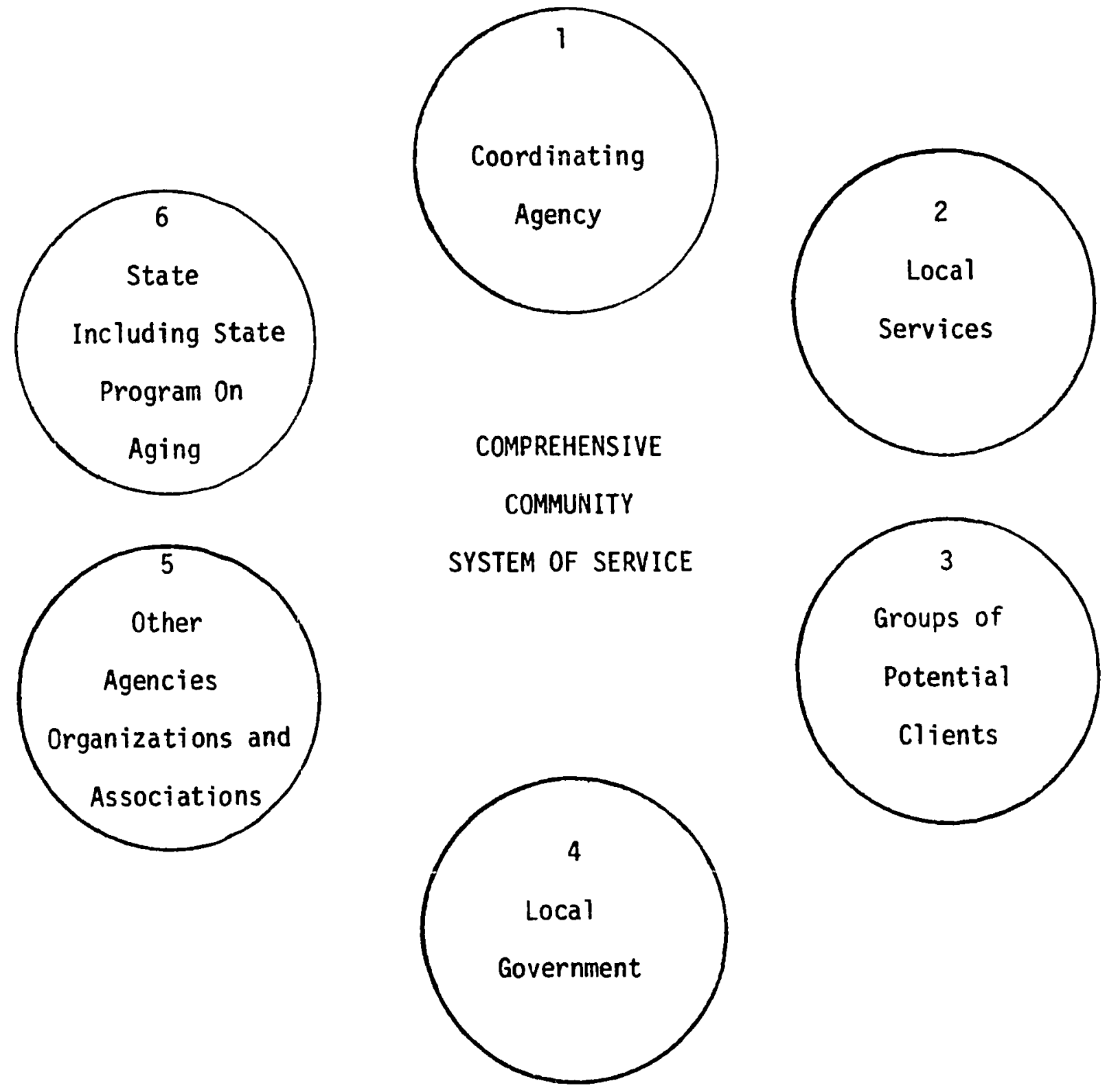

Figure 2. Community Sectors

These sectors are diagramatically presented in Figure 2. This model of the community is thought to describe the elements of the community 
which are influenced by the coordinating agency. There are two major categories of impact which are of special interest to this study. The first impact is on the relationships ariong the sectors of the model. For example, in order for a coordinated comprehensive service system (CCS) to be achieved, the interaction between Sectors II and III, Local Services and the client group must be at an optimum level. Eight such improvements are listed below. These are called the "process" elements of the model.

1. The more effective transfer of funds from the state sector including the State Program on Aging, to the services sector.

2. An increase in the amount of funds provided for services for the aged.

3. Improved and increased involvement of older clients in the policy making procedures of the service sector.

4. Increased involvement of older client groups and representatives in governmental decision making at the local level and at the state level.

5. Increased access by older clients to services.

6. Increased effectiveness of coordination of services to clients with multiple needs.

7. Increased sensitivity by all sectors to the importance of serving the elderly community at the local level.

8. Increased flow of needed information between all the sectors.

9. Increased access of individuals to key members in all the sectors for purposes of influencing local decision making. 
At the same time this research takes special interest in one sector of this model, Sector II, the Human Services Sector. This is the sector through which virtually all direct service to the client group, in this case the elderly, is delivered. Thus, changes in this sector take on special importance. Six potential improvements in this sector are listed below; these are called the "state" elements of the model.

1. Increasing the priority given older adults by all local human services.

2. Increasing the number of staff in all local service agencies with special training and knowledge regarding the service needs and intervention approaches appropriate for older adults.

3. Improving the general knowledge and information by staff of all kinds in local human services regarding the special needs, conditions and methods of intervention of older people.

4. Increasing the efficiency of the planning and evaluation functions carried out by agencies dealing with older adult clientele.

5. The filling of gaps in the local services sector so that all critical services needed by older adults do exist.

6. The development where necessary and the improvement where they already exist of critical linkage services by which to get elderly people appropriately tied into available services.

In summary, the maximization of each of these improvements, process, and state, would lead to an "ideal type" comprehensive coordinated service system. In reality, no community would ever achieve the ideal, but it 
TABLE III

COMPREHENSIVE/COMMUNITY SYSTEM MODEL (CCS)

Process Elements of the CCS regarding transactions between sectors of the community

1. More effective transfer of funds from state to local level

2. Increased level of funding for aging services from local sources

3. Increased involvement of older adults in setting service agency goals

4. Increased inclusion of older adults in governmental decision making

5. Increased accessibility of services by older adults

6. Increased coordination of services to multiply impaired older adults

7. Increase sensitivity of community to the needs of older adults

8. Improved flow of information among all sectors concerned with older adults

9. Improved access of advocates and service leaders to community influentials

State Elements of the CCS regarding the services sector of the community

1. Increase the priority level of older adults in the service agencies

2. Increase the number of staff with special competence regarding older adults

3. Improve the level of training of existing staff in service agencies

4. Increase the application of planning and evaluation technology in services

5. Fill gaps in the service matrix

6. Stimulate greater linkage of clients to services and services to each other

Note: A CCS for older persons is an ideal type state which can be approached but not achieved. In this model, a CCS is said to exist to the extent that improvement is made in the fifteen conditions as listed above. Hence, producing an improvement in those fifteen aspects of the community constitutes our interpretation of the objectives of an Area Agency on Aging. 
is possible to measure the degree to which a community changes toward such a state. Coser, after Max Weber, described the concent of ideal type.

An ideal type is an analytical construct that serves the investigator as a measuring rod to ascertain similarities as well as deviation in concrete cases. It provides the basic method for comparative study. The ideal type involves an accentuation of typical courses of conduct. It never corresponds to concrete reality but always moves at least one step away from it. It is constructed out of certain elements of reality and forms a logically precise and coherent whole, which can never be found as such in that reality (1971, p. 223).

The elements of the ideal type are presented in Table III.

\section{v. CONCLUSION}

Social exchange theory was the basis for the development of an Organizational Interaction Model. From this model were developed a series of empirical questions relative to commodities of exchange, valuing criteria, and arenas of exchange to be presented in the methodology chapter. A model of the community was developed with the purpose of constructing an "ideal type" representing the comprehensive community system. The data on these "outcome variables" are related to the information regarding manipulation, commodities, valuing criteria, and arenas by the coordinating agency to determine the usefulness of the Organizational Interaction Model (and therefore social exchange theory) in explaining organizational interactions. The next chapter presents the methodology for testing these models, 


\title{
CHAPTER IV
}

\author{
METHODOLOGY
}

\section{INTRODUCTION}

This research is a case study of the implementation of a federal initiative to cause coordination in local communities. This study focuses specifically on three examples of the case in point. The federal initiative is contained in the 1973 Comprehensive Service Amendments to the Older Americans Act of 1965 (Public Law 93-29, 87 Stat. 3645). Title III of this act has the stated purpose to "encourage and assist State and Area Agencies to concentrate resources in order to develop greater capacity and to foster the development of comprehensive and coordinated service systems to serve older people." These Area Agencies on Aging are the coordinating agencies of interest to this study.

The data were collected in indepth interviews and surveys and analyzed with quantitative, qualitative and comparative procedures. This methodology offers some of the benefits of both qualitative and quantitative research while, at the same time, avoiding some of the problems of each.

Glaser and Strauss in their book The Discovery of Grounded Theory discussed the selection of a methodology for research.

\footnotetext{
... there is no fundamental clash between the purposes and capacities of qualitative and quantitative methods or data. What clash there is concerns the primacy of emphasis on verification or generation of theory -- to which heated discussion of qualitatiy vs quantitative data have been linked historically. We
} 
bel ieve that each form of data is useful for both verification and generation of theory, whatever the primacy of emphasis. . in many instances both forms of data are necessary (1967, pp. 17-18).

Following this line of reasoning, this research sought information in a variety of forms from a number of sources. These sources included representatives of all the sectors represented by the Comnunity Sectors Model. A number of communities were surveyed in order to determine general trends which would not be evident in the analys is of a single case. The type of information collected covered a broad range. Data were collected on organizational practices, knowledge, attitudes and perceptions. Glaser and Strauss discussed this approach:

Among the many slices of data that may be collected, which one is the best to obtain? The answer is, of course, the collection technique that best can obtain the information desired, provided that conditions permit its use in some manner... Often the ... strategy will be constrained by such structural conditions as who is available to be observed, talked with, overheard, interviewed or surveyed and at what times (1967, pp. 66-67).

This broad range of data was then analyzed and refined. Trends were noted and relationships explored for the purpose of examining the Organizational Interaction Model, developed from social exchange theory. Perceptions of the impact of the Area Agency on Aging in the community were related to the efforts of the AAA as defined by this model. The usefulness of the model for understanding community transactions was determined in this way.

\section{PROCEDURES}

Two waves of communtty interviews were conducted. The first wave 
was used to test and refine the survey instrument and to develop exploratory data. The first wave took place from May through July 1975 as a part of a research project conducted by the Institute on Aging at Portland State University (funded by the Administration on Aging) to examine conflicts which arise in the coordination of social services for the elderly (0'Brien, 1975). Six geographical areas covered by Area Agencies were chosen on the bas is of population, auspice of the Area Agency (local government/council of governments/nonprofit corporation), and geography (urban/rural/urban-rural mixed) (multi vs single county). These communities covered two states and represented approximately 250,000 elderly persons. The areas were chosen with the advice of personnel from the two State Programs on Aging. *

An interview schedule was developed utilizing insights and perspectives from a review of the literature. Models were constructed as a result of that review, and commented upon by a technical panel of experienced professionals in community social service programs (See Appendix). The instrument was pretested and then taken into the fie?d. A total of 84 interviews were completed, 71 representing the community sectors impacted by the $A A A$ and the remaining 13 with representatives of the State Program on Aging and the six Area Agency Directors.

\footnotetext{
*The author wishes to thank Mrs. Marion Hughes and Mr. George Telisman for the information and judgment in this matter.
} 
The data from this phase of the study were analyzed and a more extensive review of the literature was undertaken, guided by these findings. Data from the second wave form the major findings reported in this research. The second wave of data collection took place from January through March 1976 as a part of another Institute on Aging research project, Closing the Gaps: Strategies for Technical Assistance (0'Brien, 1976). Three of the previous six communities were chosen for in-depth study representing an urban, a rural, and a mixed urban-rural setting. An interview was constructed and pretested and from this both an in-depth interview and a mailed survey were developed.

The sample was constructed in such a way as to vary level of involvement, type of service provided, and area of service. In all 175 agencies were contacted and completed surveys or interviews were obtained from 126.

It was the intent to interview (or survey) a director and a staff person in each agency. There were a total of 191 respondents. The data from these interviews were analyzed and compared to the information from the previous studies. The Organizational Interaction Model was reexamined in light of the relationships which were found to determine applicability of this model to the social service community.

\section{THE SPMPLE}

The two waves of data collection involved, for the most part, separate samples and will be described separately.

Wave I consisted of interviews with respondents from areas 
encompassing six Area Agencies on Aging. The population of these areas totaled $1,903,969$ with 244,695 persons being over the age of $60(12.8 \%$ of the total population). The smallest Area Agency studied had a total population of 35,459 with 5,972 elderly and the largest had an elderly population of 97,543 . (See Table IV).

Respondents were chosen from lists of individuals and agencies provided by the coordinating agencies. Because this wave of data collection was very exploratory, efforts were made to choose representatives of community organizations who knew a great deal about the Area Agency rather than to make a random selection of agencies in the community. Additionally, efforts were made to represent all six sectors of the community sectors model. A total of 84 respondents were interviewed, and the data from these interviews used to construct the questionnaires in the second phase.

Wave II was conducted in three areas, within a single state; urban, mixed and rural. These community types were selected as being representative of the types of communities found throughout the United States. The urban community was typified as having a city(s) with a population of 200,000 or more. The mixed urban/rural community was typified as having city(s) with a population of over 15,000 but less than 200,000, having close proximity to an urban community, and having expanses of undeveloped land. The rural community was typified as having no city(s) with a population greater than 15,000 and expanses of undeveloped land. One Area Agency on Aging was selected to represent each of the different community types. 
TABLE IV - DESCRIPTION OF SAMPLE AREAS

\begin{tabular}{llllr}
\hline AREA & AUSPICE & $\begin{array}{l}\text { URBAN } \\
\text { RURAL }\end{array}$ & $\begin{array}{l}\text { SINGLE VS. } \\
\text { MULTI-COUNTY }\end{array}$ & $\begin{array}{l}\text { \# OF PERSONS } \\
\text { OVER }\end{array}$ \\
\hline Area A & COG & Mixed & 3 counties & 45,543 \\
Area B & Local Gov. & Urban & Single & 97,524 \\
Area C & COG & Mixed & 3 counties & 38,537 \\
Area D & COG & Mixed & Single & 25,758 \\
Area E & COG & Rural & 3 counties & 5,972 \\
Area F & Private & Mixed & 5 counties & 33,361 \\
& Non-Profit & & & \\
\hline
\end{tabular}

In this study, the urban ARA contains a city of just over 350,000 population and a county population, including the city, of 556,667 . The urban AAA has a total of 97,524 persons over 60 , or $18 \%$ of its population. Twenty percent of the total population of this area have incomes below the poverty level. Local government is the auspice for the AAA.

The study's mixed urban/rural AAA contains no cities over 200,000 in population. This AAA is made up of three counties and its auspice is a Council of Governments. A11 three of the counties are immediately adjacent to the urban AAA county. This mixed urban/rural AAA has a total of 43,543 persons over 60 , or $12 \%$ of its population. Eighteen percent of the area's population have incomes below the poverty line. Many residents either commute to the city for employment or work in the nearby suburban businesses and industries. Some maintain farms. 
The largest city in the Rural AAA has a population of 10,423 . This AAA is made up of three counties and its auspice is a Council of Governments. Twenty-one percent of the persons in this area have incomes below the poverty line. Most residents depend on small businesses, farming, or ranching for their livelihood. There are 5,972 persons over 60 ; that is $17 \%$ of the total population in the Rural AAA. This information is provided in Table $V$.

TABLE V - PROFILE OF STUDY COMMUNITIES

\begin{tabular}{lccccc}
\hline $\begin{array}{c}\text { Type of } \\
\text { AAA }\end{array}$ & $\begin{array}{c}\text { Total } \\
\text { Population } \\
\text { of Area }\end{array}$ & $\begin{array}{c}\text { Percent } \\
\text { Population } \\
\text { Over } 60\end{array}$ & $\begin{array}{c}\text { Population } \\
\text { of } \\
\text { Largest City }\end{array}$ & $\begin{array}{c}\text { Number of } \\
\text { Counties } \\
\text { in Area }\end{array}$ & $\begin{array}{c}\text { Auspice } \\
\text { of AAA }\end{array}$ \\
\hline Urtan & 555,667 & 18 & 382,619 & 1 & $\begin{array}{c}\text { Local } \\
\text { Govt. }\end{array}$ \\
$\begin{array}{l}\text { Mixed } \\
\text { Urban/ } \\
\text { Rural }\end{array}$ & 352,798 & 12 & 16,379 & 3 & $\begin{array}{c}\text { Council } \\
\text { of Govts. }\end{array}$ \\
Rural & 35,459 & 17 & 10,423 & 3 & \\
\hline
\end{tabular}

The organizations surveyed were chosen from a list of "Potential Resources" provided by the director of each Area Agency, as a required part of the yearly plan of the AAA. Because these lists differed somewhat in the types of agencies included, efforts were made to make the lists more similar (for example, nursing homes were added to one list, police and fire departments to another). The sample from each area was then chosen taking into account each agency's level of participation with the Area Agency on Aging. 
The first level of participation included those organizations which were current subcontractors with the AAA. The second level included organizations which were current advisory council members, but not current subcontractors. The third level included organizations that were neither current subcontractors nor advisory council members but had been included on the list of resource organizations by the AAA. The sample was intended not to exceed ten subcontractors, ten advisory council members, and 50 other service providers from each of the three areas for a total ofnot more than 210 organizations. The actual number of organizations contacted and studied is presented in Table VI.

TABLE VI

DESCRIPTIONS OF SAMPLE ORGANIZATIONS

\begin{tabular}{|c|c|c|c|c|}
\hline Area & Contractor & $\begin{array}{l}\text { Advisory } \\
\text { Council } \\
\text { Member } \\
\end{array}$ & $\begin{array}{l}\text { Other } \\
\text { Service } \\
\text { Providers }\end{array}$ & Total \\
\hline Urban & $9 \star(8)^{\star \star}$ & $10(7)$ & $48(32)$ & $67(4)$ \\
\hline Mixed & $9(9)$ & $5(3)$ & $42(31)$ & $56(43)$ \\
\hline Rural & $4(3)$ & $3(3)$ & $45(30)$ & $52(36)$ \\
\hline $\begin{array}{l}\text { Total Agencies } \\
\text { Contacted }\end{array}$ & $22(20)$ & $18(13)$ & $135(93)$ & $175(126)$ \\
\hline
\end{tabular}

In all, 22 subcontractors, 18 advisory council members, and 135 other service providers were included in the sample. Data (either a 
completed interview or survey form) were collected from $72 \%$ of the organizations contacted. This represents a $45 \%$ return of mailed questionnaires. Because an attempt was made to contact both the director and a staff person in each organization the total number of respondents is 191.

\section{INSTRUMENTS}

The data for this study were collected utilizing two formats, in-depth scheduled interviews and mailed surveys. Additionally, technical panels served to review findings and conclusions and to provide insights regarding the interpretation of data.

\section{Wave I}

The first interview schedule (See Appendix) was 24 pages long and took from 1 to $3 \frac{3}{2}$ hours to complete. Most interviews lasted approximately $1 \frac{1}{2}$ hours. The interview schedule included both interview-asked questions and forms to be filled out by the respondent. Responses were recorded in great detail (verbatim, if possible). The interview was pretested before entering the field.

The interview was intended to collect information regarding the respondent's knowledge about the AAA, level of interaction with the AAA and other service providers, importance of certain comodities and values, and perception of outcome of the work of the AAA. Because the interviews were being conducted as part of an ongoing research project, data were also collected regarding "milestone events" of the AAA, conflicts, and mission of the AAA. Data describing the agencies themselves such as 
purpose, age, and number of staff were also sought.

The interview schedule for Area Agency directors included all the relevant questions asked the service providers as well as additional questions regarding the Area Agency's control of commodities, consideration of service agency's values in working with them, and use of exchange arenas. These interviews averaged approximately two hours, and were supplemented by follow-up calls after the interview data had been reviewed and analyzed.

Wave II

The information for wave two was collected in three phases: The second pre-test (19 respondents), the in-depth interview (48 respondents), and the mailed survey (sent to 273 people). The pre-test, the in-depth interview and mailed survey cover much of the same information and the coded data from all were analyzed together. The format for the interviews is similar to that of the mailed survey with the exception that approximately one-third of the questions on the interview are asked and recorded by the interviewer. The in-depth interview schedule was 18 pages long and took approximately $1 \frac{1}{2}$ hours to complete. The mailed survey was 10 (or 11 depending on whether to director or staff) pages long and took approximately one hour to complete. The mailed survey to agency directors differed slightly from that to staff (redundant information deleted). (See Appendix).

Respondents were asked to provide information regarding their agency's: problems, difficulties in obtaining certain commodities, 
relationships with other organizations in the community, criteria for valuing their activities, knowledge about and interaction with the $A A A$, and their evaluation of the impact of the AAA. Additionally, they were asked to evaluate the appropriateness of a number of change techniques. Because this interview was a part of an ongoing study, questions were also asked regarding intraorganizational problems, attitudes toward knowledge about the elderly, and services for the elderly.

\section{THE VARIABLES}

\section{Commodities}

The items to be included in the survey (and interviews) were determined by the model, and review of previous literature, in the following way. (See Example of Instruments in Appendix). The commodities were the first elements of the model to be considered. Previous authors had suggested that scarcity of commodities was an important factor determining interorganizational interaction. (Levine and White, 1961; Levine, et a1., 1963). Therefore, organizations were asked whether they experienced difficulty in obtaining each of the commodities. Because a major interest in this study is the role of the coordinating agency in manipulating exchange elements, organizations were asked whether the Area Agency on Aging played a role in helping them to obtain each of the commodities.

The coordinating agencies were asked the following questions regarơing côminodities. 
1. How important was each of the commodities in encouraging organizations to cooperate with the AAA?

2. How much control does the AAA have over each of the commodities?

3. Rank the commodities in terms of usefulness in influencing the behavior of organizations in the community.

Valuing Criteria

The second basic component of the model consists of the valuing criteria. Respondents were asked to rate each of the values in terms of importance to their organization. Values were presented as statements (e.g., "to be independent and self governing") rather than value title (autonomy). In order to determine behavioral components of some of these values, respondents were asked questions regarding their organization's rate of client referrals, interactions with other organizations, specific attitudes of level of training of staff, and behaviors in certain circumstances (e.g., another organization's encroachment on their organizational boundaries).

In order to determine the coordinating agencies' use of the organizations' valuing criteria, the following questions were asked

1. Had the coordinating agency ever worked with an organization that thought its (specific value) might be affected if it cooperated with the coordinating agency?

2. How did that (fear of losing/prospect of enhancing) their (specific value) affect the coordinating agency's dealings with the organization?

3. What did you do about the organizations' (fear of losing/ 
prospect of enhancingl (specific value)?

The purpose of these questions was to determine whether or not each of the valuing criteria was important to the organizations in the community. Secondly, the consideration of organizational values by the coordinating agency was determined. Specific examples were sought to better understand how coordinating agencies used these valuing criteria in their work with community organizations.

\section{Arenas}

Respondents were asked which of the five arenas of exchange they had entered (e.g., had they signed a contract with another agency, engaged in planning, etc.). The coordinating agencies were asked how each of the arenas related to the goals and objectives of the organization and also whether they had used each of the arenas to do business other than the primary purpose.

1. In the (specific arena) did organizations ever do business other than (specific arena)?

2. Has the coordinating agency ever used (specific arena) to bring people together to do business other than planning?

3. What was the outcome? (Did being involved in the primary process haye secondary effects?)

\section{Change Techniques}

The list of change techniques was developed as described in Chapter 
III, A Model for Study, utilizing various levels and types of intervention. This seventeen item list was presented to respondents to rate each item as very appropriate, somewhat appropriate, somewhat inappropriate, very inappropriate. The item read:

To what extent are the following appropriate or inappropriate means by which government should try to influence the way service organizations work with one another?

Outcome Variables

The Comprehensive Community Systems Model, presented in Chapter III, was used to develop a list of potential outcomes of the work of the coordinating agency. The wording of the items was changed to make the outcomes clear to the respondent (e.g., "more effective transfer of funds from state to local level" became "budget of service organizations" and "income and financial condition of the elderly"). In this way, the original seventeen item Comprehensive Community System model became a twenty-two item outcome list. The technical panel reviewed one list for clarity and face validity, making some changes in wording. In pretesting, four items were collapsed into two because of difficulty on the part of the respondents in differentiating between the items. In this way, a twenty item outcome list was developed.

Respondents were presented the list with the following question:

The Area Agency on Aging has been at work in your community for more than three years. What has been the effect of the AAA in the following categories?

Respondents checked one of six choices: much better off, somewhat Detcher off, no different, somewhat worse off, much worse off, not reievant 
to AAA goals. Those ratings were then compared to the data regarding control of commodities, consideration of values, and manipulation of arenas of exchange in the community. While it is recognized that many other factors during this same time period could affect the approximation of the comprehensive coordinated service system, this exploratory research is at least a beginning step in illustrating a relationship between social exchange theory and outcome in the community.

\section{DATA ANALYSIS}

Data were coded, key punched and analyzed using SPSS (Nie, 1975) programs. Prel iminary findings were reported to the technical panel for their review and comment. Their suggestions were utilized in the interpretation of the data.

The interviews are rich with insights into the relationships among organizations and the work of the AAA. Some of the flavor of these data were lost in coriing and quantification. Therefore, the questionnaires themselves were reviewed in detail for information not included in the computer printouts. Wherever appropriate, direct quotations from interview and survey forms were used to anchor the data in "real world" experience. 
CHAPTER V

RESULTS

I. INTRODUCTIDN

This chapter presents the findings of this research as they relate to the Organizational Interaction Model, and to the major questions of this research: "Under what circumstances do organizations interact?" and "How can a third party influence those interactions?" Each of the elements of the mode1: commodities, valuing criteria, and arenas of exchange are presented in turn, comparing areas as well as data from community organizations and coordinating agencies. The results related to change techniques are presented, as are the outcome data. Finally, social exchange theory is discussed in light of the findings. Results reported refer to all respondents except in those cases specifically noted.

I. THE MODEL AND ORGANIZATIONAL INTERACTION

\section{Commodities}

The respondents were asked a number of questions about the six commodities of exchange listed in the Community Transactions Model. The first question relates to the scarcity of commodities. As shown in Table VI, respondents reported the most difficulty in securing funding, followed closely by "adding or upgrading staff". The other commodities were reported as being somewhat less scarce 


\section{TABLE VI-A}

\section{REPORTED DIFFICULTY IN OBTAINING COMMODITIES}

Commodity

Funds

Obtaining or Upgrading Staff

Information

Technical Assistance

Access to Influentials

Clients
\% Reporting Trouble In Secuting

Funding. The survey asked about funding in greater detail, questioning the perceived security of budget. Forty-two (42) percent expressed concern over basic funding. (See Table VII). Eighty-three (83) percent listed insufficient funding as at least moderately hindering achieving objectives. Taken as a group, the organizations in this study derived their funding from a great mix of sources. Fed-. eral, state, and local governments were the most common sources but foundations, churches, benevolent groups, and fees for services were also tapped. Forty-five (45) percent of the organizations had three or more sources of funding. Sixty (60) percent of the organizations received at least some funding from the federal government. Since $38 \%$ of the organizations reported budgets of under $\$ 35,000$ per year, it would seem that a small amount of funding could carry great impact in influencing behavior. 
TABLE VII

PERCEIVED SECURITY OF BUDGET

$\begin{array}{lc} & \% \\ \text { Very secure, no worry } & 26 \\ \text { Annual renewal, confident } & 31 \\ \text { Annual renewal, worried } & 16 \\ \text { Insecure, constant worry } & 26\end{array}$

Even organizations with very large budgets reported willingness to make exchanges for small amounts. Said one county public health official upon receiving $\$ 400.00$ to be used for emergency medical supplies, "This is the first time in 18 years I' 11 be able to buy medication or eyeglasses for someone who needs them now. It usually takes three days to rush through an 'emergency' item." In return for this $\$ 400.00$, she was willing to enter the client tracking system, which meant providing information on all the elderly persons making contact with the county health department.

\section{Obtaining or Upgrading Staff}

Over half the organizations reported problems with obtaining or upgrading staff. Twenty (20) percent of the staff interviewed had two or fewer years of experience (note: more than half of this sample were agency directors). Forty-three (43) percent reported no special training in working with the elderly for any member of the staff, and 
$84 \%$ reported inadequate staff as a hinderance to achieving agency objectives. Almost one-fourth 1 isted turnover rate as a problem. On the other hand, $88 \%$ reported that the staff were generally satisfied with their jobs. One-fourth of the organizations had exchanged personnel wi th another agency and $85 \%$ had participated in some kind of training program provided by another agency.

Upgrading the staff, when accomplished, was not without problems. A number of agencies reported making successful efforts to upgrade staff only to have them hired away by other agencies. Programs serving the elderly tend in general to have large proportions of volunteer staff. Again, these agencies are faced with the problem of training volunteers only to have new volunteers the next month. In two of the areas, training of volunteers and staff was done on a cooperative joint basis, utilizing staff from each of the agencies involved.

\section{Information}

Information is an elusive commodity about which to collect information. About one-third of the respondents reported difficulty in abtaining information. This report is supported by an aiarming lack of knowledge by personnel regarding important demographic and service characteristics of the population aged 60 and over. When asked simple questions about the demography of this population, less than $35 \%$ could answer within a broad range of the correct response. Nearly one-half could not list the director of the AAA (the coordina- 
ting agency) and a full third has not heard of the AAA in their district. (It should be noted here that these organizations had been listed as "resource agencies" by the coordinating agency.) Seventyone (71) percent of the respondents listed "poor communications" with other agencies as a hindrance to achieving their objectives. Lack or misunderstanding of information was listed most frequently as the greatest source of conflict for the coordinating agency since its beginning.

Virtually all agencies reported having exchanged information with some other organization, and most reported having given more information than they received. Sixty-four (64) percent of the respondents reported that information specific to older adults was available to them and this covered a wide variety of sources but only $47 \%$ had ever used the source they listed.

Exchange of information was not usually accomplished in a systematic way but rather through chains of "friends and acquaintances". Said a nutrition program staff person, "If I want to know something I call , she always knows what's going on, and if I want word to get around, but not through my office, I tell her, she's better than a telephone." Another staff person reported, "No, I never talk to them. When we were getting started they were too good to help us, so why should I help them?"

\section{Technology (Technical Ass istance)}

When asked which incentives were most important for involvement, 
learning "Better service approaches" and "new planning approaches" fell behind only two other choices ("the cause of serving the elderly" and "new money"). While on the one hand, new technology is considered scarce by only about one-fourth of the respondents, it is still considered an incentive for involvement. As previously mentioned, training with other agencies was common (85\% had participated in some kind of joint training), though most was not specific to the elderiy. A transportation service director reports, "I put the head of the Taxi Company on my board, he knew more about senior citizens then anybody--anybody he could help figure out our routing. It would be hard for him to squawk later about business being taken away, too." It should be noted that there is often resistance to new technology. "I've been in social work, even before they called it that . . . for 36 years. I worked for the Red Cross and welfare. I know my clients and what they need better than they do, so I'm not going to have some 'college expert' come tell me how to help people" (an advisory board member).

\section{Access to Influentials}

Only one-fifth of the respondents 1 isted access to decision makers as a problem. (Perhaps the question should have been asked "ability to infiuence decision makers".) Interestingly, when given hyopthetical situations such as a potential cut in funding or a bill being introduced which would effect them less than half would go to the source of the decision, many of the remainder choosing to do 
"nothing". Access to influentials is a problematic commodity about which to collect data. Respondents often asked, "influence regarding what?" finding it difficult to conceptualize the issue without a concrete example.

Some respondents did have interesting access to decision makers-reported one advisory council member ". . . when I need something I just walk right into 's office (county commissioner) and plop myself down. I took care of him when he was a baby and changed his diapers. He won't look me in the eye until he can say yes." Or the senior projects director who said, "The first time I called (mayor) he was too busy to talk to me so at the next city council meeting I filled two buses with people from the potluck. The next time he returned my call real quick."

Not all respondents reported this kind of ease. A common problem was the low priority of social service programs for county decision makers. A county commissioner stated this point of view very bluntly, "I'll talk to anybody who comes to my office, but they're wasting their time . . it's county business to build roads, not to cart around people and be in the restaurant business." Decision makers were also reported to play programs aga inst sach oither. "We finally decided to form the coalition. . . each year they would tell one person, 'We can't fund you because of them' and then tell them 'We can't fund you because of those guys'... we finally got together and compared notes and then formed the coalition (of social service programs) . . People are still pretty suspicious though" (Director 
of a CAP program.)

\section{Clients}

Respondents generally did not report having difficulty obtaining clients. Sixty-eight (68) percent of the respondents reported referring $\mathrm{Cl}$ ients to other agencies during the past month and $59 \%$ reported receiving referrals from other agencies, Yet, while many organizations are actively involved in the exchange of clients, $16 \%$ of the respondents reported outreach and finding clients as a special problem in working with the elderly, and 55\% reported being involved in situations where clients were "getting the run around", indicating that $\mathrm{client}$ exchanges can be problematic.

Most client exchanges were for the purpose of obtaining a service for a client that the initial agency did not provide. However, in some cases problem clients are exchanged simply to be rid of them. A case worker, when asked about client referrals replied, ". . (chuckle) yes, I referred one today, a real pain ... she would call six times a day . . baked alligators coming through her window... and her neighbors blowing blue powder on her lawn . . . Jesus, let them hold her hand for a while." Many agency personnel will maintain contact with clients even after they have moved on in the system, "Sure, we use (an information and referral service), but I still call them (the clients) back to see if they got what they need : . I really care . . " (A senior center director). Finally, because clients are not generally inanimate 
objects (though there are exceptions) they, too, become involved in the exchange process. "Clients play games sometimes .... Before I met (a welfare caseworker) one old guy kept telling me how terrible she was... asking embarrassing questions, making him wait three or four hours when he had an appointment, stalling with his benefits and then I met her (the caseworker) and he had been telling her the same stuff about me... He was even getting carfare and lunch from both of us." (Medical services worker).

Area Differences. Reported difficulty in obtaining cormodities was examined by area, and the results are presented in Table VIII. The rural community organizations reported less difficulty in obtaining all commodities except technical assistance. The urban and mixed areas were similar for all commodities except information and technical assistance, indicating that community organizations in urban areas have less trouble obtaining information and technical assistance. 
TABLE VIII

DIFFICULTY OBTAINING COMMODITIES BY AREA

\begin{tabular}{|c|c|c|c|}
\hline & \multicolumn{3}{|c|}{$\begin{array}{c}\% \text { Respondents } \\
\text { Reporting Difficulty }\end{array}$} \\
\hline & Urban & Mixed & Rural \\
\hline Funds & $72.7 \star \star$ & $63.6 \mathrm{~d}$ & $44.9 * \star$ \\
\hline Upgrading and Obtaining Staff & 53.0 & 53.4 & 36.0 \\
\hline Information & 24.6 & 37.5 & 28.6 \\
\hline Technical Assistance & $13.2^{\star}$ & $24.6^{\star}$ & $26.5^{\star}$ \\
\hline Access to Influentials & 22.4 & 21.8 & 14.3 \\
\hline Clients & 8.6 & 8.8 & 10.2 \\
\hline
\end{tabular}

Valuing Criteria

Organizations hold values which may influence decisions to become involved with other organizations. These values may differ just as people from various cultures may differ from one another on values held. Respondents were asked to rate the importance of the following values (from the Organizational Interaction Model) in making decisions to become involved with other organizations. Results are shown in Table IX. 
TABLE IX

IMPORTANCE OF VALUES TO COMMUNITY ORGANIZATIONS

$\%$ of Those Responding Rating Value as:

Values

Important

INTEGRATION: to form 7 inkages with other

94

organizations in service system

STATUS: to maintain or increase "image"

88 in the community

WORLD VIEW: to engage in activities consistent with the philosophy of your agency

AUTONOMY: to be independent and self-governing

DOMAIN: to maintain boundaries of agency, avoid overlap of services, clients, etc.

POWER: to be able to exercise control over other organizations

\section{Integration}

The vaiue most often listed as important was integration, the formation of linkages with other organizations. Ninety-four (94) percent considered integration to be important. As behavior indicators of this value, $40 \%$ reported checking with other organizations before implementing pians and $75 \%$ reported having entered into formal contracts with other agencies. On the other hand, poor communication with other agencies was considered to be a hindrance by $43 \%$ of the respondents, In the first wave of interviews, $84 \%$ of the respondents considered "community support" to be important to the work of their 
agency. (This question was not asked in the second wave.) Levels of linkage formation were reported in the discussion of commodities, and if behavior can be taken as one of the physical "outcomes" of an attitude, there is evidence to support the view that 1 inkages are, indeed, important to organizations.

Many respondents stressed the "personal" aspect of these linkages. "You can sign all the contracts and letter of agreement you want... the important thing is who you know in the agency. I go to lunch once a week with someone from another place.... I have to have a face to call . . someone to talk to ...." (Public health nurse). "We don't ever realiy decide anything at those meetings" (advisory council). "I go to meet the people so when I need something, I know who to call" (social security office manager).

Respondents were asked to choose from a list of alternatives related to the degree of formalization of interrelationship between aging programs. Results are presented in Table $X$. Most $(85 \%)$ responses fell in the mid-range, implying support for separate organizations with, at the least, linkages which allow easy consultation. This indicates some correlation between expressed values and certain behaviors. 


\section{TABLE $X$}

\section{COMMUNITY ORGANIZATIONS' VIEWS \\ ON INTERRELATION OF AGING PROGRAMS*}

Service Programs for the Elderly:

- should be as separate and autonomous as possible

LOW from one another

$$
\begin{gathered}
\text { - } \begin{array}{c}
\text { should be organized to al low easy consultation } \\
\text { between them as the need arises } \\
\text { should be organized with the provision for } \\
\text { regular and frequent meetings, information } \\
\text { exchange, liaison regarding clients and the } \\
\text { like on a routine basis }
\end{array} \\
\text { - should be centrally coordinated to facilitate } \\
\text { the working out of common priorities, service } \\
\text { approaches and target group strategies } \\
\text { HIGH } \begin{array}{c}
\text { should be centrally administered by a single } \\
\text { agency in hopes of el iminating overlap and } \\
\text { duplication of services among agencies }
\end{array}
\end{gathered}
$$

*Non-responses excluded from totals

\section{$\underline{\text { Status }}$}

Maintaining or increasing their image in the community was considered important by $88 \%$ of the respondents. Ninety-two (92) percent of the respondents felt that most older clients they served had a "favorable attitude" toward their agency": A similar $97 \%$ reported a favorable attitude held by other agencies in the community toward their program, Respondents were more likely to respond "strongly agree" vs, "agree" for the positive attitude of the 
elderly (20\%) vs, the positive attitude of other agencies (12\%), Eighty (80) percent of the respondents were generally satisfied with their own organization though relatively few of that number (30\%) were "very satisfied".

Respondents were somewhat less eager to discuss status, as opposed to integration, though some types of service are obviously considered to be higher status than others. "We're an insurance agency, not a welfare program" (social security branch manager). Size of agency carries with it some status. One respondent (senior center) proudly proclaimed (six times during the interview), ". . we have three paid and at least 136 volunteers." Some organizations carry with them a history of high status in the community, ". . . well, then we decided to get social security on the program and a doctor, people respect that, makes it seem important." (Senior center director). It is also clear that status can change, ". . . When they first started everyone wanted one (RSVP volunteer) . . . but then it didn't work out like we thought, and they only signed up people already working so no one will have anything to do with them now" (comunity college staff).

\section{World View}

The set of values encompassed under world view are somewhat more difficult to collect data about. This was described as the "philosophy of your agency" to respondents and they were able to use that terminology in their responses, Eighty-seven (87) percent indi- 
cated that engaging in activities consistent with their philosophy was important in making the decision to become involved with other agencies .

Differences in philosophy quickly become apparent in reading through the interview transcripts, ". . and we strongly believe that everyone should pay something, even if just a little so that they feel that they are doing something... it makes them appreciate it more... " (nutrition site manager); ". . we have bake sales and a booth at the fair to raise money to pay for our trips, if one pays and someone else doesn't, it causes hard feelings ...." (senior center director); "The senior council is against needs assessments of any kind, they think they know what the elderly need but they don't know about anyone but themselves.. We have to educate them to make the 'right' decisions" (county coordinator).

Some programs actively seek federal and local support while others steadfastly refuse to take any money from the government. Others differ in their view of the appropriateness of political activity. Only $27 \%$ agree that their agency should try to organize the elderly into a viable political force. ". . I see my role as advocate for the senior citizens in county... I do what I can to keep them informed and to help them be effective" (county aging coordinator, ". , we have to be really careful, . the seniors don't like to talk about politics and since we're federally funded we don't want to get involved" (nutrition site manager). 
Finally, a broad range of philosophy exists related to the elderly themselves: ". . . we offer a service and it's my responsibility to treat all clients the same" (county health clinic director, the clinic, incidentally, spent over $70 \%$ of its budget on programs for children); ". . . we make special efforts for older clients, they've paid their dues. . . anyway our waiting list is three years long ... a lot of them might kick off before that" (housing authority representative).

\section{Autonomy}

To be independent and self-governing was considered important by a majority (83\%) of the respondents. Seventy-two (72) percent cited "too much regulation as a hindrance to achieving their objectives". Roland Warren (1975) has argued that the same agency cannot place a high value on both autonomy and integration since they are at opposite ends of a continuum. These data tend not to support that hypothesis. Sixty-two (62) percent of the respondents indicated that autonomy was "very important" and $69 \%$ indicated that integration was "yery important". A small $(r=.02)$ positive correlation existed between integration and autonomy. While this correlation is not statistically significant, Warren's argument would predict a negative correlation.

A familiar statement was made again and again about federal funding, ". . . there was just too many strings attached... you take a few dollars and the next thing you know, you're working for the government." (Senior council representative). One nutrition site has steadiastiy refused to accept any Titie vil money because of fear 
of loss of independence: ", . . we decide what we want to eat... and when ... and how we want to pay for it... we dance our own tune" (nutrition volunteer). Many agencies who are willing to cooperate with one another "voluntarity" refuse to sign letters of agreement for fear of losing autonomy. When asked why she had refused to sign a letter of agreement, a public health supervisor replied, ". . . we've always been very cooperative with them (the AAA) but when you put things in writing, people misinterpret it then hold you to it ... we can still do business but I won't put anything in writing."

Exchanges in which autonomy is lost are cause for a great deal of anger and frustration, ". . . they (State Program on Aging) told us we could run the show if we just got together to put in a grant, then they gave the money to (AAA auspice agency) and we don't have any say anymore" (senior council chairperson); ". . . when we first started working with them (the AAA) they told us that all we had to do was serve so many clients.. . then they said we had to fill out forms on each person,... then they decided to evaluate us and we had to give them the information... they took over the program" (senior transportation service manager).

\section{Domain}

Domain is defined as the maintenance of boundaries of the agency, avoiding overlap of services, clients, etc. While $67 \%$ of the respondents considered this as important, the topic of "turf protection" often came up in interviews, particularly when questions were asked about 
conflict. Respondents were asked a series of questions about five milestone events for the coordinating agency, These were: Designation of the Coordinating Agency (AAA), Selection of Staff, Preparation of the Plan, Letting of Service Contracts, and Selection of the Advisory Council. Respondents were asked the sources of conflict for each. Since the question format was open-eneded, it was assumed that the appearance of "turf problems" carries more weight than if it were offered as an option. Turf problems was the second most frequently mentioned source of conflict relative to selection of the advisory council; third most frequently mentioned source of conflict in preparation of the plan, fourth for designation of the coordinating agency, and selection of staff, and the fifth most frequently mentioned source of conflict in the letting of contracts. Other factors which closely relate to doma in such as "who should make decisions" and "lack of money" were also frequent responses.

Respondents rarely discussed their own agency's protection of domain but often volunteered comments regarding those activities on the part of other agencies: ". . he thinks he's Mr. Nutricion, that he's the only person who can deliver a meal . . he's extended himself too far.. . What does he know about our county" (senior center volunteer). "My biggest problem is all these agencies protecting turf... everyone's afraid that someone else will get a piece of the action . . if they worried half as much about their clients, there wouldn't be so many problems with aging services ... "(county commis. sioner). 


\section{Power}

Power is defined here as the ability to exercise control over other agencies. Only 16\% of the respondents considered this an important value in making decisions to become involved with other agencies. It was pointed out by a member of the technical panel that some bias may exist in the data due to a tendency to give a socially acceptable response, i.e., it is not socially acceptable to want to exercise control over other organizations. It is possible that this value may be inversely related to autonomy. If you wish to be independent and self-governing, you may respect that wish in others.

Respondents offered few comments related to power. Individuals reported, in some cases, joining advisory councils of one sort or other in order to gain some control over that or another organization. "I joined (the advisory council to the coordinating agency) so we could have some say in how the programs (aging services) were run ... " (senior representative); ". . . we joined the advisory council because we figured that if they were going to tell us what to do we might as well have a say in it . . now and then we decide about other programs, too..."(transportation coordinator).

\section{Valuing Criteria: Area Differences}

The data were examined for differences in valuing criteria among the three areas. The results shown in Table XI indicate no strong differences. The rural area held power to be somewhat less important but the difference was not large. These data indicate that the 
valuing criteria held by community organizations are quite similar in the three areas studies.

TABLE XI

IMPORTANCE OF VALUING CRITERIA BY AREA

VALUES

Integration

Status

World View

Autonomy

Domain

Power

*Significant $p$ less than .2
URBAN MIXED RURAL

$97 \quad 90 \quad 94$

$87 \quad 88 \quad 90$

$87 \quad 85 \quad 90$

$\begin{array}{lll}83 & 87 & 81\end{array}$

$\begin{array}{lll}68 & 71 & 61\end{array}$

$19 * \quad 18 * \quad 9 *$

Arenas

Respondents were asked to describe the role of the various arenas of exchange in meeting the objectives of the coordinating agency. The rationale for this open-ended question was to determine whether or not exchanges were made other than those directly related to the stated purpose of the meeting.

\section{Planning}

The planning process was described in some detail by respondents, Twenty-six (26) percent of those responding listed exchange of information as a secondary outcome of the planning process. Also 
mentioned were fiscal exchanges, advocacy, and coordination, in descending order of frequency. Planning was considered an important arena for exchange when more than one organization was involved. Eighty (80) percent of the respondents reported checking with other organizations about their plans often, while all agencies reported checking with another agency at least occasionally. ". . (A)nd then the community council called everyone together to plan I \& $R$ for the three county area . . no one seemed to be willing to give up their I and $R$ but we got some ideas on how to keep our information up to date and I also learned about some new services... we never did get done what we were supposed to ..." (CAP worker).

\section{Hearings and Meetings}

Many respondents complained about the large number of meetings they felt required to attend. "Only about one-eighth of the time spent in meetings is worth anything at all" (senior center director). Yet agencies continue to call meetings and personnel continue to attend. Respondents viewed meetings more in terms of their purpose rather than as an entity in themselves. A large amount of agency interaction occurs in meetings and business other than the convening issue is often conducted. "Everybody has their own agenda, their own ax to grind, their own back to pat . . . you just sit there and try to keep order" (small town mayor):

Public hearings also serve functions in the eyes of the respondents, though not always those expected, "Well ... when the state 
holds those hearings the $\mathrm{plan}$ is finished, they're not going to change it ... they don't want input . . . see, those meetings are for the local people to strut around and say 'see what we did' and look good for the press if they care enough to come .. "(county coord inator). "The deals are made in private... not in public, those meetings only tell what's been done" (CAP staff person).

\section{Contracts and Letters of Agreement}

While considered the formal documents of exchange, the making of contracts and letters of agreement also serve as an arena for exchanges other than those outlined on paper. Again, exchange of information was the most often 1 isted "other business" in the making of contracts. Seventy-five (75) percent of the respondents reported having entered into formal contracts with other agencies. This indicates that the process of formulating contracts and letters of agreement are situations available for exchange opportunities.

There was some resistance to signing contracts or letters of agreement on the part of community organizations stemming mainiy from fears of losing autonomy. Yet, most respondents recognized the value of the process: ". . . it sets everything on the line ... everyone knows what to expect. . " (I and R staff); "It makes for fiscal responsibilty" (county coordinator).

\section{Evaluation and Monitoring}

It should be noted that most organizations which are in positions 
to evaluate or monitor other organizations are usually involved in fairly intense exchange relationships with that other organization. Exchange of information was most often listed as the "other business". However, some respondents felt that evaluatior, and monitoring were threatening to the organization being evaluated. "They (the county) count dollars and then they tell you if your program was good ... it doesn't matter that you spent eight hours trying to get someone a ride to the doctor... they don't understand how hard it is to work with these people (the elderly)" (senior services worker). "They (the state) sent some guy right out of college and he asks me what he should do.. - what scares me is that he will decide with them what our funding is next year (multipurpose center director).

Some respondents recognized the potential benefits of good evaluation. "You give them back information so they can improve their program . . . you let them know you're on their side . . . but sometimes you have to lower the boom" (county commissioner).

\section{Client Transfers}

$\mathrm{Client}$ referrals and tracking systems offer an opportunity for organizations to exchange information according to onerthird of the respondents. Two-thirds of the respondents were involved in some kind of $\mathrm{client}$ transfers, Conversations about $\mathrm{clients}$ were often considered the best way organizations exchanged other information : ", , we found that case planning got us together and in the process we got to be friends then began to really work together" (county welfare caseworker). 
". . . it's funny . . . for a couple of years we had talked about trying to get together with (medical services coordinator), then we found out we were working with the same couple... I had the guy and she had the woman . . . we had lunch to talk about them . . decided they were both crazy... we meet a couple of times a month and it's been a real help" (county welfare worker).

The more formalized the transfers, the less opportunity there is for exchange. ". . . we used to have a little chat every time I had someone to send over... now the outreach workers do it all and we just never seem to get together anymore" (Friendly Visitor service staff). Though some agencies avoid the formalization, ". . if it's someone I really care about I still call, myself" (nutrition center staff).

\section{Arenas: Area Differences}

The data were examined for area differences. There were no major differences attributable to area. Those differences which did appear were related to the coordinating agency and will be addressed in that section.

\section{Conclusion}

A careful analys is of the data was made to determine whether or not the Community Transactions Model has any value in the explanation of behavior in the community. It has been shown that the commodities, valuing criteria, and arenas do have meaning to the responding 
agencies. The commodities exist in varying degrees of scarcity and organizations enter into transactions to obtain them. In some cases, exchanges are made of commodities considered not so scarce (clients, for example). The valuing criteria, with the exception of power, were considered important in the decisions to become involved with other organizations, though there were some differences of opinion on the relative value of a particular criteria (as were predicted). The arenas of exchange proved more difficult for the sollection of data. Respondents tended not to think of the situations listed in terms of secondary exchanges, though they often described these exchanges occurring in those arenas, when asked to describe the primary process.

It appears that the elements of Organization Interaction Model has validity in the community, in that respondents use them in explaining their behavior (albeit after the fact). Of course, this model does not take into consideration all the factors which potentially determine the exchange. The review of the literature uncovered a number of such factors, such as environment, history, etc., which were not within the scope of this research to investigate. The next step for future research might be the examination of such factors. The purpose for this research has been served, namely to investigate the applicability of the Community Transactions Model and to set the stage for the next question.

\section{HOW CAN A THIRD PARTY INFLUENCE THE INTERACTION BETWEEN ORGANIZATIONS?}

This question can be stated more generally as "How can one 
organization influence the behavior of another?" While most of this discussion will be concerned with a "coordinating agency", in this case the Area Agency on Aging, much of the information is applicable to any organization attempting to influence the behavior of another. The first step in the analysis of data was to reexamine the Organizational Interaction Model to determine potential points of impact. The data described below comes from the interviews with the three Coordinating Agency directors unless otherwise indicated.

\section{Commodities}

The directors of three coordinating agencies (CA)8 were asked, in Wave II, to rank the commodities in order of usefulness in influencing the behavior of others. They were then asked how much control the coordinating agency had over each of the commodities. Results are shown in Table XII.

\section{Funding}

There is general agreement among the coordinating agency directors that funding is the most useful commodity for influencing the behavior of others. The rural area director ranked funding second to technology but agreed that funding was very important. This is not surprising given consideration of the organization data which showed funding as the most problematic commodities to obtain. While funding was considered a useful tool, all three directors ranked their level of control over funding as "moderate". "Our budget is too small

\footnotetext{
*In this section of the report, the three areas will be referred to as urban, mixed (mixed urban/rurai), and rural.
} 
TABLE XII

\section{COORDINATING AGENCIES' PERCEPTION \\ OF USEFULNESS ANO CONTROL \\ OF EXCHANGE COIMODITIES}

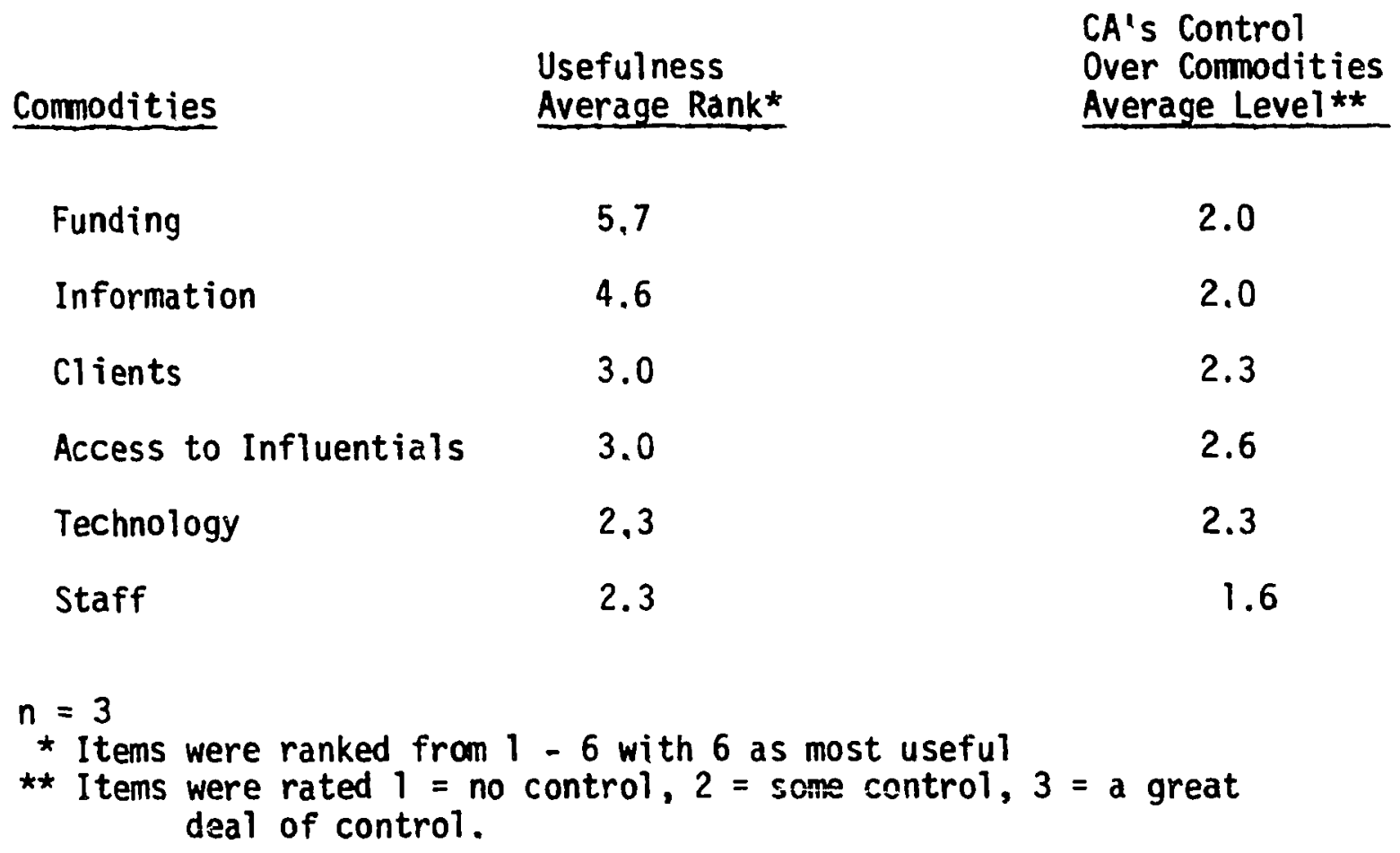

to have a big impact just on the basis of paying for programs." (Rural Area). "They (the coordinating agency) just ask too much for the small amount they give . . ." (senior center director -- Mixed). The level of funding for the Area Agency was considered a prablem not only by $C A$ staff but also the community organizations, who listed lack of money as a major source of conflict for the coordinating agency, "There are at least 17 different things the (coordinating agency) is supposed to be doing according to law : . but they (Congress) won't give us the resources to do them" (Urban). 
In spite of general agreement on lack of funding for the coordinating agency, those dollars available have been used to bring about behavior change: "We took $\$ 4,000$ from the AAA and went to the county and used it to convince them to put $\$ 20,000$ of revenue sharing in and then we went to the State (Department of Transportation) and they agreed to match the $\$ 20,000$ and that's how we bought the vans and then we went to and (city governments) and they agreed to do the upkeep... That's four vans with drivers and upkeep for $\$ 4,000$ ... not bad ..." (county CA coordinator -. Mixed).

In addition to being used as seed money to start new programs, funding was used to indirectly develop constituencies for leverage in later governmental funding cycles. "The first year they asked the city council for $\$ 2,000$ to start a senior center, it was nothing but that's what they got... nothing ... then the AAA (CA) made an agreement with the city, they (CA) would pay for one-half of a staff person who would be located in the city (hall) . . . it seemed great, the city got a free staff person and got to look good and the AAA got the start of a senior program in the area . . . that was the first year... The second year the (CA) funding went down, as planned, the seniors went to a council meeting, I (staff person) stayed low profile and the seniors got me upped to full time.. now we've got plans to build the center (with a federal grant) and I'm full time and the city, without meaning to, has a program for seniors" (senior center director :- Mixed),

The data indicate that even small amounts of funding can have 
considerable impact both on the agency being funded and others as well. In the example given above, the contract was between the coordinating agency and the city but it had major impact on the relationship between the city and the elderly, as well as other programs for the aged in the area. Other examples of this process are available: "It all started with a small grant from the State Aging Program on Aging which was match for a grant from ( national organization). The project was to last for two years and it paid my salary and a secretary and for a couple of statewide conferences... from that we started adding to the curriculum and that got us a few training contracts... We now do more for the elderly and service providers than any educational institution in the state" (community college staff -- Mixed).

Provision of funding, however, may bring about only temporary changes in behavior, ". . . we funded the program (homemaker service) for a year ... When our funds ran out, the program died ... in some ways it would have been better if we never started . . . " (Rura ..CA director).

The conscious effort of the coordinating agency director to tie the funding into other, ongoing resource bases seems to be one factor in the success of funding forlong term behavior change: ", . what we try to do is to fund them just long enough to get them on their feet so they can prove the need for their service in the cormunity ..." (CA director -. Mixed),

The data indicate that control of funding is a valuable tool in bringing about behavior change, but for that behavior change to be 
permanent, the funding must either be continuing or tied into some resource base. The use of small grants as seed money to set up "demonstration projects" also seemed an effective use of resources.

\section{Information}

Area Agency directors ranked access to information as the second most useful commodity in influencing the behavior of others. All three viewed the Area Agency as having moderate control over this commodity. It should be remembered that one-third of the respondents reported trouble in obtaining access to information. Sixty-two (62) percent of the respondents had not received information from the coordinating agency in the past month. Similarly, a very small proportion had provided information to the AAA. When asked their source of information regarding older adults, one-fourth of the agencies listed the Area Agency on Aging.

Area Agency directors differed in their perception of the value of information in achieving their goals. "It's fairly useless . . (CA director -- Rural). Interestingly, this same director listed as one of the goals of the CA "to educate the population to their responsibility to senior citizens." The other two directors saw information as valuable, "Initially, it (information) caused awareness and change in performance... mainly it's a sell-job" (CA director -. Mixed); ". : must keep community and agencies informed so that communication is maintained, " particularly where we ask people to do things" (CA director -.- Urbanl. 
Agencies in the community as well as the CA directors viewed lack of information and lack of understanding as important sources of conflict for the coordinating agencies. Interestingly, furmal dissemination of information by the $C A$ was lacking in all three communities. None of the coordinating agencies put out a newsletter of current funding sources, political decisions affecting programs, etc. (One auspice agency for a $C A$ has since begun such a newsletter.) The only regularly scheduled meetings were advisory council meetings al though in two districts (urban and mixed), representatives of the CA regularly attended Senior Council meetings to report on activities in the community.

The coordinating agency directors expressed concern over the seemingly overwhelming flow of information from federal and state government, ". . . when the ' $P I$ ' and ' $I$ ' and 'R \& $D$ ' and 'R $F$ ' stack gets to be about two feet high, I put it in a box and start over .. . if I read all of that stuff, I would never get anything else done . . after a week or two, most of it doesn't matter much anyway" (CA director -. Mixed). Much of the information provided by these sources is often considered inefficient, non-relevant or useless. Information that might be useful is often unavailable. ". . we were all writing contracts, . , in every part of the state ... most of us didn't know how to do it and no one at the state would give us a contract format . . I It would have taken a half a day and saved 160 man hours of work around the state" (CA director -- Mixed). An informal conversation with a staff person from the State Transportation Depart- 
ment revealed a similar circumstance, ". . . in a period of about three weeks, I must have gotten 20 calls all asking the same thing... how do you get insurance for their (sic,) projects, what are the laws on vehicles, who has liability ... it turns out, they were all writing applications for funding from the AAA's and needed to have a plan." A number of agencies reported one of their purposes for joining the Advisory Council of the CA was to have access to information. "I wanted to find out what was going on... I was new here and didn't know anybody ... I came to the meetings but they aren't really worth that much" (senior center director .- Mixed). On the other hand, some agencies were not convinced that the CA had that much to offer. ". . . I've been serving seniors for six years, he's (CA director -- Rural) been here six months... he should come to me to find out what's going on" (coordinator, senior program -- Rural).

It would seem from these data that information is underutilized as a commodity of exchange by the AAA's. Quality, relevant, useful information is valued by the providers of service and could be used both to change attitudes and behavior as well as bargaining tool in transactions.

\section{Clients}

Coordinating agency directors were in some disagreement over the usefulness of $\mathrm{clients}$ in influencing the behavior of others. Interestingly, the CA with the most advanced information and referral, $\mathrm{Client}$ tracking system (Urban) considered clients least useful in influencing the behavior of others of the three CA directors. Perhaps, this is 
because the process had become relatively institutionalized leaving little room for bargaining. Less than $17 \%$ of the agencies reported receiving referrals from the $C A$ at all, and less than $10 \%$ were involved with the AAA in more than five client referrals per month. These data may under-represent the number of client referrals in which the $C A$ is actually involved, in that each of the coordinating agencies contracts out a portion of their information and referral function causing some confusion in the minds of agency personnel. This may in some degree be reflected in the data provided by the CA's on client referrals and contacts with other agencies. These data are presented in Table XIII.

One of the problems in asking broad open-ended questions is illustrated by these data. Each CA respondent chose a different reference point in making his or her answer. The level of contact with local government, for example, is affected by the nature of the auspice agency for the CA. In one case, urban area local government is the auspice agency and the CA reports daily contact. One respondent (Mixed) chose to exclude the auspice agency from the calculation leading to a much lower interaction level reported. It is interesting to note that the three districts differ considerably on amount of contact with the State Program (ranging from daily to six times a month), and local services ranging from daily through twice a month.

The relevance of these data to the current question rests in the information regarding numbers of client referrals. These range from 10 - 15 /month to 1804 /month, Many factors may influence this difference. First, the size of the district varies a great deal. (See Table V). 
TABLE XIII

LEVEL OF INTERACTION OF THE COORDINATING

AGENCY BY AREA

INTERACTION

\begin{tabular}{|c|c|c|c|}
\hline & URBAN & MIXED & RURAL \\
\hline $\begin{array}{l}\text { \# of client referrals } \\
\text { to other agencies }\end{array}$ & 1804/mo & $600 / \mathrm{mo}$ & $10-15 / \mathrm{mo}$ \\
\hline \# of referrals to AAA & 199/mo & $100-200 / \mathrm{ms}$ & None* \\
\hline \multicolumn{4}{|l|}{ Contact with: } \\
\hline State & $12 / \mathrm{mo}$ & Daily & $6 / \mathrm{mo}$ \\
\hline Local Government & Daily** & Monthly & Daily** \\
\hline Local Sources & Daily & $2 / w k$ & $2 / \mathrm{mo}$ \\
\hline Senior Groups & Daily & $2 / \mathrm{mo}$ & Daily \\
\hline Other Groups &.-- & Occasionally & Daily \\
\hline
\end{tabular}

The largest area is 16 times as large as the smallest in this study. Secondly, the rural CA director does not view information and referral as part of his job. ". . . not in that business... Mildred does it." Another factor is the limited number of serivces available for the elderly in rural areas.

Working with elderly persons can present special problems to service providers. Respondents were asked about such problems and their responses were coded into the categories presented in Table XIV. 
Because of these perceived problems, many agencies do not consider the elderly as "valuable or desirable clients", In some instances, this leads to the elderly receiving less service than their need would indicate they should. ". . . we used their own statistics... we showed them (the county mental health clinic) that less than one percent of their clients were over 60 ... we had a study from California that showed elderly people needing at least twice as many mental health services... so we figured that the elderly were getting 1/20 of the mental health services that the regular population were. . . the mental health clinic is now trying to increase services to the elderly, including nursing home visits." (CA director -- Mixed). ". . the problem is getting them to see that they're (Park Bureau) responsible for old people, too... they provide special programs for kids. . and things for the general public... but nothing for the elderly... our goal in the next year is to get that started ... " (CA director .Uirban).

TABLE XIV

PROBLEMS IN SERVING ELDERLY CLIENTS

$\%$ of Respondents

Listing Problem

Physical or Psychological Problems 25

Lack of Available Services 24

Lack of Staff or Funding 21

Elderly Resistance, Pride, Self Esteem 18

Outreach, Finding Them 16

Other Probienis 17 
One of the goals of the Area Agency is to change the value of the elderly as clients. "We try to show that the elderly can be desirable clients... that they can change and learn . . that it's worth it to serve them ..." (CA director .. Mixed). The rural area director listed one of the goals of the CA as to ". . . teach them (the community) their responsibility toward the elderly ". . .after all, they (the elderly) built the community."

These data show that there are exchanges of clients occurring regularly in the community. An agency attempting to influence the behavior of another using $c l$ ients should keep in mind what aspect of the client is important to individual organizations (for example, is it important that the client be able to change or take part in his own treatment). Once the exchange of clients has become "institutionalized" there is less opportunity to use clients as a bargaining point, but those regular exchanges can serve other purposes such as providing information. The coordinating agencies differed in their attitudes and behaviors related to exchange of clients.

\section{Access to Influentials}

The three AAA directors were in disagreement over the importance of access to influentials in influencing the behavior of agencies. The CA which is housed in city-county government rated information as second only to funding in importance, ". . we are the influentials." The coordinating agencies housed in councils of government saw access as a somewhat more problematic commodity, to the point that one $C A$ 
(Mixed) stated, "In a round about way, our access to at least some 'influentials' is a hindrance... people hate (auspice agency) and we're in (auspice agency) so we have an uphill battle."

Introducing influentiais to each other is considered to be a very important role for the $C A$ by all directors. They viewed it as necessary for "coordination" and "implementation". Efforts were made to include elected officials and important agency personnel on the advisory councils of the CA. One district found its advisory council chaired first by a retired city-councilman and then by an incumbent mayor (selections carefully orchestrated by the CA director -- Mixed).

It should be noted that respondents were sometimes wary of the close ties of the CA with influentials. ". . . of course we didn't go to the CA (for help with a jurisdictional problem). . . they can't go against the city.. . there's a conflict of interest, you can't be an advocate and work for the people you're fighting" (senior program director -- Urban).

If access to influentials is interpreted more broadly to include advocacy, some respondents ( $16 \%$ on an open-ended question) viewed this as an important role for the CA. All three CA directors 1 isted advocacy as one of the roles of the coordinating agency. Their choices of approaches to advocacy differed considerably, ". " it's our job to educate them (government) about the needs of the elderly . . . to motivate change , . to ask government to do something where they're going non (sic.) . . and to help them provide leadership for the 
community" (CA director -- Urban). "It's my job to try to help them (government) to be better coordinated with other government and private organizations ... to help them to better understand their role... to get them to provide dollars "(DA director .. Mixed).

While access to influentials is of somewhat lesser importance to respondents and the $A A A$, it is often overlooked as a potential commodity of exchange, yet there are examples of its usefulness when appropriately handled by the coordinating agency.

\section{Technology}

Technical assistance, while seen to be less useful than funding, information, and clients, was considered to be under considerable control of the CA. This commodity was not perceived to be particularly scarce: one-fifth of the respondents reported a scarcity. Twenty-five (25) percent of the respondents had received technical assistance from the CA's. All three coordinating agencies had provided technical assistance in similar amounts, so that no differentiation by district was possible.

As was noted in the agency interaction section of this report, there is sometimes resistance to technical assistance from an outside source. ". . . I'm not going to have some 'college expert' come tell me how to help people" (CA adyisory board momber $\rightarrow$ Miyed), "we don't want them telling us how to run our program" (nutrition project ... Mixed). On the other hand, many agencies expressed need for help with specific problem solving. "How do I keep secretarial and support staff motivated?" 
(nutrition project -. Urban). "What do you do to keep volunteers interested but still doing the work?" (senior volunteer project -. Mixed). "We need training on how to do outreach ... not just going to a Senior Center and rounding up clients but real outreach . . getting to the isolated ones" (nutrition -. Urban).

Technology can be a valuable exchange commodity if the CA can make it specific to the needs of agencies. Care must be taken with the sense of "professionalism" of the agency personnel being assisted. Utilizing agencies in the community to provide technical assistance to others has worked well in at least two of the areas. "We got (transportation specialist) to come to each area to give 'technical assistance' . . it worked out great in two ways... she knew more about transportation than any of us so we learned a lot . . but more importantly, it have her a sense of security and she got over some of her 'holier than thou' attitude, that she was the only one doing any work" (CA director -- Mixed). ". . . and we have regular meetings of agency staff . . we use them as resources for each other, there's a lot of years of experience sitting in that room... (problems?) Yes, well, you have to bring thers together for some other reason, like to review a plan, it's hard for most of them to ask someone else (another agency) for help but when they start talking about problems in the context of the plan... someone else will say 'we had that problem and this worked', . "(CA director .. Urban),

Staff

obtaining or upgrading staff was considered by two of the areas 
(Urban and Rural) as the least useful commodity. The Mixed area, on the other hand, viewed staff as second only to funding. Efforts to coordinate the training of staff and volunteers in the Mixed area have been much greater in that area than the others. A contract with the community college provides pre-employment, in-service, and volunteer training for a wide range of services to the elderly. This is viewed as a valuable resource by both CA staff and agencies in the community. It should be noted that the community organizations viewed this cormodity as second only to funding in scarcity $(50 \%$ of the respondents listed difficulties in obtaining or upgrading staff). Eighty-four (84) percent of the resporidents reported inadequate staff as a hindrance in achieving their objectives but less than half of those answering reported having received any help from the coordinating agency in obtaining or upgrading staff.

One of the reasons for this difference between expressed need and level of service by the $C A$ is a perception on the part of the coordinating agency that there is little they can do, ". . sure, turnover rate is a problem, but at the wages the agencies can afford to pay what do you expect?" (CA director .. Urban). ". . . we thought about setting up a job file and a file of people who might want jobs but that takes a lot of work and we just didn 't have the staff" (CA director -. Rural).

\section{It appears that assistance in upgrading or obtaining staff is} an underdeyeloped, underutilized commodity by many coordinating agencies, Efforts at utilizing local resources have had positive results where 
attempted, and the efforts are appreciated by agencies in the community. This is a commodity which deserves further consideration by the coordinating agency.

\section{Commodities: Area Differences}

There was general agreement among the $C A$ directors regarding the usefulness of each type of commodity for influencing the behavior of community organizations. The most notable differences were with "obtaining and upgrading staff" and "access to influentials". The Mixed area director considered the obtaining or upgrading of staff as very useful, second only to funding, while the other two areas (Urban and Rural) both viewed it as least useful. It should be noted that the Mixed area had a very successful program at the community college for training gerontological specialists of various types, both for pre-employment and in-service training, while the other two area did not. Access to influentials was considered very useful in the Urban area and least useful in the Mixed area. This finding is probably related to the auspice of the coordinating agency. For the Urban area, city and county government serve as joint auspice giving the coordinating agency prestige and direct access while the Mixed area $C A$ is housed in a Council of Governments and suffers from the controversy surrounding that agency (the COG). The Rural CA is under the auspice of a Council of Governments which is respected in the community though not too powerful and the CA director considers access to influentials of medium usefulness. 
There is general agreement among the CA directors regarding amount of control The Urban area viewed their control over access to influentials as being somewhat greater and the Rural area viewed their control over upgrading or obtaining staff as being somewhat less.

Conclusion: Commodities

Evidence collected in this research indicates that the commodities outlined in the Organizational Interaction Model are valued and exchanged by agencies in the community. Additionally, Coordinating Agency directors have utilized these commodities in bringing about changes in behavior of organizations and in affecting the interactions that agencies have with each other. Perceptions of scarcity and usefulness of these commodities differ somewhat in the three areas studied and between the community organizations and the CA directors. A comparison of the ranking of commodities is presented in Table XV.

Agency personnel and $\mathrm{CA}$ directors are in agreement that funding is the most scarce and also useful commodity. Their ratings are similar for information, technical assistance and access to influentials. There was disagreement over the scarcity and usefulness of clients and obtaining and upgrading staff. The community agencies had difficulties with obtaining staff, whereas the coordinating agencies saw this as one of the two least useful commodities (with the exception of the Mixed areal, On the other hand, community agencies viewed clients as the least scarce commodity, while the coordinating agencies considered clients to be relatively useful in bringing about changes in behavior, 
TABLE XV

COMPARISON OF RANKING OF COMMODITES

BETWEEN CA DIRECTORS AND AGENCIES

IN THE COMMUNITY

COMMODITY

Funding

Staff

Information

Technical Assistance

Access to Influentials

Clients
Scarcity Rank Agencies*
Usefulness Rank CA Directors **

* 6 = most scarce, numerical rank ** most useful, average rank

A difficulty with these data is that agencies were asked to rate the amount of trouble they had in securing the commodities, whereas the directors of the coordinating agencies were asked to rate their perceptions of usefulness of each commodity and their level of control over the commodity. In Wave I of the study, respondents were asked how important these commodities were in making decisions to become involved with other agencies. The ranking is similar to the scarcity ranking except for the commodities of staff upgrading, which, while considered scarce, was not often the reason for becoming inyolved with other organizations. Also, technical assistance was rated as an important reason for becoming involved, even though agencies reported somewhat 
less trouble securing it. Interpretation of these data would lead to the conclusion that agencies perceive an unmet need to upgrade or obtain staff. Secondly, technical assistance is obtained from organizations in the community and is a reason for involvement.

The data were examined to determine whether there were differences among the areas, Urban, Rural, and Mixed, regarding scarcity of commodities. The results were presented in Table XVI. Differences in the various coordinating agencies' help in obtaining commodities are also presented in Table XVI.

TABLE XVI

HELP FROM COORDINATING AGENCY IN OBTAINING COMMODITIES BY AREA

\begin{tabular}{|c|c|c|c|c|}
\hline & Urban & $\frac{\text { Respondents }}{\text { Mixed }}$ & $\begin{array}{l}\text { Receiving } \\
\text { Rural }\end{array}$ & $\frac{\mathrm{Help}}{\underline{\mathrm{SIg}}}$ \\
\hline Funds & 20 & 40 & 28 & * \\
\hline Staff & 22 & 12 & 9 & * \\
\hline Information & 28 & 31 & 27 & \\
\hline Technical Assistance & 29 & 27 & 16 & \\
\hline Access to Influentials & 29 & 26 & 7 & * \\
\hline Clients & 15 & -25 & 16 & \\
\hline Average & 24 & 27 & 17 & \\
\hline
\end{tabular}

* Significant at $p$ less than, 1

Agencies in the Rural area reported less difficulty in obtaining funds, staff, and information than the Urban and Mixed areas. 
The Urban area organizations reported more difficulty with funding and less with technical assistance, The mixed Urban/Rural area organizations reported more difficulty with technical assistance than the other two areas. The data on help from the coordinating agencies reveal area differences also. The Urban area had more agencies reporting help with upgrading staff and less with funding. The agencies from the mixed Urban/Rural area reported more help with funding and with clients. The Rural agencies were midway on funding assistance and lower on access to influentials and technical assistance. These differences are not systematically related, but should be considered by a coordinating agent attempting to affect change in the community.

A Pearson correlation was computed to determine the relationships between the various commodities. Small correlations were found to exist among all commodities relative to scarcity. Thus, if an agency reported one comodity as scarce, it would be likely to report other commodities as scarce. The same relationship held for assistance from the coordinating agency. If the coordinating agency had assisted in obtaining one commodity, it had likely he?ped with others. The Pearson correlation was then used to determine the relationship between difficulty in obtaining a commodity and coordinating agency assistance, Correlations avering around 3 were found to exist with all commodities except funding, which showed no correlation between difficulty in obtaining the commodity and help from the coordinating agency. 


\section{Valuing Criteria}

The directors of the coordinating agencies were asked whether they had considered each of the valuing criteria in their work with agencies in the community. If they said yes, they were then asked to describe the situation and their actions and the outcome. Their responses will be discussed in the order of importance of the values to the community agencies.

It is important to note here that one of the coordinating agency directors had a great deal of difficulty with these questions. He explained his difficulty in this way, "They (the values) are taken into account intuitively... it's the 'art' part of coordination and community change" (Mixed area). The other two directors were very aware of the values and reported consciously taking them into consideration in many circumstances.

\section{Integration}

Two of the coordinating agencies reported having worked with agencies which perceived their integration effected by working with the coordinating agency. In one case, this perception on the part of the community agency had a positive effect, as might be expected. In the second case, the community agency held the value of integration in low esteem. The director of the coordinating agency said that re-education was the most effective approach: ", , we tried to show them that linkages were important to their health as an agency" (CA director .. Urban). Since integration is held by $94 \%$ of the community agencies as 
an important value, the coordinating agencies should capitalize on these views.

Illustrating for agencies the way in which involvement with the coordinating agency or other organizations can increase integration can lead to positive behavioral changes. In those cases in which integration is not valued highly, changing the values through re-education was shown to be successful in some instances. It has been pointed out that, integration as a value, is highly socially attractive (Mott, 1968). It is possible that agencies may "express" the importance of integration but resist actualy linkage formation. Again, the coordinating agencies may be able to use these public expressions to encourage linkage formation. On the other hand, the coordinating agent must be aware that there are sometimes differences between expressed values and actual behavior. That there is a great deal of interagency activity occurring in the community is a good indicator that integration is actually a "working value" for the agencies.

\section{$\underline{\text { Status }}$}

The value of status was considered important by two of the coordinating agency directors (Urban, Rural). The Rural area director reported an agency which saw interaction with the coordinating agency as increasing the status of the community agency, He said, "We allowed interaction... tried to fulfill their need, : it wasn't a problem to do that and we met our objectives at the same time." The Urban director had the opposite experience -- an agency which perceived working 
with the coordinating agency as a potential decrease in status. "... we tried to indicate that while we were the city, we were under a federal grant to build a system . . not just provide resources from the feds and city."

Status, as a value can be used to influence behavior: ". . we worked with the Area Agency to get funding .. . it seemed that federal money would make us (the program) more real" (transportation project .Urban).

Consideration of the value and re-education if necessary are important activities of the coordinating agency director.

World View/Philosophy

Both coordinating agents who considered values were very aware of world view. As the Rural director put it, ". . understanding of others enhanced the working relationship." The Urban director, while he recognized the importance of world view to the individual agency, said ". . . I have no real approach, no policy approach except to say that decisions are made $99 \%$ on fact not on a battle of opinions."

No approach to working with the world views of agencies was offered except, ". . . to understand them" That world views are important is evidenced by the agencies themselves; how to use them is more individualistic,

\section{Autonomy}

Autonomy appeared to be the most problematic of the values for 
coordinating agency directors to deal with. While all considered autonomy to be an important value, each had taken a different approach. ". . I tried to talk in their language with their perspective... talk with them not at them" (Rural director). The Mixed area director took a slightly different approach, ". . . you calculate the trade-offs .. . try to make the deal attractive enough." The Urban director was very candid regarding his approach, he lied. ". . . tried to deal by reassuring them it was cooperative and would not violate their integrity knowing it would."

Each of these approaches have long-term costs and pay-offs. Autonomy is generally important to organizations and can be easily threatened by agencies whose purpose it is to coordinate the activities of other agencies. As one director put it, ". . . you gotta be real careful not to step on any toes" (Mixed).

\section{Doma in}

Domain is another value seen by coordinating agency directors as both a potential asset and barrier in working with community agencies. On the positive side the Rural director explains, ". , , it helped me to deal with them . . . the prospect of enlarging their domain allowed me to work. . . I was carefur to see what they need (sic. )." The Urban director described his behavior in a situation where his agency was a threat to the domain of another, ", , took a hard line and got the greatest resistance."

One of the legally sanctioned functions of the coordinating 
agency in this case is avoidance and elimination of duplication and overlap. The avoidance function will generally not result in conflict, however, the elimination of overlap can lead to serious domain threats when agencies are asked to aiter activities. These circumstances must be handled with the utmost care if the credibility and effectiveness of the coordinating agency is to be maintained.

\section{Power}

Although few agencies considered power to be an important value, the coordinating agency directors reported a great deal of experience with agencies who perceived threats to their power. There is some indication that the declaration that power is not an important value is affected by social desirability. It is not socially desirable to appear as if power is important to your own agency but both community organizations as well as the coordinating agencies reported power as being important to "other organizations". "They (senior group) wanted to control everything ... to run our business" (transportation program -- Mixed).

Coordinating agency directors reported similar approaches to the problem. ", , I tried to know when not to threaten and to offer a carrot when necessary" (Mixed); ". . . in most cases, I had enough resources to counterbalance and appease ... implying additional resources down the 1 ine" (Urban). No one reported trying to change the value but rather used resources as a counterbalance, 


\section{Conclusion: Valuing Criteria}

Valuing cirteria are considered and used by agencies and coordinating agency directors. The data were analyzed to determine any differences among the areas; Urban, Rural, and Mixed. There were no statistically significant (at the .1 level) differences though there was a trend for the Rural area to place less value on power and domain. A Pearson Correlation was computed to determine the independence of the separate values. The two largest correlations were between autonomy/ domain $(r=.29)$ and status/world view $(r=.28)$ both significant at $p$ less than .001. A general independence was found to exist among the values.

\section{Arenas of Exchange}

The directors of the coordinating agencies were asked questions similar to those asked the community agencies regarding the arenas of exchange. For the most part, their responses are very similar. Their utilization of these arenas are presented below.

\section{Planning}

Planning was considered by all three coordinating agencies to be an arena rich with possibiltties for "technical assistance, training, coordination ... it incorporates all kinds of things . . many secondary effects" (Mixed), ", . it is a definable element of planning, information, then homogeneity builds beyond control and then when argument comes, you have more support and less difficulty with 
decisions from individual agencies... they're more friendly so less trouble with back-biting" (Urban). All areas saw positive outcomes from these "other acitvities".

\section{Hearings and Meetings}

Two of the coordinating agencies saw hearing and meetings as holding potential but as much less usefur than the planning process. Mainly the positive effects were information exchange and better understanding. The Urban director believed that hearings had generally not been well used. "Hearings were terrible... 'here's the plan .. see you later' .. . no real sol icitation of feedback or frame of reference."

All three directors viewed the purpose of hearings and meetings to be information giving (often not exchange). Although they saw the potential for other business being conducted at meetings, this was generally not an arena which they attempted to manipulate.

\section{Contracts and Letters of Agreement}

It was previously noted that contracts and letters of agreement are formalized exchange documents. However, in the process of making these agreements, other business is often conducted. The director of the Mixed, Urban/Rural area, viewed such situations as opportunities to ". . research, . find out about values held and how to change them." The Urban director encouraged future exchanges with the agreements made, "All contracts to decentralize I\&R centers were tied to other contracts . a this caused the system to function, but, more 
importantly, formed a coalition for later use."

\section{Evaluation and Monitoring}

Evaluation and monitoring is somewhat more complex; first because community organizations may find it threatening to their autonomy and secondly because they may be fearful of the results. One coordinating agency saw no positive secondary effects, ". . evaluation seen as negative... defensive . . communication impeded" (CA director -. Rural). The Mixed area director frequently used evaluation and monitoring to bring about behavior change through education, ". . . they send a person along who does it badly elsewhere to learn how to do it better." The Urban director was very direct about his purpose. "The overall agenda is to manipurate agencies to be under my control so I'm 'fussing with their innards' whenever I can . . . with many agencies, the only aging service they do is under our centers."

\section{Client Tracking}

Two of the agencies are not involved in formalized client tracking. The third, the Urban area, has a system and the director hopes to use it to find "hidden information". "Under the assumption that we allow clients to go where they want, the agencies can pick and choose., so the agencies may be hiding information,.., when the system is really functioning we 11 be able to tell who goes where and why."

The potential for the client tracking system has not been fully 
realized though each area was moving in the direction of more formalized systems, A point of caution should be noted, in that, as the exchange of clients becomes more formalized, the opportunity to negotiate other exchanges in this arena may diminish. These data support this observation, namely, the one area which has a formal system in operation is the one whose community organizations value client exchanges as the least important in providing secondary exchange opportunities,

Conclusion: Arenas

While all the arenas had been used to some degree, the most successful for secondary exchange negotiations were planning, contracts and letters of agreement. These arenas had been used more often as well as more successfully by coordinating agency directors. Evaluation and monitoring had been used with some success but sometimes offered a threat to the agencies involved. Client tracking had, as yet, been tried in only one area (Urban) but there was good indication that formalization of the process decreased rather than increased opportunity for exchange negotiations. Meetings and hearings had not been used, as reported by directors, to particularly good advantage, However, these responses were in reference to hearings on the state plan, Descriptions of advisory council meetings in another section of the interview indicated more success.

IV. CHANGE TECHNIQUES

A list of potential change techniques was developed to determine 
the attitudes of respondents toward various types of intervention by a third party. The list was constructed in such a way as to include items representing five types of intervention: training, dissemination of information, resolution of conflict, funding, and exercise of authority. Added to that list was an item on centralized client intake because of its relevance for this type of service. Items within types of intervention were written in such a way as to represent levels of intervention so that "acting as ultimate judge when organizations differ" was considered to be a higher level of intervention than "bringing together conflicting parties to clarify issues".

The respondents were asked to rate the extent to which each change technique was "an appropriate or inappropriate means by which government should try to influence the way service organizations work with one another." Their responses are presented in Table XVII.

Two general trends appear in the responses. First, tactics related to information and training tended to be considered appropriate whereas techniques related to funding and conflict resolution were considered somewhat less appropriate. Second, on the scale of intervention, generally, the lower the level of intervention, the more appropriate the tactic was considered. The latter finding should come as no surprise. Community agencies value their autonomy and generally do not wish to have government intervening in their programs. Techniques which are "helpful" without exercising "control" are considered most appropriate, There was one exception, namely "urrestricted grants to build agency capacity": One respondent summed up the feelings of many 
when he said, ". . . so why change?"

An examination of the categories by type of intervention offers more complexity, Examining type and level simultaneously, a continuum of appropriateness is developed as follows, with the most appropriate technique at the top of the list:

- Information

- Training

- Authority

- Conflict Resolution

- Funding

Thus, this finding is of particular interest qiven the primary form of intervention currently pursued by the government, namely funding. Only one level of funding, fee reimbursement for services, was considered appropriate by more than one-half of those responding. Even though funding is scarce in the community, and coordinating agency directors consider funding to be the most useful commodity, service providers do not generally consider it to be an appropriate change technique. Instead they prefer information and training which were ranked as somewhat less scarce by community agencies. There was one type of information, however, that was not generally considered as an appropriate tactic and that was, "providing profiles of individual staff of service agencies". This was particularly true in the Urban area. Toinnes (1887) in his discussion of Gemainschaft-Gesellschaft suggests that one of the elements of a rural society is that functions are dealt with by people rather than roles. This importance of the individual may be 


\section{TABLE XVII}

\section{PERCEIVED APPROPRIATENESS OF TACTICS \\ FOR PROMOTING COMUNITY CHANGE}

Tactic Considered Appropriate $\quad \underline{\%}$

1. Providing facts regarding new legislation and funding 87

2. Providing information about organizations to make it 83 easier for them to work together

3. Short term in-service training to service providers 81 for special techniques

4. Technical assistance to provide service agencies new 81 methods

5. Assessing compliance to contracts 76

6. Bringing together conflicting parties to clarify issues 75

7. Circulating future plans of service organizations and 74

8. Evaluation of program effectiveness 74

9. Fee reimbursement for services delivered 67

10. Establishing uniform standards for service delivery 64

11. Setting rules whereby differences between organizations 61 can be worked out

12. Centralized client intake for multiple service agencies 58

13. Providing profiles of individual staff of service 41 agencies

14. Utilizing competitively awarded service contracts 39

15. Acting as ultimate judge when organizations differ 36

16, Authority to approve/disapprove all aging programs 36

17. Unrestricted grants to build agency capacity 34 
evidenced by this urban/rural difference even though some writers suggest that the rural areas of the United States have become urbanized through the media and ease of movement of the population. (Bogue, 1970). Urban/rural differences were examined for all the techniques. Results are presented in Table XVIII. The most obvious finding in examining the table is that rural agency respondents generally considered most change techniques to be less appropriate. This coincides with the observation that most rural areas tend to be more politically conservative and less likely to approve any kind of government intervention. The Mixed, Urban/Rural comnunity agencies were most likely to fall between the Urban and Rural agencies or with the Urban agencies in their rankings of appropriatness. The few exceptions may be in part specific to the community, for example, training has had special emphasis in one area, client referrals in another.

Planners and staff of coordinating agencies as well as government should study this sort of data carefully. First, in determining general policy guidelines, it should be noted that some types of intervention are certainly considered less appropriate than others. Moreover, a single change technique may be considered less appropriate in one community (Rural, for example) than another (Urban). These differences should be taken into account in the development of alternative approaches.

V. QUTCOMES

One of the primary purposes of this disserataion has been met, 


\section{TABLE XVIII}

\section{DIFFERENCES IN REPORTED APPROPRIATENESS \\ OF CHANGE TECHNIQUES BY AREA}

Change Technique

1. Providing facts regarding legislation and funding

2. Providing information about organizations to make it easier for them to work together

3. Short term in-service training to service providers for special techniques

4. Technical assistance to provide service agencies new methods

5. Assessing compliance to contracts

6. Bringing together conflicting parties to clarify issues

7. Circulating future plans of service organizations and governments

8. Evaluation of program effectiveness

9. Fee reimbursement for services rendered

10. Establishing uniform standards for service del ivery

11. Setting rules whereby differences between organizations can be worked out

12. Centralized client intake for multiple service agencies

13. Providing profiles of individual staff of service agencies

14. Utilizing competityely awarded service 46

15. Acting as ultimate judge when organizations differ
Urban Mixed Rural Sig

$97 \quad 100 \quad 96$

$\begin{array}{lll}95 & 96 & 87\end{array}$

$98 \quad 92$

95

94

90

98

$87 \quad 74$

90

$\begin{array}{ll}83 & 77\end{array}$

74

$87 \quad 76$

79

$75 \quad 64$

64

78

73

60

75

72

32

57

56

48

40

49

43

33 


\section{TABLE XVIII}

(cont.)

\section{Change Technique}

16. Authority to approve/disapprove all aging programs

17. Unrestricted grants to build agency capacity
Urban Mixed Rural Sig

$\begin{array}{lll}44 & 41 & 39\end{array}$

$\begin{array}{lll}40 & 42 & 37\end{array}$

\footnotetext{
$*=p$ less than .1

$* *=p$ less than .01
} 
to examine the Organizational Interaction Model and to determine its usefulness in explaining the interactions of organizations, The data indicate that the listed commodities are exchanged and that certain values are important in determining those exchanges and that certain arenas offer opportunities for those exchanges. The second major question was then addressed, do coordinating agencies manipulate elements of the model? The answer, again, was yes. The coordinating agencies do manipulate or take into consideration in their manipulations the elements of the model. What are the impacts of the efforts of the coordinating agencies in the community?

Respondents were asked to evaluate the impacts of the coordinating agency (Area Agency on Aging) in the community during the three years of its existence. Their responses are presented in Table XIX.

The responses are divided into two categories, impact on service community and other agencies, and impact on the client population. The total list of potential impacts was devel oped from the "ideal type" comprehensive community system described in Chapter III. Twothirds of the respondents perceived the coordinating agency as having a positive impact on the older adults' knowledge of and ability to obtain needed services. The areas of lowest perceiyed impact were related to income and financial condition of the elderly. This finding is not surprising in that the coordinating agency does not make direct cash transfers nor is the budget large enough to permit supplementation of income.

No more than $12 \%$ of the respondents perceived a negative impact of the AAA on any item. The remainder either did not offer an opinion 
TABLE XIX

EVALUATION OF OUTCOMES OF COORDINATING

AGENCY ACTIVITIES

Impact Targets

Service Organizations and the Community

Ability to Arrange for Mut tiple Services

Developing Critical Linkage Services

Shared Feelings of Doing Something

Meaningful for the Elderly

Increased Priority of Elderly Clients

in All Services

Increasing Efficiency of Planning and

Evaluation

Ability to Exchange Information re Clients

Filling Service Gaps

Knowledge and Ability re the Elderly

Understanding of Each Other's Functions

Ease in Relating to State Aging Program

Service Providers' Budgets

Increasing Number of Staff with Special Knowl edge

Organizations' Ability to Affect Local

Political Decisions

Prestige of Service Providers in the Community

\section{Elderly}

Knowledge of the Elderly About Services

Ability of the Elderly to get Needed Services

Feelings of the Elderly of Contribution

to the Community

Prestige and Status of the Elderly in the Community

Ability of the Elderly to Affect Locai Service Decisions

Income and Financial Condition of the Elderly
\%+ Urban Mixed Rural Sig

$\begin{array}{llll}71 & 65 & 82 & 67\end{array}$

$\begin{array}{llll}67 & 65 & 76 & 60\end{array}$

$\begin{array}{llll}66 & 55 & 77 & 67\end{array}$

$\begin{array}{llll}65 & 63 & 73 & 48\end{array}$

$\begin{array}{llll}64 & 49 & 88 & 66\end{array}$

$\begin{array}{llll}62 & 54 & 74 & 44\end{array}$

$\begin{array}{llll}61 & 56 & 68 & 59\end{array}$

$\begin{array}{llll}61 & 45 & 64 & 55\end{array}$

$\begin{array}{llll}55 & 55 & 62 & 48\end{array}$

$\begin{array}{llll}51 & 46 & 57 & 59\end{array}$

$\begin{array}{llll}51 & 43 & 68 & 41\end{array}$

$\begin{array}{llll}45 & 41 & 53 & 41\end{array}$

$\begin{array}{llll}41 & 32 & 58 & 33\end{array}$

$\begin{array}{llll}41 & 37 & 51 & 22\end{array}$

$\begin{array}{llll}77 & 72 & 85 & 74\end{array}$

$\begin{array}{llll}71 & 64 & 81 & 70\end{array}$

$\begin{array}{llll}61 & 53 & 79 & 52\end{array}$

$\begin{array}{llll}53 & 42 & 79 & 37\end{array}$ *

$\begin{array}{llll}47 & 33 & 61 & 48\end{array}$

$\begin{array}{llll}25 & 14 & 41 & 19\end{array}$

+\% of Total Respondents Indicating Positive Impact, Non-Respondents Excluded

$\star p=$ less than .1 
or perceived no change. Those items which showed the highest negative responses were: increasing the efficiency of planning and evaluation, filling gaps in service, developing critical linkages, ease in relating to the State Program on Aging, and budget for both the elderly and service agencies,

The data were then examined to determine whether there were differences among the areas on perceived impact of their activities. The Mixed Urban/Rural area was rated as having a more positive impact on every item except for one, ease in relating to the State Program on Aging. The Urban and Rural areas, though differing on specific items, ranked similarly overall. While it is clear that the Mixed area was seen as having a much more positive impact, the data do not reveal the exact cause of that positive impact. Because onty three areas were studied, it is impossible to know whether the differences were caused by historical factors, factors special to the area, the coordinating agency's work in manipulating exchanges or other activities of the coordinating agency. However, some speculation is possible since the three areas differ in a number of ways.

In general, the Rural area respondents reported less difficulty in obtaining commodities, the major exception being technical assistance. This would lead to less ability to influence other agencies by providing commodities, If it is assumed that organizations are less likely to enter into exchanges for commodities which are easily available. Additionally, the commodity which was second only to funding in being problematic for Rural organizations was obtaining or upgrading 
staff. The Rural CA was less likely than any other area to see itself as having control over this commodity.

The valuing criteria showed no regional differences, There was a slight trend for the Rural organizations to place less importance on power. The coordinating agencies showed some differences in their use of valuing criteria. The CA Dtrector for the Mixed area was somewhat more intuitive in his approach, disclaiming, to some degree, the "conscious use" of the criteria. In his view, these considerations were the ". . . art of coordination." The observation that community organizations rated the impact of the Mixed area coordinating agency higher than the others in almost every category may support the "artform" argument. It is important to note that this area director did "take into consideration" the values held by organizations in the community.

The arenas of exchange were utilized differently in the three areas. A client tracking system was functioning in the Urban area, and formalization of client referrals appeared to have decreased the opportunity for secondary exchanges in that process. The planning process was seen as particularly useful by both the Urban and Mixed areas. Meetings had not been particularly well used in any area though the Mixed area had reported some positive outcomes, Meetings for the specific purpose of training and technical assistance was reported to be successful in the Mixed, Urban/Rural, area, This, in combination with the ongoing gerontological program at the community college, was often mentioned by respondents as helpful and useful. If one characteristic were to set the Mixed area apart from the others it would be the importance 
and resources placed in training, education, and technical assistance.

Coordinating agencies, in the short time they ha:. - been operating in the community, with small resources, have had positive impacts on the coordination of services to the client population. These impacts, while differing from area to area in relative size are generally similar in direction. Further research is needed to determine the factors related to differential impact.

This rating of impacts could prove useful to coordinating agencies in the community which might apply the scale to determine the perception of their work. This could suggest areas in which further efforts are indicated as well as some measure of their overall performance.

\section{CONCLUSION}

Data were collected on three aspects of this research. First, the Organizational Interaction Model was tested by investigating commodities, valuing criteria, and arenas of exchange. Results indicate that organizations in the community as well as the coordinating agency use the elements of this model and that the model has explanatory value. Secondly, respondents were asked to rate the appropriateness of various tactics for bringing about community change. Results show that tactics involving less intervention are viewed more favorably than those involving greater degrees of intervention. Moreover, some types of tactics (information, training) are considered more appropriate than others (authority, funding). Finally, the perceived impact of the coordinating agency was measusured, añúd was found to be generâliy 
positive. There were significant area differences, and some speculations were made regarding which factors are related to those differences. The next chapter will relate these findings to the Organizational Interaction Model and then discuss the implications of these findings for coordinating agencies, planners, and policy makers. 


\section{CHAPTER VI}

\section{CONCLUSIONS AND RELEVANCE TO}

THE COMMUNITY SETTING

\section{APPLICATION OF THE ORGANIZATIONAL INTERACTION MODEL}

This chapter reviews the findings relative to the application of the Organizational Interaction Model. That model is presented here with the elements ordered according to their usefulness and importance as indicated by the data. Each set of elements is discussed in turn, with suggestions of potential relevance for coordinating agencies, social planners, and policy makers.

\section{Commodities}

Coordinating agency directors and planners should be aware of the array of commodities available for exchange. In addition to the usual funding and technical assistance, access to information and influentials are important tools of exchange. The degree to which coordinating agency directors recognize and manipulate these commodities is related to their success, An emphasis on the utilization of funding to encourage social change may shift in light of increasing budgetary limitations. These 1 imitations may lead to the discovery of more effertive change techniques and certainly to tactics considered more appropriate by community agencies. Their view of funding of various sorts as a somewhat inappropriate change technique was not predicted, It was assumed that the prevalence of this approach was supported by 
TABLE XX

\title{
COMUNITY INTERACTION MODEL*
}

COMMODITLES

VALUING CRITERIA

Funding

Integration

Information

Status

Access to Influentials

World View

Clients

Autonomy

Staff

Doma in

Technology

Power

\author{
ARENAS \\ Planning \\ Contracts and Letters \\ of Agreement \\ Hearings and Meetings \\ Evaluation and Monitoring \\ Client Transfers
}

*Elements ordered by importance and usefulness according to results of this study. 
community agencies. This evidence strongly supports seeking of new avenues of influence for coordinating agencies.

The relative underutilization of upgrading of staff was another finding of interest. The coordinating agency could play a valuable role in the community by facilitating addition and upgrading of agency staff. Many agencies in the community hold a positive view of training and would be willing to participate in relevant coordinating agency supported programs.

Information, considered by many (Levine, et al., 1963) to be the key element of interactions, was also underutilized as a community. In many cases, agencies were asking for information, which was available to the coordinating agency but not disseminated. Coordinating agencies should note that there are differences in informational needs among agencies and among areas. The degree to which these informational needs are taken into account will affect the level of impact of the coordinating agency.

Clients are a complex commodity to exchange. Because agencies do not generally report difficulty in obtaining clients, a simple presentation of clients would not be particularly productive. Rather, the coordinating agency should attempt to influence the value placed on various types of clients. In the case at hand, the Area Agency on Aging can assist in outreach (finding clients) and referral, re-educate community agencies as to their responsibility to the elderly, and encourage agencies to revalue the elderiy as clients.

The important consideration with commodities is not the simple issue of scarcity. Whether or not a commodity will be exchanged is 
determined by how that commodity relates to the valuing criteria. For example, small amounts of funding are useful in bringing about behavior change, if there is enhancement of or no threat to the values held by that organization. On the other hand, agencies will refuse large amounts of funding if, for example, their autonomy is threatened. The coordinating agency director, in determining his use of commodities, must keep this broader picture in mind.

To summarize, the coordinating agency has a number of possibi1ities for the use of commodities to bring about changes in the behavior of cormunity organizations. They can:

1. Offer commodities in exchange for new behavior.

2. Cause a community agency to revalue a particular cormodity so that the commodity will be utilized in their exchanges.

3. Offer a commodity to agency $A$ so that agency $A$ can enter into exchange with agency $B$. This can take two forms: one is to provide the agency with a commodity desired by another agency such as money or special technology. The other is to provide information about another agency so that they are aware an exchange is possible.

\section{Valuing Criteria}

The valuing criteria act as the energy source for an exchange, serving as the motivating factors which determine perceived needs. Coordinating agencies must be aware of values both in the broad sense of community norms but also in terms of the emphases placed by individual organizations. There are two aspects of values to consider. The first is the 
expressed importance of the value, and the second is the behavioral indicators of that value. While these two aspects often correlate with each other this is not always the case. Community norms and social desirability play an important part.

Respondents showed differences between expressed and behavioral aspects of two values, integration and power. Each of these values carry with them a high level of social desirability or undesirability. In the case of integration (Mott, 1968) the community places heavy sanctions on organizations which do not appear to support integration of services. On the other hand, placing too much emphasis on control and power is not supported. This observation may, in some degree, support the findings of this study. Ninety-four (94) percent of the respondents stated that integration, the building of linkages, was important to them but fewer showed an active interest in actually building those linkages. On the other hand, only $16 \%$ of the respondents declared power as important, yet reports from community and coordinating agencies indicate a much higher level of power gaining and maintaining by community agencies.

It should be noted that there were only minor differences among communities regarding the valuing criteria, indicating that there is a common set of values at a broader level. This strengthens the potential for use of this model in various settings. While the distribution of commodities may differ from one locale to another, the valuing criteria remain relatively constant, providing social planners and community coordinating efforts an anchor point.

The degree to which coordinating agencies are aware both of 
community norms as well as values held by individual agencies directly relates to their ability to influence behavior. The following approaches are available.

1. Offer exchanges which are consistent with and may even promote the values of individual organizations.

2. Make clear how a particular exchange will promote values of the agency.

3. Attempt to change the values of an organization through information, education or coercion.

\section{Arenas of Exchange}

Coordinating agencies are able to arrange situations in which exchanges are possible. Of course, any situation in which representatives of two organizations make contact offers potential for exchange. The point here is that some situations provide circumstances which are more conducive to negotiation of exchange than others.

This research shows that the arena which offers the best potential for this is planning. The planning process offers a broad range of activities, collection of information, determination of need, discussions of available and missing services and a general bringing together of people interested in a particular area or client group. Community organizations described doing business other than planning, and coordinating agencies reported deliberately manipulating this arena with positive outcomes.

The negotiation of contracts and letters of agreement held similar potential though usually with fewer participants. Coordinating agents 
reported having utilized, with success, this arena for other business.

The remainder of the arenas are more problematic. Hearings had not been used to good adva:tage, usually because of the format which did not allow real interaction. Meetings were more successful, though outcomes were related to the purpose and persons in attendance at the meetings. Evaluation and monitoring carry a heavy potential for threat, and must be handled with care and discretion; though at least one coordinating agent reported positive outcomes.

Client transfers are of special interest. As pointed out earlier, those communities which had less formalized referral systems with little tracking reported them very useful for negotiating other exchanges. The one area, with a formalized client referral and tracking system reported it as being of little value. Thus, it would seem that the more formalized the exchange of clients, the less valuable that arena as an opportunity for other exchanges.

The coordinating agent can provide and manipulate arenas of exchange in the following ways:

1. Provide the situation, i.e., call a meeting, begin the planning process, etc.

2. Encourage participation in the process by selected individuals.

3. Arrange the situation in such a way as to encourage potential exchange, i.e., less formalized, more discussion, control of agenda, etc.

\section{CHANGE TECHNIQUES}

The techniques of change represent varying levels as well as 
different types of intervention. Respondents generally considered as most appropriate, those tactics which involved the least levels of intervention, (i.e., those which were "helpful" vs. those which were controlling). The list of types of techniques, in order from most to least perceived appropriateness is: information, training, authority, conflict resolution, and funding. Coordinating agency directors as well as policy makers and planners should consider these data carefully. Funding has been the traditional route to attempts at community change, yet these data indicate that community organizations consider this inappropriate.

As was suggested by the data on scarcity of information, this commodity is tremendously underutilized in efforts at comminity change. The data on change techniques suggest that efforts to make use of tactics, which involve dissemination of information, would not only be considered appropriate but welcomed.

Urban/Rural differences in perceived appropriateness of change techniques support the observation that rural areas tend to be more conservative and less 1 ikely to consider any change tactic as appropriate. A consideration of these differences is important to policy planners in offering flexibility of approach.

\section{OUTCOMES}

Data on outcomes were collected to determine whether the differences discovered in manipulation of commodities, values, and arenas, in addition to community held attitudes toward change tactics had any impact in the community. The data indicate that the coordinating agency, in its three years in the community, has had considerable impact, 
most of which is viewed as positive. The areas of greatest impact relate to increased knowledge, access and linkages of service. Areas of least impact include budget and the ability to affect local political decision.

Additionally, there were significant and systematic differences among the three areas. The Mixed, Urban/Rural area was rated highest on every item except "ease in relating to the State Program on Aging", by the community organizations in that area. While both the Urban and Rural areas were rated lower than the Mixed, there were no systematic differences between the two of them. Because the three areas differed in so many ways it is not possible to determine the cause of differences in outcome. This is an arena for future research. However, we can say that while coordinating agencies generally had positive impact, there were differences in effectiveness.

IV. SOCIAL EXCHANGE THEORY AND ORGANIZATIONAL INTERACTION

This study developed a model utilizing social exchange theory. This model was shown, by the data, to have explanatory value in the community. While the instrument for data collection was not intended to test the propositions of social exchange theory, the data support those propositions as being valid in the community.

Organizations in the community enter into exchanges to obtain needed goods and services. These transactions cover a broad range from formal contracts and letters of agreement through informal, sometimes transitory, exchanges. Some exchanges are public and open while others are more secretive. 
Organizations tend to seek some profit in their exchanges. No direct questions were asked regarding the perceived costs and benefits of exchanges but comments indicated that organizations sought profit. The example of the coordinating agency which struck a bargain, whereby for $\$ 400$ the county health department agreed to report on all their elderly clients for the entire year. The county health official considered a good bargain had been struck because she, for the first time, had "unencumbered" money to spend at her own discretion. The value determined as the cost or benefit of a commodity is a complex and not well understood issue, and yet, the impression is that organizations are seeking "fair" exchanges, i.e., that they perceive a profit?

Commodities exchanged by organizations include sentiments and actions as well as objects. For social service organizations, much of what they sell are "actions". That sentiments are also exchanged became obvious in the statements of respondents in discussing why they became involved with the coordinating agency or other organizations. Statements such as, "we thought it would improve our status" or "that organization is yery well respected, so we asked them to join" indicate exchanged involving sentiments.

Valuing of commodities by organizations includes both tangible and intangible considerations. The portions of this research related to the valuing criteria make this point particularly clear. At times, the economic considerations of the exchange seem minor compared to the feelings, values, and norms. Data indicate that these norms are similar in the different areas, varying only slightly.

Exchanges mày be direct or indirect. This study focused ma iniy 
on direct, restricted exchanges, but many examples of generalized exchanges appeared in discussions of values, commodities, and arenas. The coordinating agency often arranged exchanges between third parties, for which the only apparent benefit to the CA was an increase in coordination in the community.

Exchanges between and among organizations are both simultaneous and sequential. The directors of coordinating agencies in many instances used exchanges to set the stage for future exchanges. Often grants were made for many future activities, and the "benefits" of the exchange for one party, were not collected for many months. These sequential exchanges were sometimes formal, at other times not. Organizational interactions involve reciprocity. In formalized, direct exchanges reciprocity is usually assumed to be completed in the exchange. However, in less direct, less formal exchanges, lines of reciprocity become increasingly complex. Organizations recognize reciprocity and there are strong norms supporting it. One organization reported refusing to do further business (though it might have been profitabie) with an organization which had refused to reciprocate eariy efforts at information exchange. One CA director, Urban, reported providing services to community organizations so that ". . they would know they owed us something."

Organizational exchange patterns become institutionalized. This was apparent in a number of instances. CA directors utilized this concept in arranging for initial exchanges between community organizations, expecting these relationships to continue after the coordinating agency was no longer involved. This institutionalization of patterns 
sometimes had unwanted side effects, as in the formalization of client exchanges in the urban area.

This led to decreases in the use of this arena for other types of business. The institutionalization of exchanges also can limit the possibility of exchanges occurring between new organizations. This area is one in which further investigation should prove fruitful. Overa11, the data offer strong support for the applicability of social exchange theory to the interactions among organizations. The propositions are each supported by examples in the community. Whether or not this theory could withstand rigorous, systematic testing in the community is an issue of interest. Further research in this area would provide important information to students with interorganizational interests.

\section{CONCLUSION}

It has been shown by this research that coordinating agencies have a wide array of tools at their disposal for bringing about community change. The elements of the Organizational Transactions Model are representative of these tools and render this model useful in describing the behavior of organizations in the community. While there are some differences in the valuing and utilization of these elements, there is enough agreement to allow purposefur planning and implementation.

The change techniques are viewed as appropriate to varying degrees. Careful consideration of these attitudes would indicate some changes in emphasis on the parts of coordinating agencies, social 
planners and policy makers. This is particularly true in the area of funding of social programs about community change.

Finally, the coordinating agency is generally perceived to have had positive impact in the community. Differences among areas were al so shown to exist, suggesting further research to determine the coorelates of those differences. The instrument used to determine perceived impact could prove useful to community planners to evaluate their activities.

This research has shown that organizational transactions can be explained using social exchange theory, that community organizations hold values relative to certūin tactics of community change, and that coordinating agencies have had positive impact in the community. As with most exploratory research, more questions were raised than answered, but the real value may be improvements in the manner of asking the questions. 


\section{A SELECTED BIBLIOGRAPHY}

Abbott, C.J., C.R. Brown and P.V. Crosbie. "Exchange as Symbolic Interaction: For What?" American Sociological Review, 38, 4, August, 1973.

Abrahamsson, B. "Hermanson Exchange: Hedonism Revised," American Journal of Sociology, 76, 2, September, 1970.

Aiken, M. and J. Hage. "Organizational Interdependence and IntraOrganizational Structure," American Sociological Review, 33:912-30, 1968.

- "The Organic Organization and Innovation," Sociology, 5, 1, January, 1971.

Aiken, M. and R. A7ford. "Community Structure and Innovation," American Sociological Review, 35, August, 1970.

Aiken, M., R. Dewar, N. Ditomaso, J. Hage and G. Zeitz. Coordinating Human Services, San Francisco: Jossey/Bass Publishing Co., 1975.

Aldous, J. "A Framework for the Analysis of Family Problem Solving," in Aldous, J. et al. (eds.), Family Problem Solving, Hinsdale, Illinois: The Dryden Press Inc., 1971.

Aldrich, B.C. "Relations Between Organizations: A Critical Review of the Literature," a paper presented at the American Sociological Society Seminar, Washington, D.C., August, 1970.

- "Relations Between Organizations: A Critical Review of the Literature," Journal of International Associations, 1, 1972.

Aldrich, H. "Organizational Boundaries and Interorganizational Conflict," Human Relations, 24, August, 1971.

Aldrich, H. and D. Herker. Boundary Spanning Roles: A Review of the Literature, a working paper, New York State School of Industrial and Labor Relations, January, 1975.

Alonso, W. "Cities and Planners," Daedalus, 92, 4, Fa11, 1963.

Altman, I. and W.W. Haythorn. "International Exchange in Isolation," Sociometry, 28, 4, Spring, 1965. 
Ange11, R.C. "Social Integration," in Sil1s, D.L. (ed.), International Encyclopedia of the Social Sciences, Vol. 7, New York: MacMillan and Co. Free Press, 1968.

Aram, J.D. and W.E. Stratton. "The Development of Interagency Cooperation," Social Services Review, 48, 3, September, 1974.

Argyris, C. Personality and Organization: The Conflict Between the System and the Individual, New York: Harpers, 1957.

- "Personality and Organization Theory Revisited," Administrative Science Quarterly, 18, 2, June, 1973.

- Understanding Organizational Behavior, Homewood, I1linois: Dorsey Press, 1960.

- The Applicability of Organizational Sociology, 1972.

Aristotle. The Nicomachean Ethics, London: William Heinemann, 1926.

Arnott, C.C. "Married Women and the Pursuit of Profit: An Exchange Theory Perspective," Journal of Marriage and the Family, 34, 1, February, 1972 .

Azumi, K. and J. Hage. "Toward a Synthesis: A Systems Perspective," in Azumi, K. and J. Hage (eds.), Organizational Systems, Lexington, Massachusetts, Heath 1972.

Azumi, K. and J. Hage (eds.), Organizational Systems, Massachusetts, Heath 1972.

Baggaley, A.R. Intermediate Correlational Methods, New York: John Wiley and Sons, 1964.

Banfield, E.C. Political Influence, New York: Free Press of Glencoe, 1961.

Barnard, C.I. The Functions of the Executive, Cambridge: Harvard University Press, 1938.

Barnhart, C.L. (ed.). The American College Dictionary, New York: Random House, 1947, 1967.

Barrett, J.H. Individual Goals and Organizational Objectives: A Study of Integration Mechanisms, Ann Arbor: Center for Research on Utilization of Scientific Knowledge, University of Michigan, 1970.

Bass, B.M. and S.D. Deep. Studies in Organizational Psychology, Boston: A11yn and Bacon, 1972. 
Bass, B.M. "Some Observations About a General Theory of Leadership and Interpersonal Behavior," in Petrullo, L. and B.M. Bass (eds.), Leadership and Interpersonal Behavior, New York: Holt, Rinehart and Winston, Inc., 1961.

. "When Planning for 0thers," Journal of Applied Behavioral Sciences, 6, 2, April-June, 1970.

Bates, F.L. "Alternative Models for the Future of Society: From the Invisible to the Visible Hand," Sociological Forces, 53, 1, September 1-11, 1974.

Becker, S.W. and G. Gordon. "An Entrepreneurial Theory of Forma1 Organizations, Part I: Patterns of Formal Organizations," Administrative Science Quarterly, December, 1966.

Beckhard, R. Organizational Development: Strategies and Models, Reading, Massachusetts: Addison-WesTey, 1969.

Bennis, W.G. et al. "Reference Groups and Loyalties in the OutPatient Department," Administrative Science Quarterly, 2, March, 1958.

Bennis, W.G. "Leadership Theory and Administrative Behavior: The Problem of Authority," Administrative Science Quarterly, 4, 1959.

- Changing Organizations: Essays on the Development of and Evolution of Human Organizations, New York: McGraw-Hill, 1966.

- Organization Development: Its Nature, Origins and Prospects, Reading, Massachusetts: Addison-Wesley Publishing Company, 1969.

Bennis, W.G., K.D. Benne and R. Chin. The Planning of Change: Readings in the Applied Behavioral Sciences, 2nd ed., New York: Holt, Rinehart and Winston, 1969.

Benson, J.K. "The Interorganizational Network as a Political Economy," Administrative Science Quarterly, 20, 1975.

Benson, J.K., J.T. Kunce, C.A. Thompson and D.L. Allen. Coordinating Human Services: A Sociological Study of an Interorganizational Network, Columbia, Missouri: Regional Rehabilitation Research Institute, Monograph Series No. 6, 1973.

Berger, J., M. Zelditch, Jr. and B. Anderson. Sociological Theories in Progress, Volume II, Boston: Houghton Mifflin, 1972.

Bernard, J. "Community Disorganization," in Sills, D.L. (ed.), International Encyclopedia of Social Sciences, Vol. 3, New York: MacMillan Free Press, 1968. 
Black, B.J. and H.M. Kase. "Interagency Cooperation in Rehabilitation and Mental Health," Social Service Review, 37, March, 1963.

Blau. P.M. "A Study of Interpersonal Relations in Two Government Agencies," The Dynamics of Bureaucracy, Chicago: University of Chicago Press, 1963.

- The Dynamics of Bureaucracy, Chicago: University of Chicago Press, 1959.

- "A Theory of Social Integration," American Journal of Sociology, 65, 6, Miay, 1960.

- "Orientacion Toward Clients in a Public Welfare Agency," Administrative Science Quarterly, 5, Dec., 1961.

- "The Dynamics of Bureaucracy," in Etzioni, A. (ed.), Complex Organizations: A Sociological Reader, New York: Holt, Rinehart and Winston, 1961.

- "Justice in Social Exchange," Sociological Inquiry, 34, 2, Spring, 1964.

- Exchange and Power in Social Life, New York: John Wiley and Sons, 1964.

- "Theories of Organizations," in Sills, D.L. (ed.), International Encyclopedia of Social Sciences, Volume 11, MacMillan Co. Free Press, 1968.

Blau, P.M. and W.R. Scott. Formal Organizations: A Comparative Approach, San Francisco: Chandler Publishing Co., 1962.

Blumberg, A. and W. Wiener. "One from Two: Facilitating an Organizational Merger," Journal of Applied Behavioral Sciences, 7, 2, January-February, 1977.

Bogue, D.J. "The Hypothes is of Metropolitan Domination," in Cousins, A.M. and H. Hagpaul (eds.), Urban Man and Society: A Reader in Urban Sociology, New York: Alfred Knopf, 1970.

Boguslaw, R. The New Utopians: A Study of System Design and Social Change, Englewood Cliffs, N.J.: Prentice-Hall, 1965.

Bott, E. Family and Social Network, 2nd ed., New York, The Free Press, 1957, 1977.

Boulding, K.E. "Conflict Management as a Learning Process," in deReuch, A. (ed.), Conflict in Society, A CïBA Foundation Volume, London: Churchil1, 1966. 
Bredemeier, H.C. "Banfield, Gereldner, and Sociological Problems," Sociological Problems, 18, 4, Spring, 1971.

Brinkerhoff, M.B. and P. Kunz. Complex Organizations and Their Environments. Dubuque, Iowa: Wm. C. Brown Co., 1972.

Brody, R.Z. "Some Systematic Effects of the Spread of Nuclear Weapons Technology: A Study Through Simulation of MultiNuclear Future," Journal of Conflict Resolution, 7, December, 1963.

Brown, J.D. The Human Nature of Organizations, New York: AMACOM, 1973.

Burgess, R.L. and J.M. Nielson. "An Experimental Analys is of Some Structural Determinants of Equitable and Inequitable Relations," American Sociological Review, 39, 3, June, 1974.

Byrne, J.J. "Systematic Analys is and Exchange Theory: A Synthes is," Pacific Sociological Review, 14, 2, April, 1971.

Camilleri, S.F., J. Berger and T.L. Conner. "A Formal Theory of Decision Making," in Berger, J., M. Zelditch and B. Anderson, Sociological Theories in Progress, Volume 2, Boston: HoughtonMifflin, 1972.

Carison, R.0. "Environmental Constraints and Organizational Consequences: The Public School and Its Clients," in Griffiths, D.E. (ed.), Behavioral Science and Educational Administration Yearboo, Part II, National Society for Study of Education, Chicago: University of Chicago Press, 1964.

Carzo, R., Jr. and J.N. Yahouzas. Formal Organizations: A System Approach, Homewood, Illinois: R.D. Irwin, 1967.

Carzo, R., Jr. "Some Effects of Organizational Structure on Group Effectiveness," Administrative Science Quarterly, 7, 1962.

Catrice-Lorey, A. "Social Security and its Relations with Beneficiaries: The Problem of Bureaucracy in Social Administration," in Katz and Danet (eds.), Bureaucracy and the Public, New York: Basic Books, 1973.

Chein, I., S. Cook and J. Harding. "The Field of Action Research," American Psychologist, 3, 1948.

Cherns, A.B. "Can Behavioral Scientists Help Managers Improve Their Organizations?" Organizational Dynamics, 1, 3, Winter, 1973.

Clark, B. "Interorganizational Patterns in Education," Administrative Science Quarterly, 10, September, 1965. 
- "The Cooling Out Function of Higher Education," American Journal of Sociology, 65, 1956.

Coch, L. and J.R.P. Franch, Jr. "overcoming Resistance to Change," Human Relations, 1, 1948.

Coleman, J.S. "Community Disorganization and Conflict," in Merton, R.K. and R. Nisbet (eds.), Contemporary Social Problems, New York, 1971.

- "Systems of Social Exchange," Journal of Mathematical Sociology, 2, 2, July, 1972.

Collins, 0. "Ethnic Behavior in Industry," American Journal of Sociology, 51, 1946.

Conant, E.H. and M.D. Kilbudge. "An Interdiscipl inary Analysis of Job Enlargement: Technology Costs and Behavioral Implications," Industrial and Labor Relations Review, 18, 1965.

Conner, R. "A Theory of Individual Choice in Non-Zero-Sum Games," a paper read at the annual meeting of the American Sociological Association, Miami, Florida, 1966.

Conner, T.L. "A Stochastic Model for Decision Making in Non-Cooperative Games," Cooperation-Conflict Research Group, East Lansing, Michigan: Michigan State University, 1966.

Corwin, R. "Patterns of Organizational Conflict," Administrative Science Quarterly, 14, 10, 1969.

Coser, L. The Functions of Social Conflict, New York: Free Press, 1956.

Coser, L. and B. Rosenberg. Sociological Theory: A Book of Readings, New York: Hacifili ian and Co., 1954.

Crosbie, P.V. "Social Exchange and Power Compliance: A Test of Merman's Propositions," Sociometry, 35, 1, March, 1972.

Cumming, E. Systems of Social Regulation, New York: Atherton Press, 1968.

Cyert, R.M. and J.G. March. A Behavioral Theory of the Firm, Englewood Cliffs, N.J.: Prentice-Ha1T, 1963.

Davis, S.A. "An Organic Problem-Solving Method of Organizational Change," Journal of Applied Behavioral Science, 3, 1, 1967.

Defleur, M.L., W.V. D'Antonio and L.B. Defleur. Sociology: Human Society, Illinois: Scott, Foresman and Co., 1971, 1976. 
Delbecq, A.L. and Van de Ven. "A Group Process Model for Problem Identification and Program Planning," Journal of Applied Behavioral Science, 7, 4, 1971.

Deutsch, M. The Resolution of Conflict, New Haven: Yale University Press, 1973.

- "Homans in the Skinner Box," Sociological Inquiry, 34, 2, Spring, 1964.

- "Conflict: Productive and Destructive," Journal of Sociological Issues, 25, January, 1969.

Dil1, W.R. "Environment as an Influence on Managerial Autonomy," Administrative Science Quarterly, 2, 1958.

- "The Impact of Environment on Organizational Development," in Mailick, S. and E.H. Van Ness (eds.), Concepts and Issues in Administrative Behavior, Englewood Cliffs, N.J.: PrenticeHall, 1962.

Douds, C.F. and A.H. Rubenstein. "Some Models of Organization Interfaces in the $R$ and D Process," Program Reserach on the Management of $R$ and $D$, Department of Industrial Engineering and Managerial Sciences, The Technological Institute, Northwestern University, Evanston, I11inois, 1966.

Duncan, R. "Characteristics of Organizational Environment and Perceived Environmental Uncertainty," Administrative Science Quarterly, 17, 1972.

Durkheim, D. Suicide: A Study in Sociology, Spaulding, J.A. and G. Simpson (trans.), New York: Free Press, 1951.

- The Division of Labor in Society, Glencoe, Illinois: Free Press, 1960.

Easton, D. "Some Units of Exchange Theory in Politics," Sociological Inqiury, 42, 1972.

Eisenstadt, S.M. "Buearucracy and Bureaucratization: A Trend Repott and Bibliography," Current Sociology, 7, 2, 1958.

- "Buearucracy, Bureaucratization, and Debureaucratization," Administrative Science Quarterly, 4, 1959.

Ekeh, P.P. "Issues in Exchange Theory," Berkeley Journal of Sociology, $13,1968$. 
Elling, R.H. and S. Halebsky. "Organizational Differentiation and Support," American Sociological Quarterly, 6, 1961.

Emerson, R.M. "Power-Dependence Relations," American Scciological Review, 27, 1, February, 1962.

- "Exchange Theory: The Problem of Appropriate Data," paper presented at the American Sociological Association meetings, Denver, Colorado, August, 1971.

- "Power and Position in Exchange Networks," paper presented at the National Meetings of the American Sociological Society, Denver, Colorado, August, 1971.

- "Exchange Theory, Part I: A Psychological Basis for Social Exchange," in Berger, J., M. Zelditch, and B. Anderson, Sociological Theories in Progress, Volume II, Boston: Houghton-Mifflin, 1972.

- "Exchange Theory, Part II: Exchange Relations and Network Structures," in Berger, J., M. Zelditch, and B. Anderson, Sociological Theories in Progress, Volume II, Boston: Houghton-Mifflin, 1972.

Emery, F.E. and E.L. Trist. "The Causal Texture of Organization Environments," Human Relations, 18, February, 1965.

Emmerick, H. Essays on Federal Reorganization, University, Alabama: University of A7abama Press, 1950.

Ephron, L. "Group Conflict in Organizations: A Critical Appraisal of Recent Theories," Berkeley Journal of Sociology, XI, 1, Spring, 1961.

Etzioni, A. A Comparative Analysis of Complex Organizations, New York, The Free Press, 1967.

- (ed.), Complex Organizations: A Sociological Reader, 1961.

- Modern Organizations, Englewood Cliffs, New Jersey, PrenticeHalT, 1964.

- A Sociological Reader on Complex Organizations, 2nd ed., New York: Holt, Rhinehard and Winston, Inc., 1969.

Evan, W. and J. MacDougal1. "Interorganizational Conflict: A Labor-Management Bargain Experiment," Journal of Conflict Resolution, Volume 4, December, 1967. 
- "The Organizational Set: Toward a Theory of Organizational Relations," in James D. Thompson (ed.), Approaches to Organizational Design, Pittsburg: University of Pittsburg Press, 1966.

Evans, J.W. "Stratification, Alienation and the Hospital Setting," Engineering Experiment Station Bulletin, No. 184, Ohio State University, 1960 .

Federal Register, Volume 38, \#196, Part I, Aging, p. 28039-28053, Thursday, October 11, 1973.

Ferguson, C.E. Micro-Economic Theory, Homewood, Illino is: Richard D. Irwin, Inc., 1969.

Fisher, R.J. "Third Party Consultation: A Method for the Study and Resolution of Conflict," Journal of Conflict Resolution, 16: March, 1972.

Francis, R.G. and R.C. Stone. Service and Procedure in Bureaucracy: A Case Study, Minneapol is, University of Minnesota Press, 1956.

Fried, M. "Social Differences in Mental Health," in J. Kosa (ed.), Poverty and Health: A Sociological Analysis, Cambridge, Massachusetts: Harvard Press, 1969.

Friedsam, H. "Theory, Practice and Ideology: The Case of 'Applied Social Gerontolngy'." Unpublished Manuscript, North Texas State University, 1969.

Friedson, E. "Disability as Social Deviance," in Sussman (ed.), Sociology and Rehabilitation, Washington, D.C.: American Sociological Association, 1966.

- "Dominant Professions, Bureaucracy, and Client Services," in Rosengren and Lefton (eds.), Organization and Clients, Columbus, Ohio: Merill, 1970.

Gamson, W. "A theory of Coalition Formation," American Sociological Review, Volume 26, 1961.

Gawthrop, L.C. Bureaucratic Behayior in the Executive Branch: An Analys is of Organizational Change, 1969.

Gibson, G.D. "Bridewealth and Other Terms of Exchange Among the Hevevo," in Paul Bohannan and George Dalton (eds.), Markets of Africa, Evanston, Illinois: Northwestern University Press, 1962.

Ginzberg, E. and E.W. Reilly. Effecting Changes in Large Organizations, New York: Columbia University Press, 1957. 
Glaser, B.G. and A.L. Strauss. The Discovery of Grounded Theory, Chicago: Aldine Publishing Co., 1967.

Gluckman, J. "New Dimensions of Change, Conflict and Settlement," International Social Sciences Journal, 23, 4, 548-63, 1971.

Goffman, E. "The Medical Model and Mental Hospitalization," in Erving Goffman, Asylums, Garden City: Doubleday and Co., 1961, pp. 321-386.

Gold, B. "New Concepts of Service Delivery to the Aged," a paper presented to the Los Angeles, California, meeting of the American Society of Public Administration, April 3, 1973.

Goodnough, W.H. Cooperation in Change, New York: Russell Sage Foundation, 1963.

Goser, L. The Functions of Social Conflict, New York: Free Press, 1956.

Gouldner, A.W. "Theoretical Requirements of the Applied Social Sciences," American Sociological Review, Volume 22, 1, February, 1957, pp. 92-102.

. "The Norm of Reciprocity: A Prel iminary Statement," American Sociological Review, 24, 2, 1960.

Greenly, J. and S.A. Kirk. "Organizational Characteristics of Agencies and the Distribution of Services to Applicants," Journal of Health and Human Behavior, 14, March, 1973.

Grosof, E.H. et al. "Anchorage in Organization: A Dialetical Theory," Social Forces, 49, 81-90, September, 1970.

Guest, R.H. Organizational Change, Homewood, I11 inois: Dorsey, 1969.

Guetzkow, H. "Relations Among Organizations," in Raymond V. Bowers (ed.), Studies on Behavior in Organizations, University of Georgia Press, 1966.

Gyman, H. "Altruism and Egoism in Interpersonal Exchanges," 1972.

Hage, J. "An Axiomatic Theory of Organizations," Administrative Science Quarterly, 10, 3, December, 1965.

- "A Strategy for Creating Interdependent Delivery Systems to Meet Complex Needs," in Hage, J. (ed.), Organizational Theory and Interorganizational Analysis, Ohio: Kent University Press, 1973. 
Hage, J. and M. Aiken. Social Change in Complex Organizations, New York: Random House, 1970.

- "Program Change and Organization Properties: A Comparative Analys is," American Journal of Sociology, 1972.

- "Organizational Conflict and Concensus," Unpublished Manuscript, 1974.

Hage, J. and R. Dewar. "Elite Values Versus Organizational Structure in Predicting Innovations," Administrative Science Quarterly, 18, 3, 279-290, September, 1973 .

Hagstrom, W.C. "The Powers of the Poor," in Reissman, Cohen, and Pearl (eds.), Mental Health of the Poor, New York: The Free Press, pp. 205-223, 1964.

Halbertsma, H. The Concept of Credit in Social Intercourse (Eng.) (Ruel1e, Drombemss loot 28, Amsterdam 1001, The Netherlands) Presented at the World Congress of Sociology, 1970.

Ha11, D. and G. Lindzey. Theories of Personality, New York: John Wiley and Sons, 1967.

Hal1, R. "Interorganizational Structural Variation: Application of Bureaucratic Model," Administrative Science Quarterly, ?, 295-308, December, 1962.

- "Some Organizational Considerations in the Professional Organizational Relationship," Administrative Science Quarterly, $12,1967$.

Hammond, K.R. "New Directions in Research on Conflict Resolution," Journal of Social Issues, 21,2, p. 44, July, 1965.

Harrison, A. Psychology as a Sociai Science, Monterey, Câlifornia: Brooks/Cole Publ ishing Co., 1972.

Haug, M. and M.B. Sussman. "Professional Autonomy and the Revolt of the C1ient," Social Problems, 17, 153-161, 1969.

Hawkes, R. "The Role of Psychiatric Administration," Administrative Science Quarter7y, pp. 89-106, June 6, 1961.

Hawley, A.H. "Human Ecology," in Sills, D.L. (ed.), International Encyclopedia of the Social Sciences, MacMillan and Co., Free Press, 1968.

Heath, A. "Review Article: Exchange Theory," British Journal of Political Science, 1, 1, 91-119, January, 1971. 
- "Economic Theory and Sociology: A Critique of P.M. Blau's

'Exchange and Power in Social Life'," Sociology, 2, 3, pp. 273291, September, 1968.

Hilgert, R.L. "Modern Organizational Theory and Business Management Thought," The American Behavioral Scientist, 8, 18-24, 0ctober, 1964.

Hillery, G.A., Jr. Communal Organizations: A Study of Local Societies, Chicago: University of Chicago Press, 1968.

- "Freedom and Social Organization: A Comparative Analysis," American Sociological Review, 36, 51-65, February, 1971.

Hinings, C.R., D.J. Hickson, J.M. Pennings and R.E. Schneck. "Structura1 Conditions of Intraorganizational Power," Administrative Science Quarterly, 19: 22-44, 1974.

Holland, T.P. "Community: Organism or Arena," Social Work, 19: 73-80, January, 1974.

Hollister, C.D. "School as a Bureaucratic Organization," in Litwak and Meyer, Relationship Between School and Community Coordinating Procedures and Reading Achievement, Final Report for U.S. Office of Education, December, 1966.

Homans, G.C. The Human Group, New York: Harcourt-Brace, 1950.

- Social Behavior: Its Elementary Forms, New York: HarcourtBrace, 1961.

Indik, B.P. and F.K. Berrien. People, Groups and Organizations, New York: Teachers College Press, 1968.

Inkeles, A. and D.J. Levinson. "The Personal System and the SocioCultural System in Large Scaie Organizations," Sociometry, 26, p. $217,1963$.

Jacobs, D. "Dependency and Variability: An Exchange Approach to the Control of Organizations," Administrative Science Quarterly, 19, 45-59, March, 1974.

Janowitz, M. and W. Delaney. "The Bureaucrat and the Public: A Study of Informational Perspectives," Administrative Science Quarterly, pp. 141-162, September, 1967.

Jessop, R.D. "Exchange and Power in Structural Analyses," Sociological Review, Cambridge University, England, 17, 3, 415-437, November, 1970. 
Johns, R. and D. Demarche. Community Organization and Agency Responsibility, New York: Association Press, 1951.

Júnes, G.N. Planned Organizational Change: A Study in Change Dynamics, 1969.

Kahn, F.J. "Public Social Services: The Next Phase--Policy and Delivery Strategies," Public Welfare, Winter, 1972.

Kaplan, M., Gans, and Kahn. Integration of Human Services in HEW: An Evaluation of Services Integration Projections, 1973.

Katz, D. "Current and Needed Psychological Research in International Relations," Journal of Social Issues, Volume 17, 1961.

- "Nationalism and Strategies of International Conflict Resolution," International Behavior, H. Kelman (ed.), New York: Holt, Rinehart and Winston, pp. 326-389, 1965.

Katz, E. (ed.). Bureaucracy and the Public: A Reader in UfficialClient Relations, 1973.

Kaufman, H. "Toward an Interactional Conception of Community," Social Forces, 38, 1, October, 1959.

- Why Organizations Behave as They Do: An Outline of a Theory, Interdisciplinary Seminar on Administrative Theory, Austin, Texas: University of Texas, March, 1961.

- The Limits of Organizational Change, 1971.

Ke1man, H. "Societal, Attitudinal and Structural Factors in International Relations," Journal of Social Issues, 11, 1955.

Kendler, J.J. Basic Psychology, New York: Appleton-Century-Crofts, 1968.

Klonglan, G., D.A. Dillman, J.S. Wright, and G.M. Beal. Agency Interaction Patterns and Community Alcohol ism Services, Sociology Report, 73, Ames, Iowa Department of Sociology and Anthropology, Iowa State University, 1969.

Knox, J.B. "The Concept of Exchange in Sociological Theory: 1884 and 1961," Sociologica1 Forces, 41, 4, 341-345, May, 1963.

Krohn, R.G. "Conflict and Function: Some Basic Issues in Bureaucratic Theory," British Journal of Sociology, 22, p. 115-132, June, 1971.

La Rochefoucauld, F. The Maxims, London: Oxford University Press, 1940. 
Landecker, W.S. "Types of Integration and Their Measurement," American Journal of Sociology, 56, 4, January, 1951.

Larivee, J.P. "Title III in Action: Appraising Public Policy," Unpubl ished Manuscript, University of Southern California, 1973.

Lauffer, A. Area Planning for the Aging, Unpublished Manuscript, School of Social Work, University of Michigan, 1974.

Lawrence, P.L. The Changing of Organizational Behavior Patterns, Boston: Harvard University Graduate School of Business Administration, 1958.

Leavitt, H.J. "Applied Organizational Change in Industry: Structural, Technological and Humanistic Approaches," in Handbook of Organizations, James G. March (ed.), Chicago: Rand McNa17y, 1965.

- "The Yesterday, Today and Tomorrow of Organizations," European Business, 28-33, Spring, 1971.

Lefton, J. "Client Characteristics and Structural Outcomes: Toward the Specification of Linkages," in Rosengren and Lefton (eds.), Organizations and Clients, Ohio: Merrill, 1970.

Lefton, M. and W.R. Rosengren. "Organizations and Clients: Lateral and Longitudinal Dimensions," American Sociological Review, 31, 802816, December, 1966.

- Hospitals and Patients: A Theory of Clients and Organizations, New York: Atherton Press, 1969.

Lehman, E.W. Coordinating Health Care: Exploration in Interorganizational Relations, Beverly Hills: Sage Publications, 1975.

Levine, S. and P. White. "Exchange as a Conceptual Framework for the Study of Interorganizational Relationships," Administrative Science Quarterly, 5, 583-601, March, 1961.

Levine, S. and P.E. White. "The Community of Health Organizations," in Freeman, H.E., Levine, S. and Reeder, L.G. (eds.), Handbook of Medical Sociology, Englewood Cliffs, N.J.: PrenticeHa17, 1972.

Levine, S., P.E. White and B. Paul. "Comunity Interorganizational Problems in Interorganizational Care and Social Services," American Journal of Public Health, 53: 1183-1195, 1963.

Levi-Strauss, C. Les Structures Elementaires de la Parente, Presses Universitaires de France, 1949. 
- "The Principle of Reciprocity," in Coser, L. and B. Rosenberg (eds.), Sociological Theory: A Book of Readings, New York: MacMillan Co., 1964.

Light, D., Jr. and S. Keller. Sociology, New York: Alfred 0. Knopf, 1975.

Likert, R. The Human Organization, New York: McGraw-Hi11, 1907.

Lind, S.D. and J. O'Brien. "The General Problem of Program Evaluation: The Researcher's Perspective," Gerontologist, 11, 4, Part 2, Winter, 1971.

Lippett, R., J. Watson and B. Westley. The Dynamics of Planned Change, New York: Harcourt, Brace, 1958.

Litwak, E. and L.F. Hylton. "Interorganizational Analysis: A Hypothesis on Coordinating Agencies," Administrative Science Quarterly, 6, 394-426, March, 1962.

Litwak, E. and Meyer. Relationship Between School and Community Coordination Procedures and Reading Achievement, Final Report for U.S. Office of Education, December, 1966.

Litwak, E. "Models of Bureaucracy Which Permit Conflict," American Journal of Sociology, 67, 177-184, 1961.

Litwak, E. and J. Rothman. "Towards the Theory and Practice of Coordination Between Formal Organizations, in W. Rosengren, and M. Lefton (eds.), Organizations and Clients, Columbus, Onio: Charles E. Merrill Publishing Company, 1970.

Littre11, W.B. "Complex Organizations: Models and Reality," Rocky Mountain Social Science Journa1, 6, 2, 155-162, October, 1969.

Lloyd, K. and L. Lioyd. "Reciprocity, Equivalence, Normative Behavior and the Existence of Social Prices," Journal of Mathematical Sociology, 2, 2, 249-265, July, 1972.

Long, N.E. "The Local Community as an Ecology of Games," American Journal of Sociology, 64, 3, November, 1958.

Lorsch, J.W. and S.A. Allen. Managing Diversity and Interdependence: An Organizational Study of Multidivisional Firms, Boston, Massachusetts: Harvard University Press, 1973.

Lorsch, J.W. and P.R. Lawrence. Studies in Organization Design, Homewood, Illinois: P.D. Irwin, 1970. 
Lowin, A., W.J. Huapchak and M.J. Kavanagh. "Experimental Investigation of Consideration and Initiating Structure," Administrative Science Quarterly, 14, 2, 238-253, June, 1969.

Maiolo, J.R. "Organization for Social Action: Some Consequences of Competition for Control, Sociological Quarterly, 11, 463-473, Fal1, 1970.

Mal inowski, B. Argonauts of the Western Pacific, London: Routledge, 1922.

Maniha, J. and C. Perrow. "The Reluctant Organization and the Aggressive Environment," Administrative Science Quarterly, 10, 246-257, September, 1965.

Mann, F.C. and F.W. Neff. Managing Major Change in Organizations, Ann Arbor, Michigan: Foundation for Research on Human Behavior, 1961.

Mann, F. and L. Williams. "Observations on the Dynamics of a Change to Electronic Data Processing Equipment," Administrative Science Quarterly, September 5, 1960.

March J. and H. Simon. Organizations, New York: Wiley, 1958.

March J.G. (ed.). Handbook of Organizations, 1965.

Marrett, C.B. "On the Specifications of Interorganizational Dimensions," Sociology and Social Research, 56, 83-99, October, 1971.

Marsha11, A. Principles of Economics, New York: MacMillan Co., 19--.

Martin, R. "The Concept of Power: A Critical Defense," British Journal of Sociology, 22, 3, 240-257, September, 1971.

Marx, G.T. and M. Useem. "Majority Involvement in Minority Movements: Civil Rights, Abolition, Untouchability," Journal of Social Issues, 27, 1, 81-104, 1971 .

Mauss, M. The Gift, Glencoe, I11inois: Free Press, 1954,

- "Pretaciones Totales y Potlatch," "Total Exchanges and Potlach," Review of Mexican Sociology, 21, 3, pp. 1119-1125, SeptemberDecember, 1959.

- "Reciprocity," in T. Parsons et al. (eds.), Theories of Society, Glencoe, Illinois: Glencoe Free Press, 1961 .

Mayer, J.E. and A. Rosenblatt. "The Clients Social Context: Its Effect on Continuance in Treatiment," Social Casework, XLV, 9, 511-518, 1964. 
McCarthy, J. and M. Zald. "The Trend of Social Movements in America: Professionalization and Resource Mobilization," General Learning Press, 1973.

McDonough, J.F. Unpublished project memorandum, Fa11, 1968. See Social and Rehabilitative Services, Department of Health, Education and Welfare Project Number 425.

McMahone, J.T. and G.W. Perritt. "Toward a Contingency Theory of Organizational Control," Academy of Management Journal, 16, 4, 624-635, December, 1973.

McNeil, K. and J.D. Thompson. "Regeneration of Social Organizations," American Sociological Review, 36, 624-637, August, 1971.

McNulty, J.E. "Organizational Change in Growing Enterprises," Administrative Science Quarterly, 7, 1-21, 1962.

Mead, M. (ed.). Cooperation and Competition Among Primitive Peoples, New York: McGraw Hi11, 1937.

Mechanic, D. "Organizational Power of Lower Participants," Administrative Science Quarterly, 7, 349-364, December, 1969.

Meier, R.L. "Communications Overload: Proposals from the Study of University Library," Administrative Science Quarterly, 7, 521-544, March, 1963.

Meeker, B.F. "Decisions and Exchange," American Sociological Review, $36,3,485-495$, June, 1971.

Messinger, S. "Organizational Transformation," American Sociological Review, 20, 3-10, 1955.

Mindl in, S.E. and H. Aldrich. "Interorganizational Dependence: A Review of the Concept and a Reexamination of the Findings of the Aston Group," Administrative Science Quarterly, 20, September, 1975.

Miner, H.M. "Community-Society Continua," in Sills, D.L. (ed.), International Encyclopedia of Social Sciences, MacMillan Free Press, 1968.

Miner, J.B., J.R. Rizzo, D.M. Harlow and J.W. Hill. "Role Motivation Theory of Managerial Effectiveness in Simulated Organizations of Varying Degrees of Structure," Journal of Applied Psychology, $59,1,31-37$, February, 1974.

Mitchel1, T.R. "Leader Complexity and Leadership Style," University of Washington, Department of Psychology Technical Report, 70-3, March, 1970. 
Mohr, L.B. "Determinants of Innovation in Organizations," American Political Science Review, 63, 111-126, March, 1969.

Morris, R. and R.H. Binstock. Feasible Planning for Social Change, New York: Columbia University Press, 1966.

Mott, B. Anatomy of a Coordinating Council, Pittsburgh: University of Pittsburgh Press, 1968.

Mulkay, M. "Some Suggestions for Sociological Research," Scientific Studies, 1, 2, 201-203, Apri1, 1971.

Negandhi, A.R. Modern Organizational Theory: Contextual, Environmental and Socio-Cultural Variables, Kent, Ohio: Kent State University Press, 1973.

Nisbet, R.W. "Cooperation" in Sills, D.L. (ed.), International Encyclopedia of Social Sciences, MacMillan and Co. Free Press, 3,1968 .

Nie, N., C. Hull, J. Jenkins, K. Steinbrenner and D. Bent. Statistical Package for the Social Sciences, 2nd ed., New York: McGraw-Hi17, 1975.

Nix, H.L. "Concepts of Community and Community Leadership," Sociology and Social Research, 53, 4, 500-510, July, 1969.

Nord, W. "Adam Smith and Contemporary Social Exchange Theory," The American Journal of Economics and Sociology, 32, 4, 427-436, October, 1973.

Norman, R. "Organizational Innovativeness: Product Variation and Reorientation," Administrative Science Quarterly, 16, 203-215, 1971 .

O'Brien, J., B. Lebowitz, N. Mancini, R. Cherry. "Evaluation Comprehensive Community Care Systems: Organizations and Individuals," A paper presented at the Annual Meetings of the Gerontological Society's Committee on Research and Development, Miami, Florida, November, 1973.

0'Brien, J. "Issues in Evaluation Research: An Overview of Non-Technical Problems," An unpublished manuscript, Portland State University, 1974.

"The Problem of Exchange Theory for Interorganizational Analysis: A Critical Review," a paper prepared for presentation at the 1976 Meetings of the American Psychological Association, New York City. 
$0^{\prime}$ Brien, J. and T. Wetle. Analysis of Conflict in Coordination, a Technical Report to the Administration on Aging, HEW, prepared by the Institute on Aging, Portland State University, 1976.

O'Brien, J., T. Wetle and D. Montgomery, N. Whitelaw, M. Petersen and $M$. Burki. Closing the Gaps: Strategies for Technical Ass istance, a Technical Report to the Administration on Aging, HEW, prepared by the Institute on Aging, Portland State University, 1976.

01ds, J. "Self Stimulation of the Brain," Science, 127, 1958.

Otten, C.M. University, Authority and the Student, University of California Press, 1970.

Parsons, T. The Structure of Social Action: A Study in Social Theory with Special Reference to a Group of Recent European Writers, New York: McGraw-Hi17, 1937.

- "General Theory in Sociology," in R.K. Merton, L.S. Cottrell and L. Broom (eds.), Sociology Today, New York: Basic Books, 1959.

- Structure and Process in Modern Society, 1960.

- "Levels of Organization and the Mediation of Social Inter-Action," Sociological Inquiry, 34, 3, 207-220, Spring, 1964.

. "How are Clients Integrated into Service Organizations?" in Rosengren and Lefton (eds.), Organizations and Clients, Ohio: Merri11, 1970.

Partin, J. "Emerging Perspectives About Organization Planning and Development," Training and Development Journal, 27, 1, 8-17, January, 1973.

Patchen, M. "Decision Theory in the Study of National Action: Problems and a Proposal," Journal of Conflict Resolution, 9, 1965.

- "Models of Cooperation and Conflict: A Critical Review," Journal of Conflict Resolution, 14, 3, 389-407, 1970.

Paulson, S.K. "Causal Analysis of Interorganizational Relations: An Axiomatic Theory Revised," Administrative Science Quarterly, 19, 3, 319-337, September, 1974.

Perrow, C. "Goals and Power Structures: A Historical Case Study," The Hospital in Modern Society, El iot Friedson (ed.), Glencoe, Illinois: The Free Press, 1963. 
- "The Analysis of Goals in Complex Organizations," American Sociological Review, 26, 854-866, 1961.

- Organizational Analysis: A Sociological View, Belmont, California: Wadsworth Publishing Company, 1970.

Pine, R. and D.J. Levinson. "A Socio-Psychological Conception of Patienthood," The International Journal of Social Psychiatry,

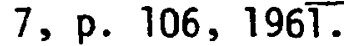

Poitra, G.E. "Welfare Bureaucracy and Clientele Politics in Mexico," Administrative Science Quarterly, 18, p. 18.

Potterf, G.W. Inter-Bureau Power Relations, A Sociological Analysis of an Ideal Type Organization Model, Portland State University, UnpubT ished Manuscript, 1972.

Pondy, L.R. "Organizational Conflict: Concepts and Models," Administrative Science Quarterly, 12, September, 1967.

Prewitt, K. "From the Many Are Chosen the Few," American Behavioral Scientist, 13, 2, 169-188, November, 1969.

Reid, W. "Interagency Coordination in Delinquency Prevention and Control," Social Service Review, 38, December, 1964.

Rhenman, E., L. Stromberg and G. Westerlund. Conflict and Cooperation in Business and Organizations, New York: Wiley and Sons, 1970.

Rice, L. and T. Wetle. "New Federalism: A Business Management Change of the Highest Magnitude," a paper presented to the Portland, Oregon, meeting of the Gerontological Society, 1974.

Ridgeway, V.F. "Administration of Manufacturer-Dealer Systems," Administrative Science Quarter1y, 2, 1957.

Riggs, E.W. and E.W. Weidner. Models and Priorities in the Comparative Study of Pub7ic Administration, Chicago: Comparative Administrattion Group of the American Society for Public Administration, 1963.

Rogers, R.E. and M. McCreery-Spencer. "The Dilemma of Change and Future Organizations: An Exploratory Review, "Sociological Focus, 6, 2, 42-60, Spring, 1963.

Rogers, R.E. et a1. "Benefits and Role Performance in Voluntary Organizations: An Exploration of Social Exchange," Sociological Quarterly, 13, 1830196, Spring, 1972.

Rondew, H.O. and P.R. Lawrence. Administrative Change, Boston: Harvard University Graduate School of Business Administration, 1956. 
Rosenfeld, J. "Strangeness Between Helper and Client: A Possible Explanation of Non-Use of Available Professional Help," Social Service Review, 38, 1, 17-25, March, 1964.

Rosengren, W.R. "Structure, Policy and Style: Strategies of Organizational Control," Administrative Science Quarterly, 12, 140-154, June, 1967.

- "Organizational Age, Structure, and Orientation Toward Clients," Social Forces, 47, 1-11, September, 1968.

- "The Careers of Clients and Organizations," in Rosengren and Lefton, Organizations and Cíenis, Ohio: Merrill Publishing, p. 117, 1970.

- Organizations and Clients: Essays in the Sociology of Service, Columbus, Ohio: C.E. Merri17 Publishing, 1970.

Roth, J.A. "The Treatment of Tuberculosis as a Bargaining Process," in A.M. Rose (ed.), Human Behavior and Social Processes, 19--.

Rothchild, D. "Ethnicity and Conflict Resolution," World Politics, 22, 597-616, Ju1y, 1970.

Rowe, L.A. (ed.). Organizational and Managerial Innovation: A Reader, 1973.

Rubin, I. "Function and Structure of Community: Conceptual and Theoretical Analysis," International Review of Community Development, 21-22, $196 \overline{9}$

Rumme1, R.J. "Dimensions of Conflict Behavior within Nations, 19461959," Journal of Conflict Resolution, 10, 1066.

Salisbury, R.H. "An Exchange Theory of Interest Groups," Midwest Journal of Political Science, 13, 1, 1-32, February, 1969.

Samuelson, P.A. Economics, New York: McGraw Hill Book Co., 7th ed., 1967.

Sargent, S.S. and R.C. Williamson. Social Psychology, New York: Ronald Press Co., 1966.

Scherer, J. Contemporary Community: Sociological Illusion or Reality, London: Tavistock Publications, Distributed by Harper and Row, New York, 1972.

Schmidt, W.H. Organizational Frontier and Human Values, Belmont, Cal ifornia: Wadsworth Publishing Co., 1970. 
Schneider, B. and C.P. Alderver. "Three Studies of Need Satisfaction in Organizations," Administrative Science Quarterly, 18, p. 489.

Schulman, I.R. "The Dynamics in the Designation of an Area Agency on Aging," University of Southern California, 1974.

Schultz, D. Psychology and Industry Today, New York: MacMillan, 1973.

Scott, W.G. "Organizational Theory: An Overview and an Appraisal," Journal of the Academy of Management, 4, 7-26, Apri1, 1961.

Selznick, P. T.V.A. and the Grass Roots: A Study in the Sociology of Formal Organizations, Berkeley: University of California Press, 1949.

Sills, D.L. The Volunteers: Means and Ends in a National Organization (reviews, letters, on goal succession and goal displacement), Glencoe, Illinois: Free Press, 1957.

Simon, H.A. Administrative Behavior, New York: MacMillan, 1945.

Simpson, R.L. and W.H. Gul7y. "Goals, Environmental Pressures, and Organizational Characteristics," American Sociological Review, 27, 3, pp. 344-351, June, 1962.

Singlemann, P. "Exchange as Symbolic Interaction Convergence between Two Theoretical Perspectives," American Sociological Review, 37, 4, pp. 414-424, August, 1972.

Sjoberg, G. "Contradictory Functional Reg̣uịrements and Social Systems," Journal of Conflict Resolution, 4, pp. 198-208, 1960.

Sleder, V.M. The Rehabilitation Agency, Waltham, Mass.: Brandeis University, 1966.

Smith, A. The Theory of Moral Sentiments, 2nd ed., London: A. Millar, 1761 .

Smith, C. "A Comparative Analys is of Some Conditions and Consequences of Intra-Organizational Conf1ict," Administrative Science Quarterly, 10, March, 1966.

Smith, C. and A.N. Ari. "Organizational Control Structure and Member Concensus," American Journal of Sociology, 69, pp. 623-638, 1966.

Smith, G. Social Work and the Sociology of Organizations, London: Routledge and K. PauT, 1970. 
Sofer, C. "The Assessment of Organizational Change," The Journal of Management Studies, 1, pp. 26-47.

- Organizations in Theory and Practice, New York: Basic Books, 1972.

Solomon, W. "On a Social Exchange Classification of Dyadic Relationships," A paper presented at the 1970 meetings of the American Sociological Association.

Spencer, P. and C. Sofer. "Organizational Change and its Management," The Journal of Management Studies, 1, pp. 26-47, March, 1964.

Straus, C. The Elementary Structures of Kinship, Boston: Benson Press, 1969.

Sugarman, B.N. "Some Inherent Sources of Change in Formal Organizations," Social and Economic Administration, 1, pp. 45-54, Apri1, 1967.

Taietz, P. "Community Complexity and Knowledge of Facilities," Journal of Gerontology, 30, 3, pp. 357-362, 1975.

- Community Structure and Aging, Final Report to AOA, DHEW, Washington, D.C. by Department of Rural Sociology, I thaca, New York: Corne11 University, 1970.

Tannenbaum, R. and S.A. Davis. "Values, Man and Organizations," Industrial Management Review, 10, 2, Winter, 1969.

Tawney, R.H. Equality, London: Allen and Unwin, 1931.

Terrien, F.W. and D.L. Mills. "The Effect of Changing Size Upon the Internal Structure of Organizations," American Sociological Review, 23, pp. 23-31, 1958.

Terryberry, S. "The Evolution of Organizational Environments," Administrative Science Quarterly, 12, p. 590, March, 1968.

Thibaut, J. and H.H. Kelly. The Social Psychology of Groups, New York: Wiley, 1959.

Thomas, E.J. "Effects of Facilitative Role Interdependence on Groups Function," Human Relations, 19, 1957.

Thompson, J.D. and W.J. McEwen. "Organizational Goals and Environment: Goal-Setting as an Interaction Process," American Sociological Review, 23, pp. 23-31, February, 1958. 
Thompson, J.D. Organizations in Action, New York: McGraw Hill, 1967.

Thompson, V. Modern Organizations, Alfred A. Knopf, 1961.

Tilly, C. "Clio and Minerva," in John C. McKinney and Edward A. Tiryakian (eds.), New York: Appleton-Century-Crofts, Educational Division, 1970.

Tonnies, F. "Gemeinschaft and Gesellschaft," Community and Society, Loomis, C.P. (ed.), Michigan State University Press, 1887, 1955.

Tsouderas, J.E. "Organizational Change in Terms of a Series of Selected Variables," American Sociological Review, 20, pp. 206-210, 1955.

Tuite, M., R. Chisholm and M. Radnor. Interorganizational Decision Making, Chicago: Aldine Publishing Co., 1972.

Turk, H. "The Policy Outputs and Conflicts of Large Communities from an Interorganizational Viewpoint," Sociological Focus, 8, 2, pp. 111-123, Apri1, 1975.

- "Interorganizational Networks in Urban Society: Initial Perspectives and Comparative Research," American Sociological Review, 35, 1, February, 1970.

- Personal Communication, 1976.

Tur ier, J.H. The Structure of Sociological Theory, Illinois: Dorsey Press, 1974.

Udy, S. "Administrative Rationality, Social Setting and Organizational Development," American Journal of Sociology, 68, p. 299, 1962.

Van de Ven, A.H. and A.L. Delbecq. "The Normal Group as a Research Instrument for Exploratory Heal th Studies, "American Journal of Publ ic Health, March, 1972.

- "Group Process Model for Problem Identification and Program Planning," Journal of Applied Behavior Science, 74.

- "Nominal Group as a Research Instrument for Exploratory Health Studies," American Journal of Public Health, March, 1972.

Wahrman, R. "Status, Deviance, and Sanctions," Pacific Sociological Review, 13, 4, pp. 229-240, Fal1, 1970. 
Waldman, S.R. "Exchange Theory and Political Analysis," Social Inquiry, 42, 3-4, pp. 101-128, 1972.

Waldo, W. "Organizational Theory: An Elephantine Problem," Public Administration Review, 21, pp. 210-225, Autumn, 1961.

- The Study of Organizational Behavior: Status, Problems, and Trends, Washington, D.C.: Comparative Administration Group of the American Society for Public Administration, 1966.

Warren, R. "The Interorganizational Field as a Focus for Investigation," Administrative Science Quarterly, 12, pp. 396-419, December, 1967.

- The Community in America, Chicago: Rand McNally and Co., 1972.

- "The Concerting of Decisions as a Variable in Organization Interaction," in Roland Warren, Truth, Love and Social Change, Chicago: Rand McNal1y, 1971.

- "Alternative Community Paradigms," A paper presented at Eastern Sociological Society seminar on community theory and research, April 6, 1974.

- Personal Communication, 1975.

Warren, R., S.M. Rose and A.F. Bergunder. The Structure of Urban Reform, 1974.

Warriner, C. "Public Opinion and Collective Action: Formation of a Watershed District," Administrative Science Quarterly, 6, pp. 167-184, December, 1961.

Weber, M. The Theory of Social and Economic Organizations, New York: Oxford University Press, 1947.

Weissman, H.H. Community Councils and Community Control: The Workings of Democratic Mythology, Pittsburgh: University of Pittsburgh Press, 1970.

Wellman, B. and P. Craven. "Informal Interpersonal Relations and Social Networks," Sociological Inquiry, 143, 1973.

Wesson, A.F. "The Apparatus of Rehabilitation: An Organizational Analysis," in Marvin B. Sussman (ed.), Society and Rehabilitation, Washington, D.C.: American Sociological Association, pp. 148-178, 1966.

Whetten, D. "A General Contingency Model for a Design of InterOrganizational Service Delivery Systems:" Unpublished Manuscript, 1974. 
Wildarsky, A. "The Self-Evaluating Organization," Public Administration Review, XXXII, 5, 1972.

- "The Political Economy of Efficiency: Cost-Benefit Analysis, Systems Analysis, and Program Budgeting," Public Administration Review, December, 1966.

Wilkenfeld, J. (ed.). Conflict Behavior and Linkage Politics, New York: David McKay Co., 1973.

Wilson, R.C. et al. "Social-Psychological Accessibility and FacultyStudent Interaction Beyond the Classroom," Social Education, 47, pp. 74-92, Winter, 1974.

Wilson, T.P. "Conceptions of Interaction and Forms of Sociological Explanation," American Sociological Review, 35, pp. 697-710, 1970.

Wolfe, D.M. and J.D. Snock. "A Study of Tensions and Adjustment under Role Conflict," Journal of Social Issues, 18, 3, pp. 102121, July, 1962.

Worthy, J.C. "Organizational Structure and Employee Morale," American Sociological Review, 15, pp. 160-179, 1950.

Wright, Q. "The Escalation of International Conflicts," Journal of Conflict Resolution, 9, 1965.

Young, K. Sociology: A Study of Sociology and Culture, 2nd ed., New York: American Book Co., 1949.

Young, 0. "Intermediaries: Additional Thoughts on Third Parties," Journal of Conflict Resolution, 17, March, 1973.

Yuchtman, E. and S.E. Seashore. "A System Resource Approach to Organizationai Effectiveness," American Sociological Revien, $32,891-903 ; 1967$.

Zald, M. and P. Denton. "From Evangelism to General Service: The Transformation of the YMCA," Administrative Science Quarterly, 8, pp. 214-234, September, 1963.

Zaltman, G., R. Duncan and J. Hollbek. Innovations and Organizations, New York: John Wiley and Sons, 1973. 


\section{APPENDIX I}


APPENDIX I

TECHNICAL PANEL

\author{
Roger 01 son \\ Jerry Jamison \\ Tom DeJardin \\ Larry Forsythe \\ Ed Sage \\ Leen Pollinger \\ Nohad Toulan \\ Len Tritsch \\ Ruth Shephard \\ Jewell Goddard \\ Jody Miller \\ Betty Johnson \\ James Bennett \\ John Estelle
}

Mary Henrick
County Social Services

Community Council

Council of Governments

Community College and

Board of Nursing Home

Examiners

State Program on Aging

State Program on Aging

Graduate Urban Studies

Program

State Board of Education

Special Aging Assistant

State Human Resources Dept.

Director, County Human Services

Area Agency on Aging

Area Agency on Aging

School of Dentistry

Manager of Manpower Development

State Human Resources

County Health Department 
APPENDIX II 
The purpose of this study is to gather information regarding the work of agencies which provide or could provide services to older adults in your community. Your responses will be reported in the aggregate so as not to be identifiable to any one agency or individual. We very much appreciate your willingness to cooperate with us by filling out this questionnaire. It is very important that your responses be included in our study. We will send you a report of information gathered for your comments and use.

PLEASE COHPLETE AND MAIL THIS SURVEY NO LATER THAN FRIDAY, FEBRUARY 13 th. 
NAME OF AGENCY AGE OF AGENCY

PURPOSE OF AGENCY

RESPONDENT'S NAME RESPONDEKT'S AGE

HOW LONG HAVE YOU PERSONAL:.. BEEN INYOLVED IN PROVIDING SERVICES TO THE ELOERLY?

Characteristics of Your Organization

HDW MANY PEOPLE ARE EMFLOYED BY YOUR ORGANIZATION?

HOW MANY VOLUNTEER HOURS ARE CONTRIBUTED TO YOUR ORGANIZATION EACH WEEK?

WHAT IS YOUR TOTAL ANNUAL AGEHCY BUDGET FOR: 1 1) PERSONMEL

2) ALL OTHER COSTS

HOW MANY JOB POSITIONS ARE THERE BETHEEN THE CHIEF ADMINISTRATOR AND THE EMPLOYEES WORKIMG ON PROVIDING SERVICES TO THE ELDERLY?

LIST THE SERVICES YOUR AGENCY OFFERS. CIRCLE THOSE PROVIDED TO THE ELDERLY.

CHECK YOUR PRESENT ELIGIBILITY CRITERIA OR REQUIREMENTS FOR SERVICE PROYISION. DESCRIBE "OTHER" AGE FEE FOR SERVICE IHCOFE LIAITS GEIGRAPHIC LOCATIDN OTHER OTHER DTHER

WHAT PROPORTION OF YOUR CLIE!ITS ARE ELDERLY?

HAVE YOU OR ANY OF YOUR STAFF HAD SPECIAL TRAIHING FOR HORKING WITH THE ELDERLY? PLEASE DESCRIBE 
WHAT SPECIAL PROBLEMS (CONSTRAINTS) DO YOU HAVE IN KORKING WITH OLDER ADULTS AS CLIENTS?

LIST THE TOPIC AREAS IN WHICH YOUR ORGANIZATION COULD UTILIZE TRAIHING.

DO YOU HAVE STAFF MEETIMGS? YES

no

WHAT ARE THE FUNCTIONS OF YOUR STAFF MEETINGS?

WHAT PROBLEMS DO YOU HAVE WITH STAFF MEETIHGS? (WHAT IMPROVEREMTS $: \cdots n$ YOU MAKE?)

PLEASE MafK THE ChOICE MiTCh beST dESCRIBES YOUR AeENCY.

HOW FREQUENTLY DOES EVERYONE HAVE A SPECIFIC JOB TO COP

HOW FREQUENTLY IS GOING THROIGH CHAMHELS STRESSED?

HOW FREQUENTLY DOES THE STAFF PARTICIPATE IN CLIENT SERVICES DECISIONS?

HOW FREQUENTLY DOES THE STAFF PART ICIPATE IN NEN PROGRAM DECISIONS?

\begin{tabular}{|l|l|l|l|}
\hline NEVER & \multicolumn{2}{c|}{ SEL DOM } & \multicolumn{2}{c|}{ SOMETIMES } & OFTEN \\
\hline & & & \\
\hline & & & \\
\hline & & & \\
\hline & & & \\
\hline & & & \\
\hline
\end{tabular}


PLEASE INDICATE HOW MUCH OF A PROBLEM EACH OF THE FOLLOWING ARE FOP YOUR AGENCY.

PROBLEMS IN PRIORITIZING TASKS TO PURSUE.

DIFFICULTIES IN PLANNING TO MEET DEADLINES.

LACK OF INTEREST AND/OR SUPPORT FROM COMANITY ORGANIZATIONS (Eg RED CROSS) POOR COMMUNICATION WITH OTHER AGENCIES IN THE COMNUNITY. UNCLEAR MESSAGES OR REQUIREMENTS BY GOVERNMENTAL OR FUNDING SOURCES

SOME ORGANIZATIONS NEED MORE SUPPORT FROA THE GENERAL COMANITY THAN OTHERS. CHECK THE ONE STATEMENT BELOW WHICH COMES CLOSEST TO DESCRIBING THE SITUATION OF YOUR ORGANIZATION

IT COULD NEVER ACCOMPLISH ANYTHING HITHOUT STRONG COMNUITY SUPPORT

COMMUNITY SUPPORT IS IMPORTANT TO IT BUT HOT ABSOLUTELY ESSENTIAL FOR EVERYTHING IT DOES. COMMUNITY SUPPORT IS DESIRABLE, BUT NOT REALLY A MWOR FACTOR IN ITS SUCCESS.

IT DOES NOT REALLY MATTER WHETHER THE COMNHAITY SUPPPORTS THE PROGRAM OR NOT.

IT HOPES TO ACCOMPLISH ITS GOALS OESPITE OPPOSITION FROM A MAJOR ELEMENT OF THE COMNUNITY.

COMPLETE THE FOLLOWING BY FILLING IN THE BOXES WITH A YES OR NO, WHICHEYER IS APPROPRIATE FOR YOUR AGENCY.

\begin{tabular}{|c|c|c|c|c|c|c|c|}
\hline & CLIENTS & $\begin{array}{l}\text { INFORMATION } \\
\text { ABOUT FUTURE } \\
\text { EVENTS (I.E. } \\
\text { FUNDING, NEH } \\
\text { REGUI.AT IONS) }\end{array}$ & $\begin{array}{l}\text { ACCESS TO } \\
\text { INFLUENTIALS } \\
\text { AKD DECISION } \\
\text { MAKERS }\end{array}$ & $\begin{array}{l}\text { ADDING AND } \\
\text { UPGRADING } \\
\text { STAFF }\end{array}$ & $\begin{array}{l}\text { KHONLEDGE } \\
\text { ABOUT HON } \\
\text { TO PROYIOE } \\
\text { SERVICES } \\
\text { BETTER }\end{array}$ & $\begin{array}{l}\text { COOPERATION } \\
\text { FROM OTHER } \\
\text { ORGANIZATIONS }\end{array}$ & FUNDS \\
\hline $\begin{array}{l}\text { DOES YOUR } \\
\text { ORGANIZATION } \\
\text { HAVE DIFFICILTY } \\
\text { OBTAINING..... }\end{array}$ & & & & & & & \\
\hline $\begin{array}{l}\text { DOES THE AAA } \\
\text { PLAY A ROLE IN } \\
\text { HELPING YOU TO } \\
\text { OBTAIN........ }\end{array}$ & & & & & & & \\
\hline
\end{tabular}


TO WHAT EXTENT ARE THE FOLLOWING APPROPRIATE OR INAPPROPRIATE MEANS BY WHICH GOVERNMENT SHOULD TRY TO INFLUENCE THE WAY SERVICE ORGANIZATIONS WORK WITH ONE ANOTHER. PLEASE MARK YOUR CHOICE.

POTENTIAL GOVERNMENTAL INFLUENCES

1. USING COMPETITIVELY AHARDED SERVICE CONTRACTS FOR DESIRED BEHAVIOR

2. UNRESTRICTED GRANTS TO BUILO AGENCY CAPACITY

3. CIRCUIATING FUTURE PLANS OF SERVICE ORIIANIZATIONS AND GOVERNMENT

4. ACTING AS THE ULTIMATE JUDGE WHEN ORGANIZATIONS DIFFER

5. EVALUATION OF PROGRAM EFFECTIVENESS

6. BRINGING TOGETHER CONFLICTING PARTIES TO CLARIFY ISSUES

7. FEE REIMBURSEMENT FOR SERVICES OELIVEREO

8. PROVIDING INFORMATION ABOUT ORGANIZATIONS TO MAKE IT EASIER FOR THEM TO WORK TOGETHER

9. SHORT TERM IN - SERVICE TRAINING TO SERVICE PROVIDERS FOR SPECIAL TECHNIQUES

10. PROVIDING PROFILES OF INDIVIDUAL STAFF OF SERVICE ACINECIES TO ONE ANOTHER

11. ASSESSING COMPLIANCE WITH CONTRACTS

12. TECHNICAL ASSISTANCE TO PROVIOE SERVICE AGENCIES NEW METHODS

13. CENTRALIZED CLIENT INTAKE FOR MULTIPLE SERVICE AGENCIES

14. PROVIOING FACTS REGARDING NEW LEGISLATION AND FUNDING,

15. SETTING RULES WHEREBY OIFFERENCES BETWEEN ORGANIZATIONS CAN BE WORKED OUT

16. AUTHORITY TO APPROVE/DISAPPROVE ALL AGING PROGRAMS

17. ESTABLISHING UNIFORM STANDAROS FOR SERVICE DELIVERY

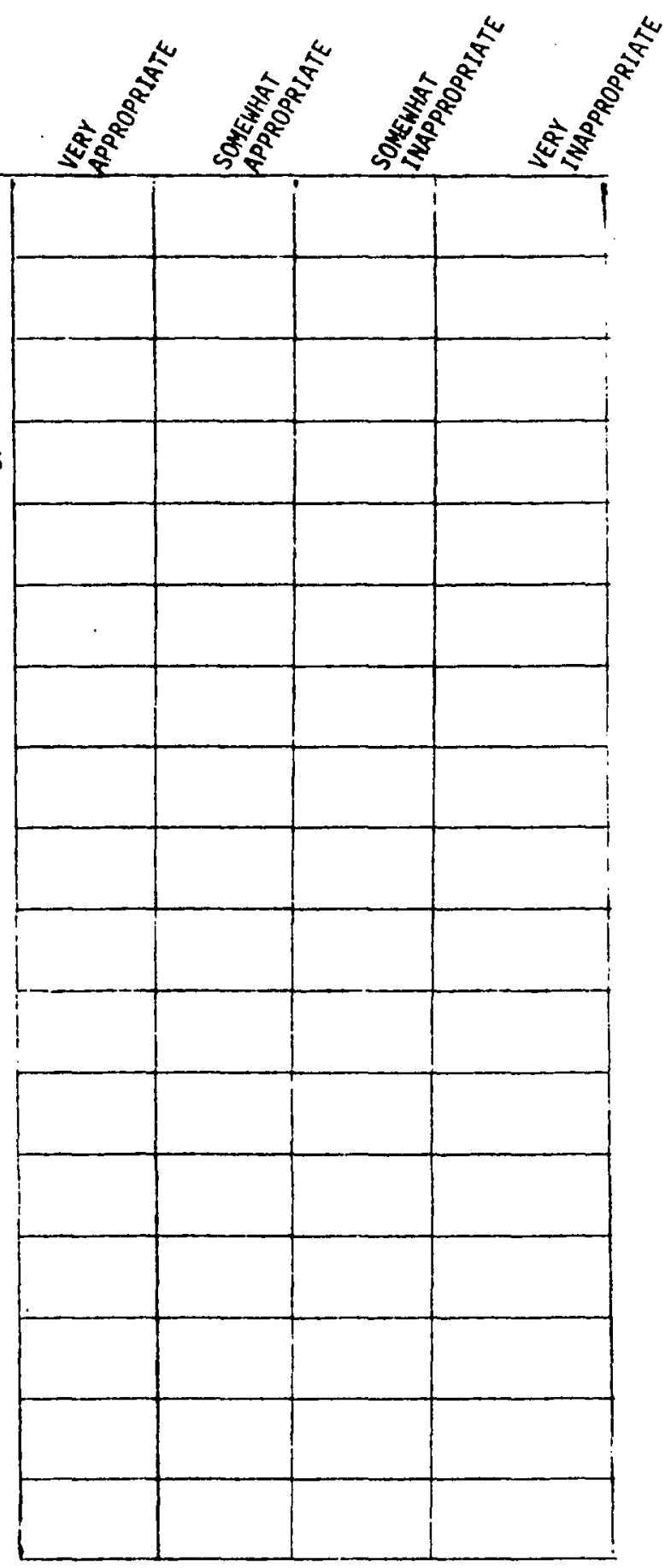


HOW IMPORTANT ARE EACH OF THE FOLLOWING TO YOLIR ORGANIZATION?

TO BE INDEPENDENT AND SELF GOVERNING

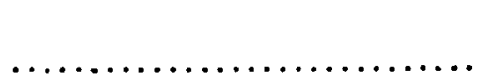

TO FORM LINKAGES WITH OTHER ORGANIZATIONS IN THE SERVICE SYSTEM

TO BE ABLE TO EXERCISE CONTROL OVER OTHER ORGANIZATIONS

TO MAINTAIN OR INCREASE PRESTIGE OR "IMAGE" IN THE COMMUNITY

TO ENGAGE IN ACTIVITIES CONSISTENT WITH "PHILOSOPHY" OF YOUR AGENCY.

TO MAINTAIN "BOUNDARIES" OF AGENCY (i.e., AVOTD OVERLAP OF

SERVICES, CLIENTS, ETC) WITH OTHER ORGANIZATIONS

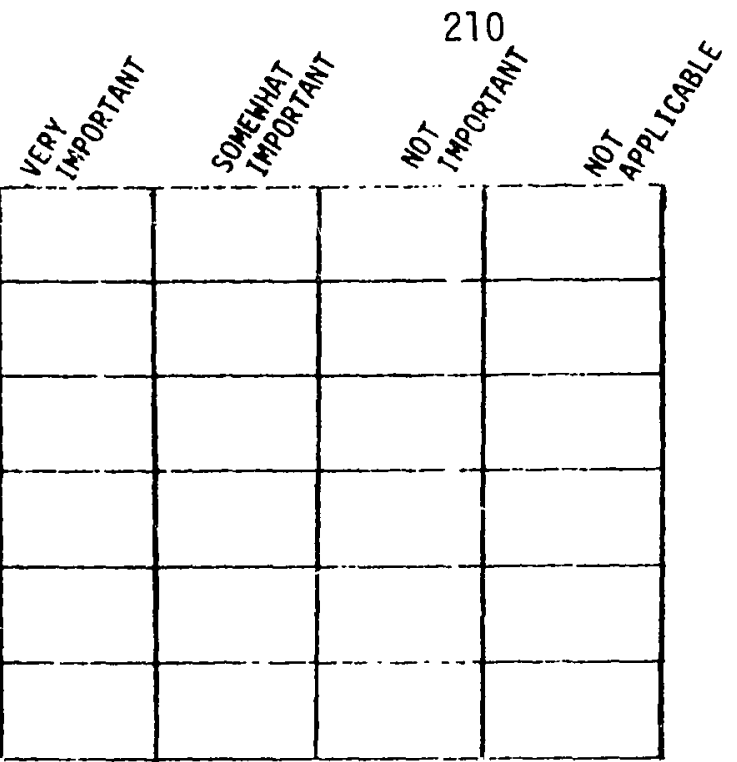

THE AREA AGENCY ON AGING (AAA) IS AN ORGANIZATION ESTABLISHED THROUGH FEDERAL LEGISLATION TO PROVIDE COORDIHATION OF SERVICES TO THE ELDERLY. THE DIRECTOR IN YOUR REGION, DISTRICT III-A, CLACKAMAS, COLUMBIA, AND WASHINGTON COIJNTIES, IS V.J. HUFFMAN. THE PAST OIRECTOR WAS JODY MILLER. THE AAA IS HOUSED UNDER THE AUSPICE OF CRAG (COLUMBIA REGION ASSOCIATION OF GOVERNMENTS). YOUR AAA IS SOMETIMES CALLED THE COUNTY AREA AfENCY ON AGING AND OFTEN WORKS CLOSELY WITH THE COUNTY COUNCIL OF SENIORS.

HAVE YOU HAD ANY CONTACT WITH V.J. HUFFMAN OR JODY MILLER? YES NO HOW FREQUENTLY DO YOU HAVE CONTACT WITH THAT DERSON OR OFFICE?

HOW! MANY OF THE MEMBERS OF THE AAA ADVISORY"COUNCIL CAN YOU NAME? (WRITE NUMBER)

IS YOUR DRGANIZATION REPRESENTED ON THE ADVISORY COUNCIL OF THE AREA AGENCY ON AGING? YES NO DOES YDUR ORGANIZATION HAVE A CONTRACT HITH THE AREA AGENCY ON AGING? YES NO

HAS THE AAA EVER ENCOURAGED YOU TO CHANGE THE WAY YOU DO BUSINESS (i.e., SIZE OR TYPE OF STAFFING, NATURE OF SERVICES, TYPES OF CLIENT, CHANFING FEES OR AREA OF BUSINESS)? YES NO 
IN THE PAST MONTH, HOW MANY CLIENT REFERRALS HAS YOUR ORGANIZATION MADE TO OTHER AGENCIES?

IN THE PAST MONTH, HOW MANY CLIENT REFERRALS WERE MADE TO YOU FROM OTHER AGENCIES?

IN THE PAST MONTH, HOW MANY CLIENT REFERRALS HAS YOUR ORGANIZATION MADE TO THE AAA?

IN THE PAST MONTH, HOW MANY CLIENT REFERRALS MAS THE AAA HADE TO YOUR ORGANIZATION?

IN THE PAST MONTH, HOW MANY TIMES HAS THE AAA PROVIDEO INFORAATION TO YOU?

IN THE PAST YEAR, HOW MANY TIMES HAS YOUR ORGANIZATION PARTICIPATED IN TRAINING PROGRAMS ORGANIZED BY SOME OTHER AGENCY?

CHECK THE ONE STATEMENT WHICH COMES CLOSEST, IN YOUR VIEW, TO DESCRIBING THE BEST POSSIBLE WAY OF INTERRELATING THE PROGRAMS AND SEPVICES SPECIFICALLY FOR THE AGED IN THIS CORANNITY.

SHOULC BE AS SEPARATE AHD AUTONOMOUS AS POSSIBLE FROM ONE ANOTHER.

SHOULD BE ORGANIZED TO ALLOW EASY CONSLLIFATION BETHEEN THEM AS THE NEED ARISES.

SHOULD BE ORRANIZED WITH THE PROVISION FOR REGULAR AND FREQUENT MEETINGS, INFORMATION EXCHANGE, LIAISON REGARDING CLIENTS, ETC. ON A P.JUTINE BASIS.

SHOULD BE CENTRALLY COORDINATED TO FACILITATE THE WORKING OUT OF COMAN PRIORITIES, SERVICES APPRORCHES, AND TARGET STRATEGIES.

SHOULD BE CENTRALLY ADMINISTERED B! A SINGLE AGENCY IN HOPES OF ELIMINATING OVERLAP AND DUPLICATION OF SERVICES AMONG AGENEIES.

IF THE AREA AGENCY ON AGING WERE TO HAVE ITS BUDGET REDUCED, WHICH FUNCTIONS WOULD YOU RETAIN AND WHICH WOULD YOU ELIMINATE? RANK, IN ORDER, USING 1 TO INDICATE THE FUNCTION YOU WOULD KEEP TO THE VERY END, AND 8 TO INOICATE THE FUNCTION YOU HOULD ELIMINATE FIRST. TKUS, 1 IS THE MOST IMPORTANT FUNCTION AND 8 IS THE LEAST IMPORTANT FUNCTION.

TITLE VII - NUTRITION

INFORMATION AND REFERRAL

COORDINATION OF SERVICES IN COMANITY

STAFF EXPERTISE IN GERONTOLOGY
EFFORTS TOWARD SEEKING FUNDING

LOBBYING WITH DECISION MAKERS

ACTING AS ADVOCATE FOR THE ELDERLY

FUNDING TO FILL SERVICE GAPS 
THE AREA AGENCY ON AGIHI HAS BEEN AT HORK IN YOUR COMOUNITY FOR MRRE THAN THREE YEARS.

WHUT HASS BEEN THE COMMUNITY CFFECT OF THE AAA IN THE FOLLOWING CATEGORIES?

1. ABILITY TO ARRANGE FOR MULTIPLE SERVICES FOR THE ELDERLY HHO HEED THEM.

2. SERVICE PROVIDERS' ABILITY TO EXCHANGE INFORMATION ABOUT CLIENTS.

3. SERVICE PROVIDERS' LNDERSTANDING AND AISEPTANCE OF EACH OTHER'S FUNCTIONS.

4. SHARED FEELINGS ABOUT DOING SOMETHING MEANINGFUL FOR THE ELDERLY.

5. EASE IN RELATING TO THE STATE PROGRAM ON AGING.

6. BUDGET OF SERVICE ORGANTZATIONS.

7. PRESTIGE IN THE COMMUNITY OF SERVICE ORGAN IZAT IONS.

8. ABILITY OF SERVICE ORGANIZATIONS TO EFFECT POLITICAL AND BUDFET DECISIONS.

9. KNOWLEDGE AND ABILITY RELATIVE TO THE ELDERLY.

10. INCREASING THE PRIORITY OF OLDER CLIENTELE FOR ALL LOCAL HUMNW SERVICES.

11. INCREASING THE NUMBER OF STAFF IN SERVICE AGENCIES WITH SPECIAL TRRITIKE AND WHONLEDGE AEOUT ELDERLY NEEDS AND PROGRAMS.

12. INCREASING THE EFFICIENCY OF PLANNING ANC EVALUATION OF PROGRAMS FOR OLDER AOULTS.

13. FILLING CAPS SO THAT NLL CRITICAL SERVICES NEEDED BY OLOER AOULTS APE AYAILABSE.

14. DEVEL TPING AND IMPROVING CRITICAL LINKACES TO GET THE ELDERLY TO PROGRANS THEY NEED.

15. INCOME AND FINANCIAL CONDITION OF ELDERLY.

16. PRESTIGE OR STATISS OF ELDERLY IN COMMUNITY.

17. ELDERLY'S FEELING OF CONTRIBUTION TO CCMMUNITY.

18. ELDERLY'S ABILITY TO INFIUENCE POLITICAL AND BUDISET DECISIONS.

19. THE ELDERLY'S KHOWLEDGE IIF SERVICES.

20. THE ELDERLY'S MBII. ITY TO GET NEEOED SERYICES.

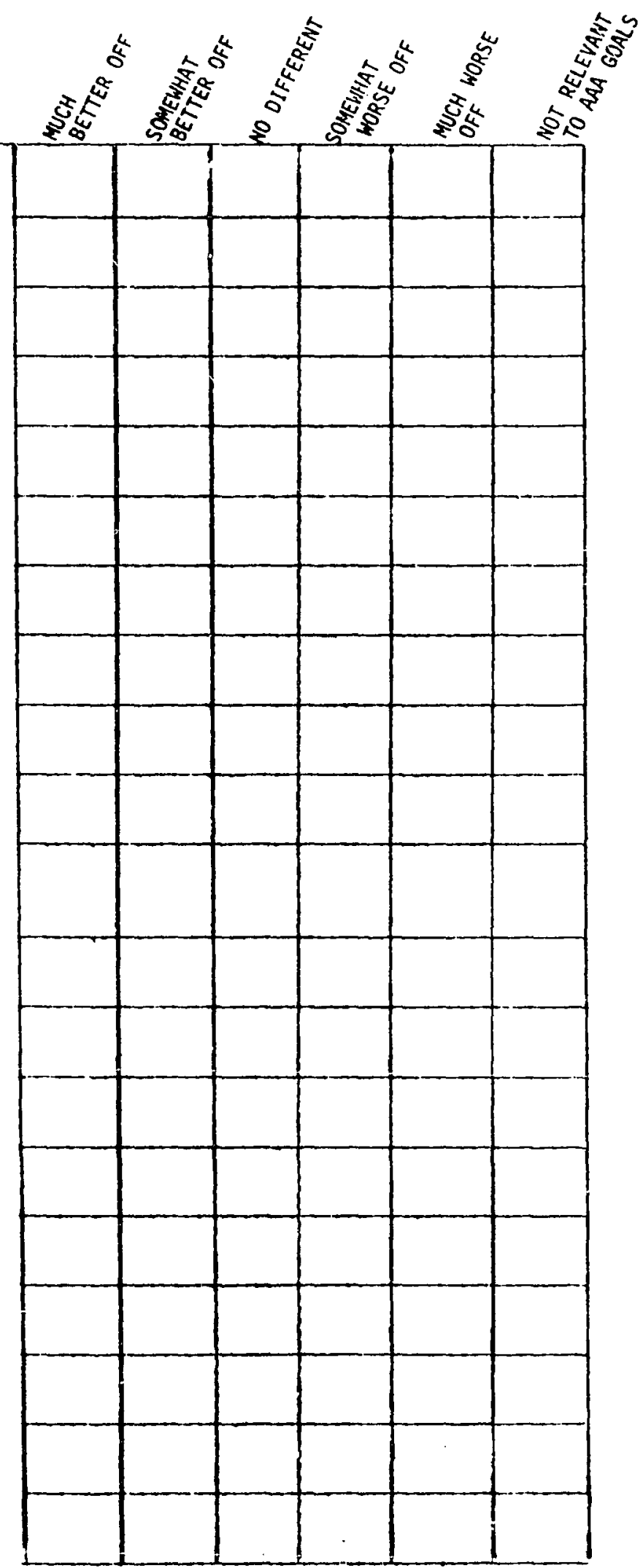


PLEASE INDICATE THE FOLLOWING BY A CHESK IN THE APPROPRIATE BOXES:

HAS YOUR AGENCY HAD CONTACT WITH ANY OF THE FOLLOWING AGENCIES?

DID YOUR AGENCY SEEK SERVICES FOR YOUR CLIENTS FROM THESE PROGRAMS?

HOW SATISFIED WAS YOUR AGENCY WITH THE SERYICES PROVIDED?

\begin{tabular}{|c|c|c|c|c|c|c|c|}
\hline & & & & CES? & & F SATISF & \\
\hline & YES & No & YES & NO & HIGH & MEDIUM & LOW \\
\hline AREA AlGENCY ON & & & & & & & \\
\hline NUTRITION PROGR & & & & & & & \\
\hline STATE PROGRAM 0 & & & & & & & \\
\hline SOCIAL SECURITY & & & & & & & \\
\hline PUBLIC WELFARE & & & & & & & \\
\hline SENIOR CENTERS & & & & & & & \\
\hline
\end{tabular}

PLEASE DESCRIBE ANY PRDBLEMS YOU HAVE HAD IN WORKING WITH THE AREA AGENCY OH AGING?

WHEN YOU NEED INFORMATION REGARDING DEMOGRAPHIC AND SOCIAL CHARACTERISTICS OF OLDER ADULTS, IS IT GENERALY AVAILABLE TO YOU? YES NO IF YES, FROM WHAT SOURCE(S)?

HAVE YOU EVER USED THIS SOURCE (S)? 
PLEASE MARK YOUR LEVEL OF AGREENENT DP. OISAGREEMENT WITH THE FOLLOWING ITEMS:

1. CHRONOLOGICAL AGE, OR THE NUMBER OF YLARS LIVED, IS A USEFUL INDEX FOR SOC IAL PLANNING AND SERVICES PROVISION.

2. THE PERIOD OF LIFE AFTER AGE 65 IS ONE OF INCREASING LOSS AHD DECLINE.

3. THE OLDER ADULT'S CHRONOLOGICAL AGE IS NOT AS IMPORTANT AS HIS OR HER ABILITIES AND CAPACITIES.

¿. MOST OLDER ADULTS DON"T MIND BEING DESCRIBED AS "SENIOR CITIZENS."

5. MOST OLDER PEOPLE PREFER THE COMPANY OF OTHER OLDER ADULTS (VS. YOUNGER PEOPLE).

6. "SENIOR POWER" is AN IMPORTANT POLITICAL FORCE TODAY.

7. CONSIDERED COLLECTIVELY, OLDER ADULTS HAVE SIMILAR PROBLEMS. NECDS AND DFSIRES.

8. MODEQN SOCIETY HAS LITTLE USE FOR THE OLD.

9. MOST OLDER ADULTS ARE SATISFIED WITH RETIREMENT, FEWER RESPONSIBILITIES AND SOCIAL DEMANDS.

10. MOST OLDER ADULTS PREFER TO BE BUSY AND ACTIVE.

11. OPPORTUNITIES FOR SOCIAL INTERACTION ARE CRUCIAL FOR ALL OLDER ADULITS.

12. WHEN YOU COME RIGHT DOWN TO IT, MOST OLDER ADULTS ARE VERY DIFFICULT.

13. AS YOL KNOW, MANY OLDER PEOPLE SHARE A HOME WITH THEIR GROWN CYILDREN. GENERAILY, THIS IS A GOOD IDEA.

14. IT IS BEST FOR PEOPLE TO LIVE IN NEIGHBORHOUDS WHERE EVERYOHE IS ABOUT THE SAME RGE.

15. OLDER PEOPLE ARE BETTER OFF IF THEY ARE GIVEN THE THINGS THEY NEED RATHEN. THAN INANEY TO GUYY THE THINAS THEY NEED.

RELATED TO YOUR AGENCY

16. YOUR AGENCY SHOULO ATIEMPT IO ORGANIZI THE ELDERLY INTO A VIABLE POLITICAL FORLS.

17. MOST DLDER CL ICNTS YOII SERVE HAVE A FFVORABLE ATTITUDE TOWARD YOUR ATENCY.

18. THE GENERAL ATT ITUDE DF OTHER AGENCIES IN THE COMUNITY IS FAVORABLE TOWARD YOUR PROGRAM.

19. I AM FAIRLY WELL SATISFIED WITH HY PRESENT J0B.

20. GENEP.ALLY. THE STAFF DISLIKES THEIR W'RK.

21. BEFORE ASSIGIING NEW TASKS, THE SUPERVISOR CONSULTS WITH THE STAFF INUNLVED.

22. ACCESS TO THE SUPERVISOR IS AVAILABLE WHEN NEEDED.

23. THE SUPERVISOR. SHOWS APPRECIATION FOR WORK, SHOWS CONFIDENCE IN STAFF.

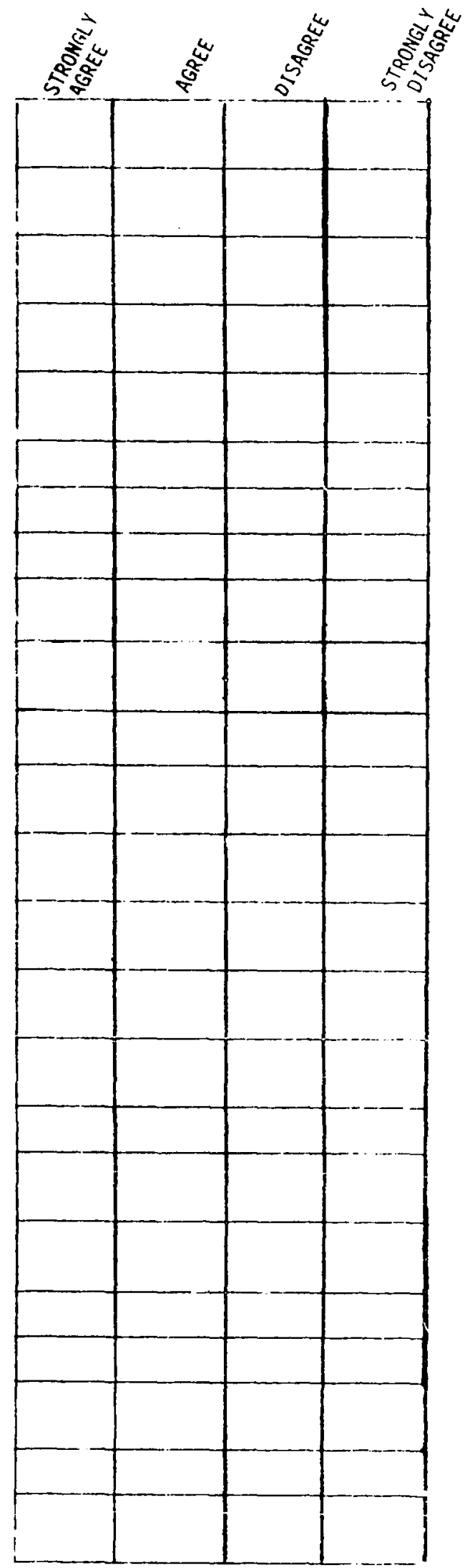


THINKING OF OLDER PERSONS YOU KNOW WITH INADEQUATE INCOMES, RANK IN ORDER, THE NECESSITIES THEY MOST OFTEN GO WITHOUT. USE \#1 TO INDICATE THE NECESSITY MOST OFTEN GONE WITHOUT, \#2 TO INDICATE THE NEXT AND SO ON. (PLEASE DESCRIBE "OTHER")

CLOTHING

F00D

HOUSING

MEDICAL CARE
TRANSPORTATION

RECREATION

OTHER

OTHER

PLEASE INDICAIE HOW THE FOLLOWING SERVICES ARE PROVIOED IN YOUR AREA.

\begin{tabular}{|c|c|c|c|c|}
\hline SERVICE OR FUNCTION & $\begin{array}{l}\text { PROVIDED } \\
\text { BY AAA }\end{array}$ & $\begin{array}{l}\text { PROVIDED BY } \\
\text { AAA THROUGH } \\
\text { CONTRACT }\end{array}$ & $\begin{array}{l}\text { PROVIDED } \\
\text { BY OTHER } \\
\text { AGENCY }\end{array}$ & $\begin{array}{l}\text { NEEDED } \\
\text { BUT NOT } \\
\text { PROVIDED }\end{array}$ \\
\hline \multicolumn{5}{|c|}{ TRANSPORTATION SERVICE ....... } \\
\hline \multicolumn{5}{|c|}{ 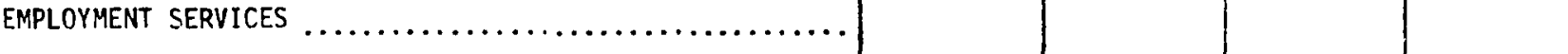 } \\
\hline \multicolumn{5}{|c|}{ NUTRITIONAL (MEALS) SERVICE $\ldots \ldots \ldots \ldots \ldots \ldots \ldots \ldots \ldots$} \\
\hline \multicolumn{5}{|c|}{ 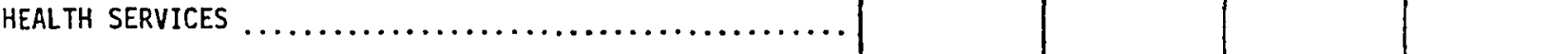 } \\
\hline \multicolumn{5}{|l|}{ MENTAL HEALTH SERVICES } \\
\hline \multicolumn{5}{|c|}{ HOUSING SERVICES $\ldots \ldots \ldots \ldots \ldots \ldots \ldots \ldots \ldots \ldots \ldots$} \\
\hline \multicolumn{5}{|l|}{ INCOME SERVICES } \\
\hline \multicolumn{5}{|l|}{ LEGAL SERVICES . } \\
\hline RECREATIONAL SERVICES & & & & \\
\hline
\end{tabular}

THANK YOU FCR YOUR PATIENCE AND PERSISTENCE. WE REALIZE THAT WE MAY NOT HAVE ASKEU OTHER IMPORTANT QUESTIONS. WE WOULD APPRECIATE YOUR COAAENTS, QUESTIONS OR SUGHESTIONS. (USE ADDITIONAL PAGE IF NEEDED) 